\title{
Lady Gaga, Little Monsters and the YoÜ AND I/HAUS OF Ü Communications: Mobilizing New Media to Transgress Hegemonic Identities
}

by

Courtney Constable

A thesis submitted to the Faculty of Graduate and Post Doctoral Affairs in partial fulfillment of the requirements for the degree of

\author{
Master of Arts \\ in \\ Women's and Gender Studies
}

Carleton University

Ottawa, Ontario

(C) 2013

Courtney Constable 
Library and Archives

Canada

Published Heritage

Branch

395 Wellington Street

Ottawa ON K1A ON4

Canada
Bibliothèque et

Archives Canada

Direction du

Patrimoine de l'édition

395 , rue Wellington

Ottawa ON K1A ON4

Canada
Your file Votre référence

ISBN: 978-0-494-94610-7

Our file Notre référence

ISBN: 978-0-494-94610-7
NOTICE:

The author has granted a nonexclusive license allowing Library and Archives Canada to reproduce, publish, archive, preserve, conserve, communicate to the public by telecommunication or on the Internet, loan, distrbute and sell theses worldwide, for commercial or noncommercial purposes, in microform, paper, electronic and/or any other formats.

The author retains copyright ownership and moral rights in this thesis. Neither the thesis nor substantial extracts from it may be printed or otherwise reproduced without the author's permission.
AVIS:

L'auteur a accordé une licence non exclusive permettant à la Bibliothèque et Archives Canada de reproduire, publier, archiver, sauvegarder, conserver, transmettre au public par télécommunication ou par l'Internet, prêter, distribuer et vendre des thèses partout dans le monde, à des fins commerciales ou autres, sur support microforme, papier, électronique et/ou autres formats.

L'auteur conserve la propriété du droit d'auteur et des droits moraux qui protege cette thèse. $\mathrm{Ni}$ la thèse ni des extraits substantiels de celle-ci ne doivent être imprimés ou autrement reproduits sans son autorisation.
In compliance with the Canadian Privacy Act some supporting forms may have been removed from this thesis.

While these forms may be included in the document page count, their removal does not represent any loss of content from the thesis.
Conformément à la loi canadienne sur la protection de la vie privée, quelques formulaires secondaires ont été enlevés de cette thèse.

Bien que ces formulaires aient inclus dans la pagination, il n'y aura aucun contenu manquant. 


\section{Abstract}

Lady Gaga is known for her catchy music, outrageous fashion, and shocking performances, but her activist involvement and close relationship with her fans is also pivotal. Elements of her career are enabled by new media websites, such as Twitter, Facebook, YouTube, and her own website, LittleMonsters.com. The music video for her 2011 single YOÜ AND I and corresponding HAUS OF Ü films exemplify the unique ability of online networking capabilities to facilitate individual participation in activism, community interaction that transcends real world barriers, and the dissemination of transgressive activist images. I investigate Gaga's embodiment of 'othered' gender and sexuality identities through five transgressive personas and how these constitute activism through their distribution as new media phenomena. I explore the implications of fan participation in convergence culture through the creation of reception texts, using new media to transform passive consumers of Gaga's original materials into active producers of new activist texts. 


\section{Acknowledgments}

This thesis would not have been possible without the enthusiasm and support of Lori Burns, who kept me on the 'Glitter Way' when expectations lead me away from what I really wanted. I am so grateful for the opportunities she gave me to combine academia and creativity. I would also like to thank Anna Hoefnagels for bringing a new perspective to my writing. Her attention to detail helped transform my thesis into a much more enjoyable read. My thanks also go to Debra Graham, whose positivity kept me passionate about my work. I am so lucky to have been able to work with such inspiring women - who else's professors would get excited about underwear presentations, drag king beards, and mermaid gills?

Caden Brown, thank you so much for your support through the excitement, anger, tears, and sickness. I wouldn't have survived without you always reminding me that I'm a 'master'. Thank you for loving me even though I dress like a man sometimes. I love you! Jill Thayer, you're the light of my life! Thank you for constant therapy through good food, online shopping, brightly coloured hair dye, and karaoke. Your support means the world to me, and I'm so proud of you! Mom, thank you for deciphering my incoherent text messages at all hours of the day and night. Thank you for care packages and amazing thrift shop finds. Thank you for being the world's best example of what a strong woman is. I can't wait to go into business with you and open our animal shelter that is also a consignment store that also supports human rights. I love you. Thank you to my dad, brother, family and friends. I love you all. Finally, thank you to Lady Gaga for creating materials so special than I can analyze every second of them for two full years and still enjoy them in my spare time. You're an inspiration. 


\section{Table of Contents}

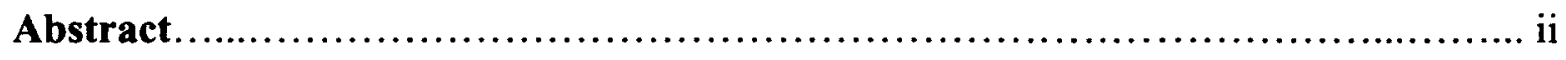

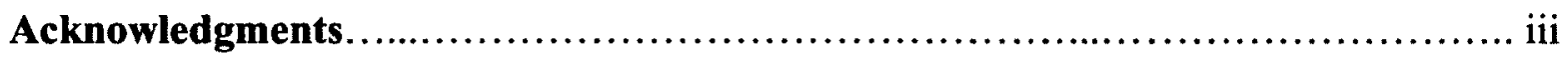

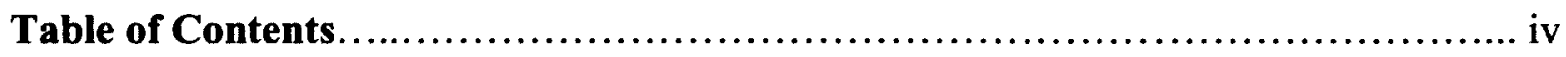

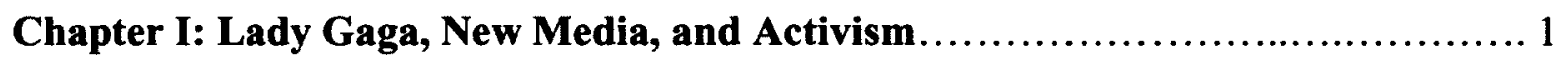

1.1 Introducing Lady Gaga and Her Little Monsters......................... 1

1.1.1 Lady Gaga and Identity Activism............................ 5

1.1.1.2 Using New Media in Activism....................... 5

1.2 Research Process: Investigating Lady Gaga's New Media Usage and

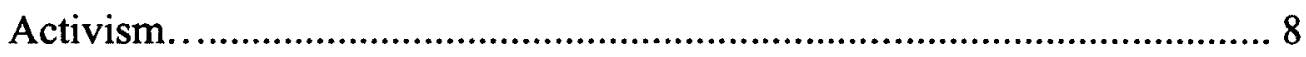

1.2.1 Research Objectives......................................... 8

1.2.2 Contexts for the Music Video YoÜ AND I.......................... 9

1.2.3 Key Themes and Categories of Analysis....................... 15

1.2.4 Putting Gaga's Activism in the Context of New Media............ 17

1.2.4.1 The Architecture of Lady Gaga's New Media Usage..... 17

1.2.4.2 Fan Reception Texts and Gaga's New Media Usage....... 22

1.2.4.2.1 Maria Aragon............................................. 23

1.2.4.2.2 Helen Green............................................... 24

1.2.5 New Media Extensions of Yoü AND I...................................... 26

1.2.6 The HaUS OF Ü Videos...................................................... 28

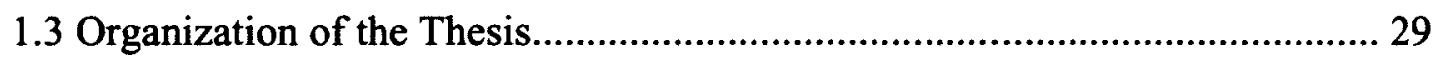




\section{Chapter II: Building A Theoretical Foundation: Situating Lady Gaga's GLBTQ}

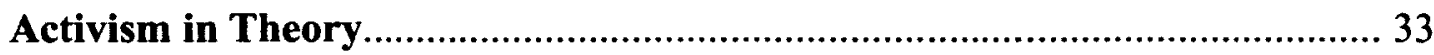

2.1 Theories of Gender, Sexuality, and Subjectivity ............................................ 33

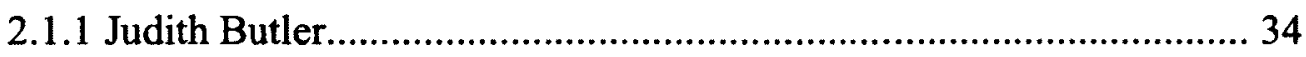

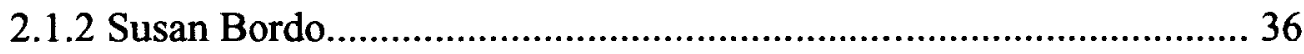

2.1.3 Iris Marion Young............................................................................ 38

2.1.4 Positioning Gender, Sexuality, and Subjectivity Theory in Gaga's

Work

2.2 Theories of New Media and Participatory Culture........................................ 40

2.2.1 Convergence Culture...................................................................... 40

2.2.2 The Developing Phenomenon of Online Activism.......................... 47

2.2.3 Convergences of Online and Offline Activism................................5 50

2.2.4 Community Building Through Participatory Culture...................... 52

2.2.5 The Role of the Celebrity in Activism............................................ 55

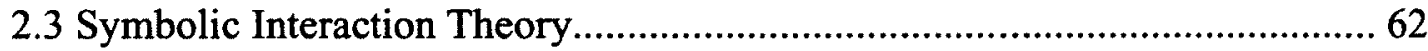

2.3.1 Situating YOÜ AND I and HAUS OF Ü in Symbolic Interaction

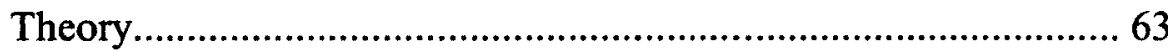

2.4 Reception of Lady Gaga's Work: Emergent Themes.................................... 64

2.4.1 Interpreting Gaga's Work Through the Lens of

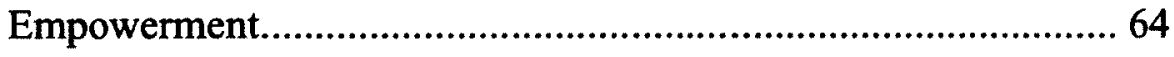

2.4.2 Receiving Gaga's Work as Raunch Culture and Hyper-

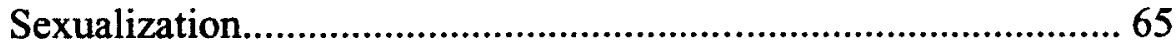

2.4.3 Seeing Beyond the Performativity of Gaga's Work......................... 66 
2.4.4 Integration of Reception Themes with Theories of Gender and Sexuality 67

2.5 Methodology 70

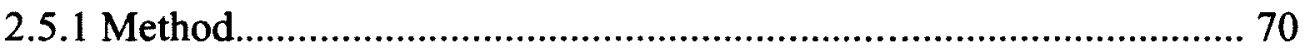

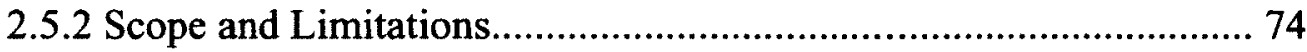

\section{Chapter III: Analysis of Lady Gaga's YoŨ AND I Video and HAUS OF Ü:}

Representations and Transgressions of Hegemonic Femininity, 'Othered'

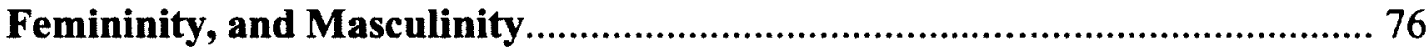

3.1 Transgressions of Hegemonic Femininity: Lady Gaga's Performances of

Nymph, Mother, and Barn Hooker......................................................... 77

3.1.1 The Nymph-Jo Relationship in YOÜ AND I: Representations and

Transgressions of Heterosexual Norms............................................. 77

3.1.1.1 Nymph's Performance of Gender and Sexuality in HAUS OF

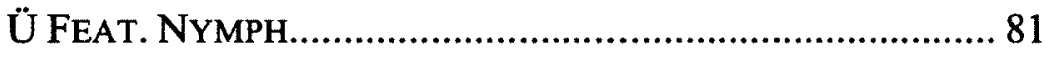

3.1.1.2 Responding to Nymph: Fan Reception Texts................... 83

3.1.2 Mother and Barn Hooker: Representing Binary Conceptions of

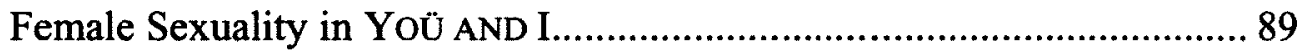

3.2.1 The 'Virgin-Whore Dichotomy: Mother and Barn Hooker in

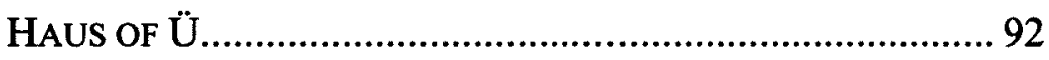

3.2.2 Responding to Mother and Barn Hooker: Fan Reception

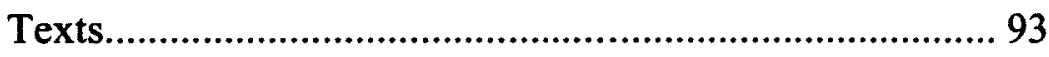

3.2 'Improper' Femininity and Transgress of the Physical Body: Lady Gaga's

Performances of Bride and Yüyi............................................................... 96 
3.2.1 The Robotic Bride: Sexuality, Ability and the Non-Normative

Female Body

3.2.1.1 Undressing the 'Improper' Female Body: Lady Gaga's

Performance of Bride in HAUS OF Ü................................. 98

3.2.1.2 Responding to Bride: Fan Reception Texts....................... 99

3.2.2 Understandings of Dependence and the Non-Normative Body:

Yüyi the Mermaid in YoÜ AND I

3.2.2.1 Alternative Ability and Femaleness: Performing Yüyi in

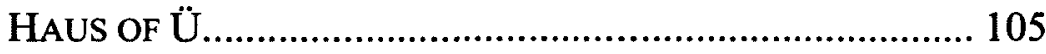

3.2.2.2 Responding to Yüyi: Fan Reception Texts..................... 108

3.3 Transgressions of Hegemonic Masculinity: The Complexities of Jo

Calderone.

3.3.1 Perceived Maleness: Jo Calderone in YoÜ AND I.

3.3.1.1 Undressing Transgressive Gender Performance: Jo

Calderone in HAUS OF Ü.

3.3.1.2 Responding to Jo Calderone: Fan Reception Texts

3.4 Summary 122

Chapter IV: Discussion and Conclusion.............................................................. 123

4.1 Discussion.

4.1.1 Lady Gaga's Personas, Transgression, and New Media as Activism. 123

4.1.2 Fan Reception Texts, New Media, and Activist Participation. 126 
4.1.3 Risks of Online Activism: Voyeurism, Misinterpretation, and Over-

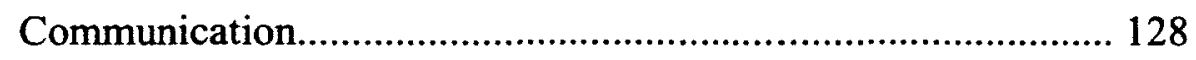

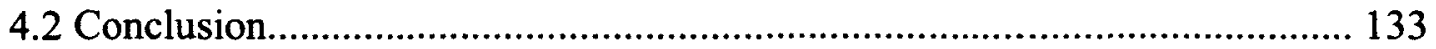

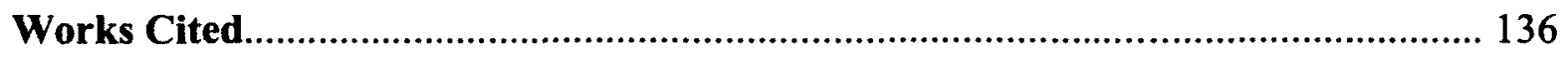




\section{Chapter I \\ Lady Gaga, New Media, and Activism}

\section{Introducing: Lady Gaga and Her Little Monsters}

Since 2008, pop music sensation Lady Gaga has been a magnet for public and media attention, with her catchy dance hits, unique music videos, and outrageous fashion choices. Gaga (née Stefani Joanne Angelina Germanotta) was born in 1986 and was raised by Roman Catholic parents in New York City, where she attended a private allgirls school, the Convent of Sacred Heart (notable for having also educated public figures such as Paris Hilton). She was trained classically in piano and voice, and briefly attended New York University's prestigious Tisch School of the Arts before dropping out in her sophomore year to pursue an artistic and musical career ("Lady Gaga: Biography"). Gaga has spoken openly about her father's attempts to simultaneously support her dream and keep her grounded. She told MTV in their Inside the Outside special that he agreed to pay half of her rent for a year on the condition that she return to Tisch if she was not signed to a record label within that year (Russo 2013, Inside the Outside). In 2006, Germanotta recorded her first official EP, entitled Red and Blue, which featured five piano driven soft rock songs. Her musical project, The Stefani Germanotta Band, began performing songs from this EP at clubs in Manhattan's Lower East Side. Musical producer and talent scout Rob Fusari was intrigued upon hearing about her talent, and the two began recording together and transforming Germanotta's music into a more electro-pop sound. They also reportedly dated for a period of time. Fusari's comparison of Germanotta's voice and style with that of Queen's Freddy Mercury eventually elicited the stage name Lady Gaga, inspired by Queen song Radio $\mathrm{Ga} \mathrm{Ga}$; Fusari has claimed that the name actually resulted 
from a text message that auto-corrected "Radio" to "Lady" (Peters 2012, "Gagapedia: Rob Fusari"). Later that year, Fusari convinced head of Def Jam Records L.A. Reid to take a chance on Lady Gaga's unique and experimental brand of electro-pop, and she was signed for one album. Three months later, however, Reid dropped Gaga from the label, a decision that he has since admitted regretting ("L.A. Reid Regrets Dropping Lady Gaga: 'I Was Having A Bad Day"').

Lady Gaga began working with Interscope Records, the label responsible for such musical acts as Britney Spears, after she was allegedly discovered by R\&B artist Akon in 2007. Akon claims that he was impressed by her performance in a Burlesque show that she created in collaboration with another musical artist known as Lady Starlight (Colleen Martin), entitled 'Lady Gaga and the Starlight Revue'. Since then, however, Tamar Braxton, the wife of Vince Herbert, a producer for a division of Interscope Records called Streamline Records, has refuted Akon's story, claiming that Herbert found Lady Gaga on MySpace and liked what he saw (Lace 2012). Despite confusion surrounding her discovery, Gaga was hired to write songs for Interscope recording artists, such as Britney Spears and the Pussycat Dolls. Following her success as a songwriter, Gaga was then signed as a recording artist. Gaga burst onto the mainstream pop music scene in 2008, with the release of her single "Just Dance". Her first album, The Fame, was released that same year, and it sold over 12 million copies and earned Gaga her first Grammy for Best Electronic Dance Album ("Gagapedia: The Fame [album]”). Coinciding with the release of The Fame was the launch of Gaga's six-month long Fame Ball Tour, during which she performed at notable clubs, theatres, and convention centres in cities across North America, Europe, and Asia. 
The release of The Fame impassioned Lady Gaga to create the Haus of Gaga, inspired by Andy Warhol's Factory; a creative collective through which she would realize her artistic and creative goals in terms of fashion, live performances, music videos, and the overall management and evolution of her public persona. The Haus of Gaga is comprised of makeup artists, wig and hair stylists, dancers, choreographers, fashion designers, artists, and business managers, all of whom travel with Gaga on tour and play pivotal roles in the creation of her artistic career ("Gagapedia: Haus of Gaga"). The Haus is responsible for such notable achievements as the Disco Stick; an everchanging prop of Gaga's own fashioning that serves as a metaphor for a male genitalia in her song lyrics (ex. "I wanna take a ride on your disco stick", from the song "Love Game"), features in her music videos, and still steals the spotlight in live performances on tour.

Lady Gaga's success continued with her second album, The Fame Monster, which earned her another Grammy Award. Coinciding with this album, Gaga's Monster Ball Tour was launched, which lasted 18 months and left Gaga bankrupt as a result of set and costume costs, a situation she only recovered from due to the success of her ticket sales ("Lady Gaga Admits She Went Bankrupt After Spending Millions on Tour Costumes"). Gaga's third and most recent album, Born This Way, was released in May 2011 and sparked frenzy in her fans, establishing a whole new 'era' in her career. Born This Way became the fastest-selling album worldwide in June 2011, selling 288,000 copies in the first day of its release ("Born This Way [album]"). The title track has since been embraced as a mantra of love and acceptance for Gaga fans, and served as the inspiration for her own foundation for youth empowerment and bravery, the Born This 
Way Foundation. Gaga's year-long tour, The Born This Way Ball, proved to be her biggest and most extravagant Ball yet, selling out enormous stadiums all over the world before coming to an unexpected end in Montreal in February 2013. Gaga tore her labrum near the end of the show after over-exerting herself during a case of chronic joint swelling, which she had hidden from her fans and most of her team. Following the injury, the remainder of the tour was postponed and eventually canceled so that she could undergo hip surgery and begin recovery (Lindner 2013).

In the midst of her artistic success, Lady Gaga has also captivated the spotlight for many reasons outside of her role as a musical spectacle. In March of 2011, for example, Google conducted an exclusive interview with her, entitled Google Goes Gaga, to celebrate her status as one of the most Google-searched people in the world. She also held the record for the most Twitter followers in history, but was recently replaced by Justin Bieber as ruler of the Twitter-verse, as users often refer to the phenomenon of Twitter interaction (Robertson 2013). In February of 2012, she launched her own interactive social networking website (http://www.littlemonsters.com) exclusively for Lady Gaga fans, whom she affectionately refers to as her 'little monsters', making her their 'Mother Monster'. Over the course of her career, Gaga's little monsters have grown in numbers and become increasingly supportive of her every move; they are often constructed by the media as devout worshippers thrown into fits of hysteria at the sight of their idol, and several sources have even accused little monsters of being crazy or violent due to the way that some fans jump aggressively to Gaga's defense in the face of criticism (Nessif 2013). Even so, it is undeniable that Gaga's love for her fans, as well as her dynamic interaction with them using online tools like LittleMonsters.com and 
Twitter, has created a unique and groundbreaking form of interactive relationship and a sense of community largely facilitated by contemporary new media.

\section{Lady Gaga and Identity Activism}

Perhaps most notably, Lady Gaga has received media coverage for being heavily involved in several well-publicized activist campaigns for Gay, Lesbian, Bi-sexual, Transgender and Queer (GLBTQ) rights, anti-bullying action, and youth empowerment initiatives ("Lady Gaga's 'Don't Ask, Don't Tell Speech: The Full Transcript", "Gay Advocates Hail Lady Gaga's Activism, VMA Drag Act", Vaiani 2011). Lady Gaga's pivotal role in advocating for the repeal of American military 'Don't Ask, Don't Tell' policies served as an empowering illustration of her social involvement (Parker 2010). Gaga has also mobilized her activist tendencies in her musical output and artistic career, establishing and promoting the ideology of self-love as a dominant theme in her music. First, audiences were introduced to the concept of being "Born This Way", coinciding with her 2011 single and album of that same title, within which individuals were encouraged to love themselves and each other regardless of differences in gender, sexuality, or other identity. A year later, in February of 2012, Lady Gaga and her mother, Cynthia Germanotta, launched the Born This Way Foundation, a manifestation of the "Born This Way" ideology intended to promote and facilitate youth empowerment and bravery during Gaga's international 2012 Born This Way Ball concert tour ("Lady Gaga Launches Born This Way Foundation").

\section{Using New Media in Activism}

Since the beginning of the Born This Way Ball in April 2012, Gaga has presaged her new album, $A R T P O P$, set for release in 2013. With this fourth album, she will 
establish a second concern of the self-love ideology, which she identifies as the Body Revolution 2013. Sparked by negative media criticism of Gaga's own body, the Body Revolution 2013 is an online campaign that began as her way of responding to harsh accusations of weight gain and unhealthy living ("Looking Meatier! Lady Gaga Shows Off Her New Fuller Figure After 'Gaining 30lbs' in Her Favourite Carniverous Creation") and grew into an international phenomenon in a matter of hours, facilitated by Gaga's social networking fan site, LittleMonsters.com. Lady Gaga sparked the Revolution by posting pictures of herself in her underwear, accompanied by the revealing caption, "Bulimia and anorexia since I was 15 " (www.littlemonsters.com/abodyrevolution). She explained to fans, using a series of pictures of her own body, that each person should be comfortable and confident in their body, regardless of whether it adheres to media standards, because all bodies are beautiful. Body Revolution 2013 caught the attention of LittleMonsters.com users immediately, and within hours, millions of fans were posting similar pictures of their own bodies, baring their insecurities for the world to see and encouraging each other to embrace the beauty within themselves (Maya 2012). This reception prompted Lady Gaga to encourage her little monsters' participation in the campaign further, choosing several fans to feature in the weekly LittleMonsters.com newsletter as inspiring examples of what Body Revolution 2013 is all about.

What is perhaps most interesting about Body Revolution 2013 is its existence as a media phenomenon that takes place between Gaga and her fans solely through the Internet. Lady Gaga's establishment of the dynamic new media platform LittleMonsters.com and her combined use of other social networks, such as Twitter, 
Facebook, and YouTube, have enabled a new form of communication between the celebrity and the public audience, an Internet-based phenomena that has completely changed the way fans interact with each other and their idol (Scholz 2008). Body Revolution 2013 is just one contemporary example of how Internet capabilities have evolved to facilitate international participation in discussions and campaigns to which individuals would otherwise not have direct access. This campaign, among other Internet-based artistic texts created by Lady Gaga and her little monsters, some of which I will analyze specifically later in this thesis, exemplifies the changing role of the Internet user in social change and popular culture development, as the individual evolves from a passive consumer into an active consumer/producer of new media texts (Jenkins 1992, $223-4 ; 2006,1-16)$. 


\section{Research Process: Investigating Lady Gaga's New Media Usage and Activism Research Objectives}

My research aims to uncover the dynamic new media processes in and through which Lady Gaga is able both to develop her activist causes and to gain public support for them. Due to her status as an international icon, Lady Gaga's image and actions are widely circulated in online media and social networking websites enabling mass communication with her fans. The use of new media to spread information and facilitate the involvement of people over large geographical areas is a relatively recent phenomenon, with the launch of Facebook in 2004, YouTube in 2005, Twitter in 2006, and, for Lady Gaga fans, LittleMonsters.com in 2012. My research examines these interactive new media communications in order to understand how the public receives and perceives newer forms of gender and sexuality activism. Much of Gaga's social advocacy takes place in the technological spaces where real-world activism and online campaign strategies converge (Harris 2008, Hirzalla \& van Zoonen 2011). My analysis of not only Gaga's artistic communications but also audience responses aims to interpret how the public receives her innovative performances of gender and sexuality as a potential new manifestation of activism (Renegar \& Sowards 2006, 58-60). This examination allows for better comprehension of how different social groups perceive Gaga's performances, specifically within the context of gender and sexuality as socially constructed identities. Finally, my examination contributes to developing spheres of research surrounding convergence culture through my analysis of Lady Gaga's career as a socially significant field of academic concern and an effective, multi-layered case study of how activism can be conducted using new media platforms. 
This thesis explores selected artistic materials through which Lady Gaga and her fans express contentious messages about the ways in which gender and sexuality become developed socially (West \& Zimmerman 1987). By conducting an intertextual analysis of her new media creations and their corresponding fan response texts, I examine the dynamic nature of Gaga's communications with her fans. The materials selected for this study are innovative media forms that have no precedents in the music video genre: that is, for one of her major video releases, the official music video for her 2011 single "Yoü and I", she created a series of complementary videos, short films entitled HAUS OF Ü, that explore the diverse gendered and sexual subjectivities that are enacted and embodied in and through the primary personas of the music video. These complementary HAUS OF Ü videos were shared exclusively with her fans through social media. Public responses to these original and innovative media texts provide insight into audience reception of Gaga's expressions and performances of gender and sexuality. My study examines how Gaga's use of new media technologies raises consciousness about the construction of gender and sexuality identities within contemporary society. I investigate the mobilization of images of gender transgression, queerness, and 'othered' forms of masculinity and femininity enacted in Gaga's live performances and artistic creations as constituting a form of GLBTQ and identity activism.

\section{Contexts for the Music Video Yoủ AND I}

Lady Gaga draws attention to the socially constructed nature of her art by transcending normative ideals of gender and sexuality and by disseminating these images in a wide variety of new media forms. In the video and live performances of her 2011 song "Yoü and I", Gaga embodies several different forms of 'othered' sexual and gender 
identities. In addition to analyzing this original text, along with a number of "Yoü and I"related live performances, I examine the five short fashion films theoretically and artistically linked to the music video Yoü AND I, entitled HAUS OF Ü and created by Lady Gaga in partnership with Dutch fashion photographers Inez Van Lamsweerde and Vinoodh Matadin, and fashion director Nicola Formichetti. These pieces depict each of the characters central to the storyline in the Yoü AND I music video-Bride, Nymph, Yüyi, Jo Calderone, Mother, and Barn Hooker-as embodiments of varying forms of gender or sexuality performance (Gibson 2011).

The song "Yoü and I", from Lady Gaga's third album Born This Way, was released as a single in August 2011. Dedicated fans were particularly excited about the single and its subsequent music video because more than a year before, while debuting the song at Elton John's White Tie and Tiara Ball in June 2010, Gaga had stated that "Yoü and I" was "...a bit of a rock and roll tune, so it will most likely never be used as one of my singles..." (Kaufman 2011). The performance was filmed by an audience member and posted to the Internet, and the video went viral within hours. The song became so popular that audiences began demanding it during tour dates on Gaga's year and a half long Monster Ball Tour, and she even performed it live during several television appearances. Despite her assertion to the contrary, "Yoü and I" was released, and the official music video, which leaked to the Internet early, stayed true to the song's country-like rock and roll sound (Lamb 2012). Fans were particularly interested to note that several phrases of the song deal with some of Gaga's actual life experiences. For example, the repeated lyrical emphasis on Nebraska indicates meaning behind its inclusion, while the phrase "Six whole years" suggests that actual events took place over 
this period of time, as opposed to the timeframe being mentioned arbitrarily. Given that many of Gaga's earlier music videos have been interpreted by the media as attentionseeking performative spectacles, the text of YOÜ AND I stood out for their elements of reality, despite images in the video of Gaga playing several fantasy, and even non-human, characters. Following the release of Yoũ AND I, which gave audiences a glimpse into the characteristics and story of each persona, the release of the HAUS OF Ü film series allowed fans to see the personality of each persona in more detail, learn their names according to the title of each film, and better understand the role of each character within the storyline of the original music video.

Gaga reinforced the connection between the lyrics of "Yoü and I" and reality shortly before the video premiered. Usually very private, she revealed to Omaha's KAT 103.7 that her inspiration for the song was on-and-off love interest Luc Carl, who hails from Nebraska (Daw 2011). Carl and Gaga began dating in 2005 and remained together until Gaga's career took off in 2008 (Talarico 2011). In July 2010, they reportedly rekindled their romance for an additional year (US Weekly 2011), but by May of 2011, Gaga had confessed on The Graham Norton Show that she did not have a boyfriend and had not been on any dates recently ("Lady Gaga Confirms She's Split From Beau Luc Carl"). During the interview with KAT 103.7, Gaga discussed Carl in relation to "Yoü and I", confirming a connection and saying "He's had about 8 number one's about him on the radio, so I'm sure he's happy!' (Daw 2011). With this history for context, the line "Six whole years" confirms the element of reality in YOÜ AND I, as this is the exact length of time that Carl and Gaga were involved. This allows for a rare relation to the artist as a person despite the prominence of persona, and the dynamic between reality and 
transgressive fantasy inherent in each character; these factors cause YoU AND I to stand out among Gaga's other music videos.

The original YOU AND I music video presents audiences with a multidimensional storyline depicting several trangressive characters interacting with each other. Lady Gaga herself enacts each of the central female characters, and even one of the male characters. In YOÜ AND I, we are greeted first by Bride, a partially robotic, futuristic character who looks entirely out of place walking down a country road in her high fashion stiletto heels. Gaga developed the character Bride as a New York girl who has walked all the way from her city home to find her past lover in the cornfields of Nebraska (Daw 2011). Her robotic arm and dark, slightly masculine style of dress set her apart from other more feminine representations within the storyline, drawing a contrast between her and the other characters despite the fact that she never actually comes in contact with any other personas for the duration of the video. Bride spends her time independently pursuing what she wants, challenging her surroundings with her presence as she does so.

Throughout the video, we see images of Bride's search intercut with images of several Frankenstein-esque versions of Gaga being created, experimented on, and brought to life by male actor Taylor Kinney ${ }^{1}$. Most prominently among these, we see another of Lady Gaga's personas named Mother, a pale and zombie-like character in an old fashioned wedding dress, depicted only in the company and embrace of the man who has created her. Though Mother is shown only a few times in comparison with some of the more prominent characters, her complete dependence upon her male lover is made

\footnotetext{
${ }^{1}$ Kinney is Lady Gaga's current boyfriend; a detail many fans find interesting, considering she wrote the song for which the video was created about her previous boyfriend, Luc Carl. Kinney is best known for his roles in the television shows True Blood and Chicago Fire.
} 
evident; he is both her purpose and her literal reason for being. Mother's presence serves as a commentary on idealized social views of women fulfilling the role of passive and devoted wife.

Upon entering the cornfield itself, audiences are introduced to Nymph and Jo Calderone, a seemingly heteronormative couple who spend the duration of the video absorbed in each other's presence. Upon closer examination, however, it becomes apparent that a transgressive sexuality is being represented. Calderone, played by Gaga herself, dressed in drag, sits atop the piano smoking, stamping his feet, and occasionally kissing or fondling Nymph, also played by Gaga, while she looks on him adoringly in her girlish attire and serenades him. Even as they appear to be the most outwardly 'normal' relationship in the video, Calderone (who caused confusion for fans and media sources alike, to be discussed in more detail later in this thesis) and Nymph challenge hegemonic conceptions of heterosexuality, femininity, and masculinity. By assuming both the female and the male role in this relationship, Lady Gaga transgresses heteronormativity and represents gender and sexuality as performative roles.

As we enter the barn, we are introduced to Barn Hooker, a teal-haired representation of exactly what her name denotes. Barn Hooker and her crew of dancers are juxtaposed with more docile representations of femininity such as Mother, flaunting their semi-naked bodies while dancing suggestively. Barn Hooker's outfit of leather straps and fish net tights contrasts with both Mother's modest wedding dress and Nymph's soft (if slightly small) dress and ballet shoes, allowing her to embody a form of overt female sexuality often demonized in dominant society; she is, after all, a barn hooker. 
Finally, we encounter Yüyi the mermaid, a seemingly female but, like Bride, not entirely human character. Though Yüyi appears captive inside the barn, relegated to a small washtub and unable to relocate herself due to having a tail and fins in the place of human legs, she is seen being cared for by Kinney in a more gentle way than he treats his many Franken-Gaga's throughout the video. Yüyi engages in sexual physical contact with the man, representing images of an inter-species relationship and once more transgressing normative practices of sexuality. Though Yüyi is not 'properly' feminine, she is depicted as a happy and willing participant in a relationship that appears to fulfill her partner more than the relationships he puts so much effort into fabricating with the women he has created. Even so, the video concludes with a white wedding between Kinney and Mother, throwing his relationship with Yüyi into stark contrast with this stereotypical heterosexual union with a more 'properly' feminine zombie wife.

Building upon the music video for Yoü AND I, Lady Gaga created five short fashion films entitled HAUS OF Ü. These films were distributed online, one by one, over the course of a year, the significance of which I will discuss specifically in subsequent sections of this thesis. Each short film depicts one or two of the YOÜ AND I personas in a way that highlights their transgressive characteristics. This is done through dance, the act of undressing to reveal parts of the character's body, or through the alternation of images of the character and other individuals (members of Gaga's creative team and even a few fans) to highlight similarities and differences in style of dress, looks, and behaviour. Throughout my chapters, particularly in Chapter III, I seek to analyze both YoÜ AND I and the HAUS OF Ü film series, as well as Gaga's Internet-based method of distributing these materials, by unpacking the transgressive elements of each of Gaga's personas. 
Furthermore, I will examine the fan-produced video responses that emerge via LittleMonsters.com, in order to investigate the activist potential of image distribution with a mainstream audience through dynamic new media platforms.

\section{Key Themes and Categories of Analysis}

This thesis is structured around several key points of analysis that enable effective deconstruction of the ways in which Lady Gaga's YoÜ AND I and HAUS OF Ü texts constitute a new media manifestation of gender and sexuality activism. By examining Gaga's original materials within each of the following contexts, I can identify not only the presence of key theories of gender subjectivity and identity construction within each performance, but also tangible examples of convergence culture theory as it pertains to her work and the successes she has had in the activist sphere thus far.

I examine Lady Gaga's transgressive performances of gender and sexuality within YOÜ AND I and HAUS OF Ü primarily using three over-arching categories of analysis. Firstly, I investigate how the characters Nymph, Mother, and Barn Hooker resist hegemonic notions of femininity through their dress, behaviour, relationships, and symbolic significance within the video. For example, I am able to use this category of analysis to deconstruct the relationship between Nymph and Jo Calderone, the modest dress and passive behaviour of Mother, and the significance of Barn Hooker's overtly sexual presence in juxtaposition to Mother.

In contrast, I analyze Jo Calderone's character as a transgression of hegemonic social ideals of masculinity. By deconstructing his dress, movements, physical body, and relationship with Nymph (as well as the inclusion of Barn Hooker and her dance crew in his own HAUS OF Ü film), I examine the two-fold nature of Lady Gaga's performance as 
Calderone. This character presents a deliberate performance of stereotypical masculinity, but also a simultaneous transgression of that same hegemonic identity by virtue of its existence as precisely that - a performance.

My third main category of analysis is formulated in relation to the first, but as an independent extension of previously presented ideas. Continuing from my arguments about Gaga's performances as transgressions of hegemonic femininity, I analyze Bride and Yüyi as representations of the 'improperly' feminine. This analysis investigates their physical bodies, actions, and relationships as challenges to social conceptions of what qualifies a person as a 'woman' or 'female lover', based on images of these characters within both YoÜ AND I and HAUS OF Ü.

In addition to these central categories of analysis, several common themes emerge from within my examination of each transgressive character. Most prominently, concepts of empowerment, hyper-sexualization or raunch culture, and performativity, often as a tool of transgression, are revealed within Lady Gaga's activist performances. While some public audiences might view her transgressions of hegemonic gender and sexuality as a positive resistance to normative standards that helps work toward more open conceptions of identity, other individuals might interpret the involvement of sexual images as detracting from potential activist messages and serving rather to objectify the female body. Similarly, those who associate Lady Gaga's work with a high level of performance art might conceptualize many of her materials as gaining attention for their unconventionality or performativity rather than their activist nature.

Empowerment, hyper-sexualization, and performativity emerge as key concepts in my investigation of certain fan-produced texts posted on various new media platforms in 
response to Gaga's original activist materials. The consideration of these themes within my examination will help to structure my over-arching categories of analysis according to what audience reception texts actually convey. The nature of these texts (whether they embody a sense of Gaga's work as empowering, raunchy, or performative) and their expression of individual interpretation of Gaga's work contribute to the overall consideration of transgressive performances like theirs or Gaga's as a new form of activism by actively exemplifying how audience perception is included as a part of Gaga's creative process through the use of new media. It is important to note that my analysis of these fan reception texts distinguishes these online users, and others like them, from more generalized conceptions of 'the fan' as a passive consumer of artistic or celebrity materials. Based on both their participation in online communities that allow them to interact with Gaga and other fans, as well as their active production and communication of transgressive new media materials, the users in my analysis distinguish themselves from the more homogenized 'fan base' through their critical engagement with both the online community and the social messages presented within Gaga's original work.

\section{Putting Gaga's Activism in the Context of New Media}

The Architecture of Lady Gaga's New Media Usage

The Body Revolution 2013 was sparked by Lady Gaga using the unique architecture of her LittleMonsters.com website. Here, fans create a personal profile, which they can use to communicate and connect with other fans, as well as members of the Haus of Gaga and Lady Gaga herself, in several ways. The Body Revolution 2013 existed primarily on the media board, where fans can post pictures and video links with 
descriptions in a virtual pin board style, to be viewed, 'liked', and commented on by others. The website also contains a discussion board, where fans can make text posts in order to ask questions, share thoughts, and communicate about things like personal stories and their feelings about Gaga's latest materials. Additionally, there is a chat room with live translation technology, a news forum where online media coverage of Gaga and her creative partners is shared, and an events page where fans can keep track of concert dates and locations, and even sign up for exclusive presale codes at certain venues. Every post made by a fan appears publicly and can be 'liked' or commented on by any other user, unless a user has been reported to Backplane (which powers the website) for spam or harassment. This enables fans to view not only what other audience members are sharing, but also what members of the Haus of Gaga (Gaga's costume designers, makeup artists, dancers, etc.) are doing online, and vice versa. Similarly, fans can see and interact with Lady Gaga's personal activity, and she can do the same to theirs. In order to weed out impersonators, the site is designed so that members of the Haus of Gaga are identified by a 'badge' on their profile, which shows up on any public post that they 'like' or comment on. Lady Gaga is also explicitly identified as "Mother Monster", and her 'badge' informs users any time she interacts with a post or appears in a public chat room. This system ensures that legitimate connections are made between Lady Gaga and her fans, and she uses it often to make public statements about current media stories, provide updates about music and performances, share her feelings with her followers, encourage them to adopt/abandon certain behaviours, and sometimes even to sneak unofficial tidbits of information to lucky fans in a chat room. Each feature of LittleMonsters.com plays a 
role in distributing activist messages related to causes that Lady Gaga has become publicly involved with, such as issues of identity, self-image, bullying, and acceptance.

Throughout the history of social networking, many musical artists have used these tools to their advantage, establishing discussion forums and sharing capabilities on their own websites in order to facilitate online fan interaction, or taking advantage of already existing networks to promote their music, a phenomenon that began as early as the days of MySpace (founded in 2003). Since then, celebrity involvement in social networking has skyrocketed, with online usage extending outside of the common celebrity Twitter profile. Celebrity presence on the Internet ranges from websites inspired by celebrities that may not actually be associated with the person themselves, but rather started by fans as a place to discuss their career, to those that are actually begun by a particular celebrity for the purposes of self-promotion or perhaps the promotion of a cause that they support (Aune 2008). While Lady Gaga is not the first public icon to establish a strong online presence, her pivotal role in the development of LittleMonsters.com, as well as the unique architecture of and combination of features within the website itself, blazes trails in terms of how individuals can become involved with not only their favourite artist, but also with topics of personal interest, important social movements, and each other. Through LittleMonster.com, Lady Gaga maximizes the potential of social media tools and creates a truly unique platform for communication and activist involvement, both her own and her fans'.

The Body Revolution 2013 was not the first time that Lady Gaga employed the Internet and social networking websites to distribute an activist message and involve the public in a particular cause. In August of 2011, Gaga released the music video YOÜ AND 
I, from her third album Born This Way. In keeping with her history of leaking her own material before official release dates, Gaga used her personal Twitter account to distribute a YouTube link to her followers, launching it onto the Internet two days before schedule, following a more small-scale leak of the video earlier that day ("Gagapedia: You and I [song]; 7. Music Video"). Over the course of the following year, Gaga also revealed her five HAUS OF Ü complementary videos, using Twitter, Facebook, and YouTube to link fans to the media materials, which exist solely as online presentations.

By releasing her HAUS OF Ü videos via Twitter, Facebook, and YouTube, Lady Gaga allows fans to view her materials internationally, repeatedly, and at their own convenience; a luxury not afforded by previous methods of media distribution such as television (Jenkins 2006 [1], 3). In addition, these social networking capabilities allow audience members to share-with Lady Gaga and the global internet community-their own interpretations of her work (in the form of tributes, parodies, artwork etc.) and to distribute their personal representations of the messages that they received from Gaga's original HAUS OF Ü films. This process of actively interpreting and responding to Gaga's open representation of 'othered' identities enables individuals from around the world to participate in the ongoing promotion of equality and self-love and become part of a movement that they would not necessarily have access to otherwise. By creating and distributing reception texts using new media capabilities, fans become key participants in the dissemination of Gaga's original messages, contributing to activist campaigns by increasing the visibility of socially oppressed identities, raising consciousness about gender and sexuality as social and historical constructions, and even extending from those original messages to consider other elements of identity not addressed in Gaga's 
own videos (for example, age). Gaga's use of such dynamic online forums invites audiences to get involved in the process of highlighting and debating forms of discrimination experienced by individuals who identify outside of hegemonic binaries of gender and sexuality.

By virtue of using dynamic platforms such as Twitter, Facebook, and YouTube to distribute their materials, fans claim the role of the producer and enable Lady Gaga, as the original creator of the HAUS OF Ü texts, to adopt the role of consumer in viewing their receptions texts. Although there are recent studies of the consumer as the producer, accounting for audience remixes and new materials (Jenkins 1992, Hermes 2005, Bruns 2008, Lessig 2008, Sinnreich 2010, Miller 2011), the relatively new online phenomenon of the original producer acting as a consumer of audience reception texts has not yet been widely investigated. Gaga has viewed, interpreted, and responded to innumerable reception texts created and communicated to her by fans using the very same new media platforms that she herself employed in the original distribution of her material. This exemplifies what Henry Jenkins refers to as convergence culture, a concept that I elaborate on in Chapter II. Gaga's use of social networking technologies converges more traditional forms of media, such as news articles, television interviews, and music videos, with new forms of media, like online discussion forums and video sharing capabilities (Jenkins 2006 [1], 4). Although LittleMonsters.com was established after most of the HAUS OF Ü films were released, it has served to facilitate even further a dynamic online relationship between Gaga and her fans, one that is exemplary of the changing worlds of celebrity, community, and activism (Eaton 188). The interactive sharing of videos and images between Gaga and the public, as well as between and among the audience 
members, enables the development of an online community at both local and global levels, and facilitates wide distribution of the messages within her music (Brunsting \& Postmes 2002). The public sharing of reception texts by audience members allows for a better understanding of the ways in which Gaga's activist messages about gender and sexuality are perceived by individuals and applied to their own conception of identity. It also enables fans to actually do activism and, in this case, engage with discourses surrounding gender and sexuality. They do not simply become a part of the activist campaigns that Gaga has already established, but rather they participate in wider social activism in their own right by adding new interpretations and layers of transgression to their conceptions of Gaga's messages and materials. Dynamic new media relationships between fans and with Gaga reveal new ways that the public circulates its own conceptualizations within an ongoing, socially relevant debate (Brickell 2012, Howe \& Rigi 2009).

\section{Fan Reception Texts and Gaga's New Media Usage}

Following each analysis of Lady Gaga's original characters, as they are represented in the video and short films, I conduct a comparative analysis of a responding fan-made reception text. These fan videos are significant tools for the analytical deconstruction of activism through new media, because they both respond to and include transgressive images. In addition, these fan videos extend the audience impact of Gaga's new media forms. That is, the fan videos that I have selected for study are posted publicly to YouTube, where they can be accessed and viewed by people who may have also seen the transgressive images in Gaga's original texts. By virtue of their existence as openaccess materials on YouTube, anonymous viewers might also have shared these videos in 
other social media platforms, such as Facebook, Twitter and LittleMonsters.com. Moreover, the wide dissemination of these fan videos, especially through Gaga's own social networking website, leads to the possibility that Lady Gaga herself might also have viewed them, thus completing the loop of dynamic interaction with the artist.

\section{$\underline{\text { Maria Aragon }}$}

The interactive nature of new media was exemplified in 2011 by perhaps the first of Gaga's news-worthy replies to an audience reception text, her response to 10-year-old Maria Aragon. In February 2011, Aragon posted a video to Youtube of herself performing an acoustic piano version of Lady Gaga's "Born This Way". The video became popular and was brought to the attention of Lady Gaga herself, who tweeted it along with the message: "Can't stop crying watching this. This is why I make music. She is the future" (Hsieh 2011). Following this tweet, Aragon's video went viral on the Internet, drawing public attention to her musical talent. She was interviewed by Winnipeg's local radio station, Hot 103, where she received a phone call from Lady Gaga, as well as an invitation to attend one of Gaga's Monster Ball Tour dates in Toronto (Hsieh 2011). During this performance, Gaga brought Aragon on stage for a duet performance of "Born This Way". This interaction sparked a musical career for Aragon, who has since been signed by Star Records, a Filipino recording label ("Maria Aragon Signs Record Deal"). Although Aragon's reception text did not respond to Gaga's YoÜ AND I materials, her experience highlights how the use of new media enables genuine interaction and response not only from audience members to Gaga, but also back again. 


\section{Helen Green}

Since Maria Aragon, perhaps the most famous example of Gaga's dynamic online relationship with fans is 20 -year-old Helen Green, a young British artist from London. Green began drawing portraits of Gaga at different events and posting them to a personal Tumblr account (http://dollychops.tumblr.com/), as well as to LittleMonsters.com, where they received attention from other Lady Gaga fans. Green's first recognition from Gaga came when Gaga stumbled across one of Green's many magazine cover-esque portraits online. Loving what she saw, Gaga tweeted fans in an attempt to find the artist, saying "Monsters, who made this? I'm obsessed" (Frank 2012). A few weeks later, Green posted a mock Disney princess movie poster featuring Gaga and the title "Born This Way" to LittleMonsters.com. Gaga saw it and liked the drawing so much that she reposted it to her own LittleMonsters.com account and tweeted it to her 30 million plus followers on Twitter (https://littlemonsters.com/post/5010534f408ef922550025a6). She also arranged for Green to attend the Born This Way Ball at Twickenham in England in September 2012 as a guest of Skype, a free video chat service often employed by Gaga to air events like her Fame Perfume launch on LittleMonsters.com. Green was taken backstage to meet Lady Gaga, and upon viewing her artwork up close, Gaga inducted Green as an official artist into her Haus of Gaga collective (London 2012). Since then, Green has continued to illustrate Gaga at various events, posting them to Tumblr, Twitter, and LittleMonsters.com and selling them as graphics on phone, laptop, and tablet cases, tshirts, pillows, and art prints on Society6.com. Gaga continues to use Green's portraits as profile pictures and backgrounds for her various social networking profiles. She even included Green's art in the visuals featured by the Born Brave Bus, a traveling 'tail gate' 
gathering put on by the Born This Way Foundation alongside several American Born This Way Ball Tour dates, where fans were encouraged to discuss mental health and youth empowerment and given access to private time with professional counselors ("Lady Gaga Changing Lives With Touring Youth Services").

Although none of my chosen video responses in particular have received recognition from Lady Gaga herself, they were nonetheless communicated via new media platforms, meaning that each of them bears the potential for a response. These videos have yet to reach the 'viral' status that Aragon's performance or Green's artwork achieved, likely because they have not been shared among the various kinds of social networking websites to the same degree. YouTube user FashionedbyLies, whose materials will be discussed in Chapter III, did in fact receive recognition for a cos-play picture (short for 'costume play'; creating costumes as homage to a public or pop culture figure) of herself dressed as one of Green's Yüyi Disney-based drawings of Gaga (https://littlemonsters.com/post/508479492227662d4f00091f). The picture was 'liked' on LittleMonsters.com by Lady Gaga and commented on by Green, and was subsequently featured in the section of the website's weekly newsletter that highlights notable fan posts from that week. Despite the fact that the specific videos I have chosen for analysis have not elicited direct response from Gaga, they are still effective examples of how online users employ their personal new media capabilities to respond to Gaga's materials. Fans are not simply consuming her images, but reproducing, remixing, and reinterpreting them in order to perpetuate activist messages and become active participants in a greater cause. Analysis of the different ways in which fans re-communicate these messages in the 
reception videos provides insight into the ever-growing phenomena of participatory culture, online communities, and Internet activism.

\section{New Media Extensions of Yoü AND I}

Although most of the characters introduced to audiences in the YoÜ AND I music video were created specifically for this storyline, Yüyi and Jo Calderone made public appearances before the video was released. Lady Gaga originally conceptualized Yüyi via her personal Twitter account as being Gaga's own 'alter ego', calling the mermaid "a reincarnation of my birth+artistic spirit. An incubation, awaiting a human lover to save her..." (“Gagapedia: Yüyi the Mermaid”, https://twitter.com/ladygaga/statuses/84397628393127936). Yüyi's existence as an online persona was further established by the creation of her very own Twitter account, from which Gaga sends 'tweets' to her fans as the mermaid herself (https://twitter.com/TheMermaidYüyi). Yüyi was also featured in two live performances in July of 2011, before the release of the YOU AND I music video- the first on the French television show Le Grand Journal while performing her song "The Edge of Glory", and the second during her performance of "Yoü and I" at the special event Gaga Live at Sydney Monster Hall in Sydney, Australia ("Gagapedia: Yüyi the Mermaid"). This second performance resulted in significant backlash toward the singer from outraged disability rights advocates, as a result of Gaga mobilizing herself on the stage despite her mermaid tail by singing from a wheelchair (McGinnis 2011, Perpetua 2011). She also received harsh criticism from singer-songwriter, actress, and comedian Bette Midler, who accused her via Twitter of stealing Midler's own alter ego, a wheelchair-ridden mermaid named Delores Delago. Midler tweeted “Dear @ladygaga Ive been doing singing 
mermaid in a wheelchair since 1980 -- You can keep the meat dress and the firecracker tits -- mermaid's mine" (Duerst 2011). Midler later retracted her anger, however, tweeting “@ladygaga, let's drink this over at the Emmys in September. Fabulous mermaids can coexist!" (Duest 2011). This clash brings to light the prevalence of referencing past acts and artists in the musical world, something in which Lady Gaga undoubtedly participates (Burns and Woods 2011).

Lady Gaga is not the first musical artist to use transgressive personas in order to resist hegemonic conceptions of gender and identity. Gaga's embodiment of a drag identity in her performances as Jo Calderone, for example, hearkens back to such historical musical moments as Annie Lennox's performance of her song "Sweet Dreams (Are Made of This)" in drag at the 1984 Grammy Awards. Musical artist David Bowie, an icon that Gaga has spoken often about being heavily influenced by, is also well known for dressing in ways that blur the lines of the gender binary. Far from simply serving as a copycat performance, however, Gaga's continuation of the drag presence in mainstream music through Calderone introduces the idea of gender transgression and the ability of performance to be used as a tool of social commentary to the next audience generation. Like Yüyi, Jo Calderone was also brought to life for audiences using new media platforms before his starring role in the music video YoU AND I. Calderone was first featured in a men's fashion editorial for the Autumn/Winter edition of Vogue Hommes Japan in June 2010, the culmination of a collaborative relationship between Lady Gaga and British fashion photographer Nick Knight ("Gagapedia: Jo Calderone"). When the pictures were released, Calderone was only suspected to be Gaga, but official confirmation was not given until August of that year (Bain 2010). A year later, a short 
film of Calderone's photo shoot was featured in the SHOWstudio Shop exhibition Practice to Deceive: Smoke \& Mirrors in Fashion, Fine Art and Film (“Gagapedia: Jo Calderone"). Calderone's most notable appearance outside of YOÜ AND I, however, was his monologue at the 2011 MTV Video Music Awards. Lady Gaga stayed in character as Calderone throughout the event, even having him do a live performance of the song "Yoü and I". Gaga was transformed into Calderone two days before the VMA's, and the performance piece engulfed her identity for the entirety of the evening ("Gagapedia: Jo Calderone"). Some audience members even questioned whether it was really Gaga on the stage, or if she had actually sent a man in her place. Following Calderone's attentiongrabbing appearance at the live event, media sources dissented over whether the performance was successful; some posited that Calderone put Gaga on the map as not simply a singer but a performance artist (Garibaldi \& Vena 2011), while others argued that the performance was confusing and that Gaga had finally taken things too far (Wallace 2011).

\section{The Haus OF $\ddot{U}$ Videos}

Over the course of 2011 and 2012, Lady Gaga released five short films starring her pivotal alter egos from the YoŨ AND I music video. The videos, entitled HAUS OF Ü, were released solely through Internet-based new media platforms specifically intended for online viewing. While each video was published on the website for fashion photographers and co-creators Inez Van Lamsweerde and Vinoodh Matadin (http://inezandvinoodh.com/video/130911-2/), Gaga took to her personal Twitter account to distribute a URL to her followers, which linked fans to the videos via her official channel on YouTube (www.youTube.com/user/ladygagaoffical). This process 
exemplified the dynamic architecture of new media capabilities, especially in the case of HAUS OF Ü FEAT. JO CALDERONE. Gaga altered the video settings for this film so that, for the first few hours of release, only individuals with the link could view it. A few hours later, the tweet containing the link was deleted, but by that time fans had already downloaded and re-distributed additional copies of the video all over the Internet using their own YouTube and Twitter accounts. All of the HAUS OF Ü videos are now available on Gaga's own channel.

Each of the five HAUS of $\ddot{U}$ videos depicts one (or several) of the characters from Gaga's Yoü AND I music video, embodied once again by Gaga herself. Transgressive characteristics of each alter ego are highlighted as they dance, writhe, and interact with the camera (though not each other). The ways in which each video represents 'othered' forms of gender and sexuality identities were not lost on the public or the media, leading to vast discussion across the online sphere. Because of the sexual and deliberately 'different' nature of the characters, however, many sources maintained that the videos were simply yet another attempt on Gaga's part to shock the public, push boundaries, and most importantly, make headlines (Rubenstein 2011). I argue instead that, while the HAUS OF Ü series does indeed resist limitations and shock viewers, their wide distribution increases mainstream representation of 'othered' identities, raises consciousness about the restrictive nature of hegemonic social ideals of gender and sexuality, and serves as an example of how new media platforms enable new forms of online activism.

\section{Organization of the Thesis}

My analysis is based primarily upon theories of gender performativity and the construction of sexuality, which are reviewed and deconstructed in detail in Chapter II. I 
have structured my exploration of Lady Gaga's transgressive YoÜ AND I and HAUS OF Ü texts according to three central categories of analysis. The first deals with hegemonic representations and transgressions of femininity as it pertains to 'feminine' behaviour and social expectations of 'female' individuals. My second category of analysis explores transgressions of normative femininity as it relates to society's expectations of how the 'female' body should look and function. Finally, I investigate transgressions of normative masculinity in terms of both 'male' behaviour and the 'male' body. In Chapters III and IV, I employ these categories as organizational tools, facilitating the investigation of each of Lady Gaga's YoÜ AND I personas in a manner that allows me to categorize similar or related characters together in order to draw on the ways in which they compare and contrast. Chapter III consists of a detailed analysis of specific images of transgressive identity presented in Gaga's YoÜ AND I and HAUS OF Ü texts, as well as in several corresponding fan reception texts. Chapter IV uses Chapter III's analysis as a foundation for discussion about the implications of these images as they are presented to mainstream musical audiences, based on their social meaning as they relate to identity politics, as well as their precedence-setting existence in the world of new media and online activism. Within these key categories of analysis, several previously identified themes are considered as they relate to my theoretical deconstruction of gender and sexuality. Throughout my analysis of each character, I examine images of performativity, in terms of both artistic and musical performance, and the transgressive performance of identity. Images of Gaga physically embodying 'othered' identities and intentionally employing performativity for the purpose of social transgression are key to my analysis of her materials. In addition, I explore images of sex and sexualization as they relate to 
normative understandings of gender, sexuality, and the physical body. Images of Gaga's characters behaving in a sexual manner bear several implications for viewers' interpretations of her materials, including the risk of audiences constructing her performances as hyper-sexualized or objectifying. Next, I examine the empowering nature of Gaga's transgressive personas, investigating how images of a prominent social figure actually embodying and giving mainstream representation to 'othered' identities communicates an activist message and encourages a more fluid understanding of identity based on gender, sexuality, and the body. Finally, I consider audience response videos, using each of these emergent themes to inform my understanding of how different audience members convey their interpretation of the messages communicated in Gaga's original texts. Each of these themes, as they apply to my analysis of Lady Gaga's work and its activist potential, is developed in further detail in the next chapter.

Throughout my exploration of Lady Gaga's materials, using the previously described theories, themes and categories of analysis, several intersectional axes of identity emerge. A thorough investigation of Gaga's transgressive Yoü AND I personas reveals over-arching messages about the intersectional relationship between gender, sexuality, the physical body, ability, and age. The recurrence of these themes throughout the original texts is emphasized per my analysis of fan reception texts based on each character, due to the fact that the same central intersectional themes can be identified in fan-made materials. It is important to note, however, that this is not a result of simple repetition of Lady Gaga's original images, but rather fan interpretation, reconceptualization, and extension of her ideas based on themes of gender, sexuality, the body, ability, and age. Although not all of these themes are concretely theorized 
individually within my next chapter (for example, it would be outside the scope of my thesis to begin a thorough theoretical investigation of the politics of how society understands aging), each one can be identified and linked with the prominent theoretical concepts that are discussed and reviewed. 


\section{Chapter II}

\section{Building A Theoretical Foundation: Situating Lady Gaga's GLBTO Activism in Theory}

In this chapter, my goal is to establish the theoretical tools upon which I will rely for my analysis and interpretation of gender performativity and new media activism. First, I discuss theories of gender, sexuality, and subjectivity as they have been put forth by several notable feminist scholars. Theories pertaining to new media and participatory culture, the use of the Internet for the purposes of activism, the role of the celebrity in social advocacy, and symbolic interaction theory will also be outlined. Alongside my discussion of each theory, I will make vital connections with Lady Gaga's work in order to establish the pertinence of these scholarly claims to my research. Once I have established my theoretical tools, I provide an overview of several key themes that emerge throughout the course of my analysis. Finally, I include a breakdown of my methodological structure, as well as the scopes and limitations of my research.

\section{Theories of Gender, Sexuality, and Subjectivity}

In order to conduct a critical analysis of Lady Gaga's performances of gender and sexuality, I rely on the theoretical writings of Judith Butler, Susan Bordo, and Iris Marion Young. These notable scholars have theorized extensively about identity as a performative process and gender and sexuality as socially and historically established constructs. Their observations on issues of identity in society are pertinent to my study of the contemporary examples of Lady Gaga's YoÜ AND I music video and its corresponding live performances (for example, Jo Calderone's previously mentioned VMA monologue) and HAUS OF Ü films. 


\section{Judith Butler}

Gender theorist Judith Butler has written extensively on the ways in which human beings control their bodies in order to deliberately perform gender and sexuality according to socially established standards. She argues that a person is not simply born with an inherent gender identity due to their physical sex, but rather that each person establishes his or her gender through the performances of repetitive daily actions (Butler $1988,519)$. Gender is not a natural state of being, but rather a hegemonic cultural construct that is based on a binary conceptualization of gender, in which individuals are presented with only two possible gender identities: male or female (Butler 1999). Butler reveals the problematic nature of this binary construction and explores how individuals can subvert the hegemonic normative model. Her notion of gender performativity is important in this regard, as individuals have agency to resist the norms and construct new and subversive forms of gendered subjectivity. If one's 'male-ness' or 'female-ness' is unrestricted biologically, aside from the normative association that is made between sex organs and identity, then these physical traits can be distinguished from the repetitive acts that socially constitute gender, making it possible for gender to be performed in diverse ways (Butler 1988).

Butler further theorizes the relationship between gender, sexuality, and the body using ideas put forth by Foucault about subjectivity and the self (Butler 1989). In this analysis, she establishes once more that the body is a site upon which social construction takes place; it is a site of power where discourses are established (Butler 1989, 601). By determining the body as constructed, however, the implication is that there exists, or once 
existed, a 'body' before and outside of this construction. Based on this understanding, Butler argues that the ideas now considered 'natural' to a body are merely one historical conceptualization. For example, the distinction between male and female is simply one binary manner of constructing the physical body. If a person's ability to 'be' that gender is dependent on the repeated performance of associated actions, however, then it is feasible that other manners of performing those actions, regardless of one's physical body, are possible (Butler 1989, 602). A different performance- outside of the normative social or historical understanding of the body in relation to being 'male' or 'female'could conceivably result in the construction of alternative forms of gender that are different to society's dichotomous understandings.

The concept of sexual desire is also considered by Butler and Foucault as socially or historically constructed. If current dichotomous understandings of gender are based on the physical sexual organ as a signifier, and desire is understood as depending on what gender a person embodies, then sexuality may also be understood as being constructed upon the body as a site of discourse and power as well (Butler 1999, 11). Butler emphasizes Foucault's claim that concentration on heterosexual desire is a cultural construction motivated by the need for reproduction, rather than an understanding based on actual desire. So, the categorization of bodies into a gender binary sets the stage for social enforcement of compulsory heterosexuality (Butler 1988, 524). Butler argues that, in order to understand heterosexuality as a construction and theorize about the possibility of other forms of sex and desire based on this, we must begin by deconstructing the link between assumed sexuality and gender, as well as the concept of gender as a mundane social performance $(1988,525)$. We may then take steps toward analyzing how notions of 
gender and sexuality may be re-conceptualized by examining how the body might be considered a site of cultural resistance and unlimited constructions outside of compulsory heterosexuality and the gender binary (Butler 1999, 602).

Butler's emphasis on gender and sexuality as performative social and historical constructs is particularly important to my analysis of Lady Gaga's YOÜ AND I and HAUS OF Ü texts. The idea of disconnecting gender identity and sexual desire from sex organs and the physical body is featured prominently in Gaga's original texts, particularly in the persona of Jo Calderone. These notions are also re-communicated by audience member reception texts, some of which feature even further alternatives to the gender binary than Gaga's original performances. Such materials illustrate and substantiate Butler's theories about multiple constructions of gender and sexuality outside of normative binaries.

\section{Susan Bordo}

In conjunction with Butler's theoretical analyses of gender, sexuality, and the body, Susan Bordo's approach to the body, gender reproduction, and the self are valuable for the analysis of Lady Gaga's gender transgressive performances. Bordo argues that one's body is regulated by the ways in which we dress, care for ourselves, and perform daily rituals, according to what is culturally expected $(1989,11)$. Like Butler, Bordo builds upon Foucauldian theory, claiming that the body is also a tool of social control $(1989,13)$. Our bodies are not arbitrarily assigned identities of gender and sexuality, but are regulated, organized, and constrained by historical conceptions of masculinity, femininity, and desire. Bordo argues that although these identities constitute sites of oppression and limitation, a transformation of meaning can take place through the process of practicing different social actions $(1989,14)$. Much of Bordo's work 
concentrates on the female body, and specifically the issues around eating disorders, which she interprets as a political action against normative ideals of femininity. By specifically controlling the intake, and therefore the weight gain and shape, of the body, Bordo argues that women can use anorexia as a way to subvert "...our cultural conceptions of the body, norms of beauty, models of health, and so forth" $(1993,321)$. With this statement, Bordo is not attempting to proclaim anorexia as a positive experience, nor recommend it as a course of action, but rather she outlines how the physical body can be used as practical a tool to take control of identity and subjectivity despite constraining social norms. Lady Gaga's YOÜ AND I and HAUS OF Ü texts do not necessarily deal with weight or food intake specifically (although several fan reception texts draw weight and body image into the visual discussion, as investigated in Chapter III), but the physical nature of her transgressive identity embodiment and her use of the body as a tool of resistance can be traced back to theories like Bordo's.

In addition to these concepts, Bordo contributes to gender and sexuality studies by theorizing how gendered subjectivity may be 'decentered' from hegemonic ideals, as well as exploring the opportunities that this postmodern process of 'decentering the self' provides for individual identity. Bordo interrogates the notion of the 'postmodern' in intellectual and social thought processes, drawing connections between these and concepts such as "heterogeneity, discontinuity, displacement, [and] destabilization..." $(1992,161)$, all of which are terms that might conceivably be linked to the transgression of normative social limitations achieved by Gaga's use of the body to resist binary understandings of identity. By fragmenting oneself from dominant epistemologies and understandings of culture and identity, one can begin to claim one's subjectivity in new 
ways that may not have been previously possible due to social or cultural constraints. The fragmented self also enables new manners of bonding between people and allows for the transformation of identities and emphasis of multiple conceptions of gender and sexuality (Bordo 1992, 164). Bordo argues that the embodiment of decentered selfhood takes nonnormative identities that have developed in the margins of hegemonic culture and brings them to the forefront. In this way, dominant subjectivities and norms can be challenged and alternative forms of sexuality and gender identity can be performed (Bordo 1992, 164).

Bordo insists “...there are many who do see the body—both as a living cultural form and as a subject of scholarly theorizing - as a significant carrier and register of culture" $(1992,166)$. This concentration on the body as a physical means of cultural determination and resistance can be clearly identified in the works of Lady Gaga, particularly in the form of the YOU AND I and HAUS OF Ü personas.

\section{Iris Marion Young}

Finally, my analysis of Lady Gaga's work can be situated using theories outlined by Iris Marion Young. Concentrating on women as a social collective within the feminist movement, Young highlights the problematic nature of defining women as a group based on gender. In attempting to identify collective experiences based on one element of a person's identity, we risk essentializing lived experience and excluding certain individuals by not acknowledging other factors of their lives that influence them in conjunction with gender (Young 1994, 713). While attempting to organize others and ourselves for the purposes of social advocacy, it is necessary to acknowledge the risk of isolating one aspect of identity. If assumptions are made about collective experience on 
the basis of gender alone, then important differentiations due to race, class, etc. might be homogenized. Conversely, concentrating too hard on difference risks losing any sense of commonality and ultimately may break down the collective. Young argues that, in order to respond to these problematic aspects of identity isolation, it is necessary to acknowledge that social constructions, of which gender is only one, are bound up in intersectional power relations (Young 1994, 715). The same holds true for groups attempting to enact social change based solely on sexuality. While some emphasis on shared experience is essential for identifying key issues, the homogenization of various sexual identities under one name or history must be avoided (Young 1994, 716).

Due to the socially constructed nature of sexual (or gender) identities, it is inherently problematic to allow one to become more normative than others within a specific collective and alternative performances of identity must be equally valued. Young deconstructs the tendency of Western culture to ignore difference and instead emphasize more generalized understandings of individual experiences. The homogenizing history of contemporary society can be seen in the socially constructed natures of both gender and sexuality (Young 1986, 52). Hegemonic social identities have historically been used as the standard by which people are measured, regardless of whether their varied experiences are represented in those constructed ideals. As a result, those who do not fall within the parameters of normative gender and sexuality (among other identities) are 'othered', or understood as outside of the norm (Young 1980, 141). Young's emphasis on abandoning hegemonic norms as the social standard by which identity is measured, especially for the purposes of organization and collective action, is effectively exemplified by Lady Gaga's Yoü AND I and HAUS OF Ü texts. By 
intentionally embodying marginalized gender and sexuality identities within a mainstream media forum, Gaga (and, in response, fans that create reception texts) exposes audiences to 'othered' subjectivities to which they may not otherwise have exposure, raising awareness of constraining social binaries and increasing representation for marginalized groups.

\section{Positioning Gender, Sexuality, and Subjectivity Theory in Gaga's Work}

My research is thus framed within the works of these three pivotal gender theorists. The concepts developed by Butler, Bordo, and Young can be clearly identified within the creative and performance processes of Lady Gaga and in the way she executes her social activism. Butler's notions of gender and sexuality as performative, Young's emphasis on lived experience even in commonality, and Bordo's theories regarding the use of the body as a tool for social change are all prevalent ideals throughout Gaga's embodiments of 'othered' gender and sexuality identities in her YOÜ AND I and HAUS OF Ü texts. In terms of my analysis, these theories influence which images I identify as advocacy within Lady Gaga's work by informing my understanding of gender and sexuality performances and enabling me to recognize how the body can challenge hegemonic ideals of identity. These theories also help me to reveal how her portrayals of gender and sexuality are interpreted and applied by audiences in their own reception texts.

\section{Theories of New Media and Participatory Culture}

\section{Convergence Culture}

My analysis of audience response texts to Lady Gaga's performance pieces contributes to knowledge about the evolving nature of communication, activism, and 
individual participation in Internet culture. According to Michael A. Peters, "Lady Gaga-the brand and the image-is a multimedia mix of music, fashion, art and theory that utilizes an iconic self-stylization drawing on diverse traditions in cabaret, stagecraft, and choreography" (2012, 216-7). In the past two years, however, Lady Gaga has taken the concept of 'multimedia' to a new level with her mobilization of new media. Due to her use of new media platforms, Gaga's 'little monsters' may access and interact with her work in ways that were not previously possible. For example, Gaga sometimes communicates new details about upcoming music to fans by entering LittleMonsters.com's live chat rooms, which feature simultaneous translation technology in order to facilitate conversation between individuals speaking different languages. Unique tools like this are key factors in allowing her online and offline performances to constitute perpetuations of actual social activist messages. When fans view a picture, video, or recording of a performance, they may subsequently use their own new media capabilities to produce things such as tribute videos, remixed versions of songs, mashups, parodies, or backlash images and blog posts. These individuals can then access their own social networking and new media accounts and not only distribute their perceptions of Gaga's materials to other members of the public, but also respond to her directly (Jenkins et al. 2009, 5-14). This cultivation of the original content contributes to Gaga's activist messages, because others are now able to join her causes, produce and distribute their own interpretations, and express their own perceptions of her musical and artistic performances (Brunsting \& Postmes 2002). What makes this process unique is the fact that, by way of using these interactive media for consciousness raising, Lady Gaga becomes not only the original producer of her activist artifacts, but also a respondent to 
her initial audience when her messages elicit reception texts. Gaga's mobilization of new media platforms to perpetuate activist messages and interact with audiences presents an effective case study for new media theories established by scholars such as Henry Jenkins, Suzanne Brunsting and Tom Postmes, and Fadi Hirzalla and Liesbet Van Zoonen.

Henry Jenkins investigates concepts of collective knowledge, participatory culture, and media convergence, the latter of which he describes as the place "...where old and new media collide, where grassroots and corporate media intersect, where the power of the media producer and the power of the media consumer interact in unpredictable ways" (Jenkins et al. 2006 [1], 2). By this, he means that as our society's technologies evolve, our methods of doing things such as seeking knowledge, entertaining ourselves, and communicating with one another become increasingly centralized around privileged media tools such as computers. As a result, individual ability to engage in the social world in different ways increases due to the fact that innovative new platforms of interaction (like LittleMonsters.com) allow for participation in discussions, activist issues, etc. that a person may not have previously possessed access to. Jenkins posits that "participatory culture is emerging as the culture absorbs and responds to the explosion of new media technologies that make it possible for average consumers to archive, annotate, appropriate, and recirculate media content in powerful new ways" (Jenkins et al. 2009, 8). Building on this concept, Jenkins explores the changing subjectivity of the 'fanatic', a category that many Lady Gaga fans undoubtedly fall into. He concludes that, due to new media capabilities, fans have evolved from stereotypes constructing them as obsessed, maniacal, and lacking interest in anything but 
the object of their fierce admiration (Jenkins et al. 2006 [2]). Through the use of tools like LittleMonsters.com, fans can now claim a more active identity through what Jenkins has termed 'textual poaching'. By recreating, editing, remixing, and redistributing the texts that they originally consumed, fans now qualify themselves as producers, transcending real-world boundaries like time and space to form community links and perpetuate messages about pop culture and society (Jenkins et al. 1992).

Suzanne Brunsting and Tom Postmes build upon this idea of increased individual participation using new media and online tools. They analyze characteristics of online community building and argue that these groups hold the potential for social influence, qualifying online communities as a forum for collective action (Brunsting \& Postmes 2002). They posit that new media platforms (Facebook, Twitter, YouTube, LittleMonsters.com, etc.) facilitate a sense of social collective despite their individualized and separated nature, based on the fact that people internalize aspects of our social world in order to form a social identity. When we participate in online communities, we maintain this social identity in how we conduct and present ourselves, conserving our beliefs about social issues and what areas of our world might benefit from positive change. They conclude "that social influence is strong even when group members are separated [which] implies that social influence is not merely exerted by the presence or direct influence of others in the immediate environment", but may also be achieved by individual participation in an online community $(2002,259)$.

Fadi Hirzalla and Liesbet van Zoonen build even further upon these theories, exploring the connection between online and offline collective action and how these converge. They argue that online participation can be viewed as an extension of offline 
action, based on the fact that online activities are more accessible and use up fewer resources. As a result, individuals that cannot physically access offline activist efforts because of real world barriers such as time, space, or lack of finances might still become involved in a cause, using online activity to transcend these limitations (Hizalla \& van Zoonen 2011,484$)$. In addition, they argue that “...youth might benefit from opportunities online. They are, after all, the most avid Internet users, and they in particular might lack access to or resources required for participation in several activities offline" $(2011,484)$. This is exemplified in the way young Lady Gaga fans are able to contribute to discussions about anti-bullying and acceptance, despite the fact that they are located internationally and often lack the resources to participate in Gaga's real world activist events. For example, Gaga's Born This Way Foundation built the Born Brave Bus, a bus that travels on the Born This Way Ball concert tour and hosts a pre-show tailgate party where young fans are encouraged to discuss and seek information about mental health (Sheppard 2013). The Born Brave Bus, however, only travels to concert venues in the United States. Even so, little monsters from other parts of the world are active in the online perpetuation of mental health awareness through the use of LittleMonsters.com.

The importance of the dynamic relationship between Lady Gaga and her fans on LittleMonsters.com is that the use of new media platforms bears huge potential for developing concepts of online activism. Lady Gaga's career presents a clear example of how real-world activism in the offline world converges with social advocacy in the online sphere through the posting of videos and pictures on social networking websites (Hirzalla \& Van Zoonen 2011, 481). For example, Lady Gaga made a clear statement in 2010 
when she invited several American soldiers to walk the red carpet with her at the MTV Video Music Awards. These soldiers had been discharged on the basis of homosexuality according to 'Don't Ask, Don't Tell' military policy (O'Keefe 2010). Following the show, video recordings, pictures, and written interviews were quickly published online by various news websites, including Gaga's own, and thereby became methods of consciousness raising in the online world as well. Similarly, because several characters featured in Gaga's HAUS OF Ü series have appeared in real-world performances in which their presence transgressed social norms of gender and sexuality identity, viewers can link the HAUS OF Ü videos in the online sphere with Gaga's ongoing activism offline (Halberstam 2012, 67).

Media theorist Marshall McLuhan has played a large role in establishing academic knowledge about participatory culture and the evolution of the ways in which we communicate based on technological advancement. He argues that our society is shaped not solely by the content of our communication (i.e. the topics that we choose to communicate about), but by the media through which we choose to communicate as well (McLuhan \& Fiore 1967, 8). Due to the manner in which our current technologies transcend physical and social barriers, McLuhan argues that every aspect of our lives is influenced by a constant barrage of communication from not only our immediate circle of influence, but also a much wider sphere of interaction than previously experienced by society. Extending from this, he posits that we can no longer categorize individuals so rigidly in order to separate ourselves from 'others'. The increased participatory nature of new forms of communication renders it impossible for us to avoid information and knowledge about, as well as interaction with, social 'others' (McLuhan \& Fiore 1967, 10- 
24). As a result of this increased exposure to and communication with new information and groups of people through media, our perceptions of the world around us, and therefore our actions, are undeniably altered (McLuhan \& Fiore 1967, 41).

In her own activist career, Gaga exemplifies this increasingly participatory shift in our communicative media by the manner in which she uses new media platforms and social networking capabilities to create a community with her fans and provide a global stage for the discussion of her consciousness raising materials. McLuhan's arguments about increased exposure to the 'other' can also be seen in the inclusion of images and embodiment of transgressive identities in Gaga's YoÜ AND I and HAUS OF Ü texts, especially when viewed in conjunction with the various fan reception texts that interpret, recreate, and re-communicate her messages about gender and sexuality as performative constructs. Gaga's mobilization of video and images in her YOÜ AND I and HAUS OF Ü texts is also exemplary of McLuhan's argument that, as society progresses, an emphasized interaction with and relation to photographs, television and movies emerges. Using these image-based media, we increasingly communicate our perceptions of society, the world and ourselves that inherently influence our actions and behaviour, as well as the actions and behaviour of others (McLuhan 1964). The relationship between fan reception texts and Lady Gaga's original messages about gender and identity, expressed through transgressive images in the form of short films, highlights the manner in which we are able to communicate new ideas about our society, identities, and bodies through images, and thereby influence social conception of those ideas. These characteristics of new media and convergence culture shed light on how Lady Gaga's transgressive activist 
images are able to raise consciousness about social limitations on identity and create social change.

\section{The Developing Phenomenon of Online Activism}

Exploration conducted by various scholars of the ever-changing world of online activism has established several characteristics inherent to this new manner of consciousness raising. In order to understand how the relatively new concept of enacting social change in the online sphere works, we must examine the politics of how identity can be performed online in an alternative manner to how it is enacted in the real world, the ways in which online and offline activism converge, and how a sense of community can be developed through the participation of individuals in online forums. In this thesis, my deconstruction of these issues will reveal how Lady Gaga's YOÜ AND I and HAUS OF $\ddot{U}$ texts employ the body, the use of physical space, and the use of new media platforms and online space in conjunction with one another in order to perpetuate activist messages about hegemonic notions of gender and sexuality.

Much like Butler, Bordo, and Young, Alkeline Van Lenning views gender and sex as social constructions that have been historically determined $(2004,27)$. Conceptualizing identity in this way allows for the body to be understood as a site of discourse and power. If the body is a site of power, then it can conceivably be used to perform gender alternatively to normative conceptions of masculinity and femininity (Van Lenning 2004, 38). These performances have great social implications, as they can “...create a distance between identity and sex and this opens a space for liberty" (Van Lenning 2004, 40). Lady Gaga's Yoü AND I and HAUS OF Ü use this notion of the body as a site of power to raise consciousness about the limiting nature of societal gender norms, 
effectively employing the body as a tool of social change. This use of the body is transferred to the online world through Gaga's mobilization of Twitter and YouTube in the release of her HAUS of Ü videos. By perpetuating her messages about gender and sexuality this way, Gaga uses new media to increase their reach, open her original texts to fan recreation and redistribution, and infuse images of her body as a transgression of hegemonic gender and sexuality in mainstream online spaces that are largely influenced by real-world social norms. This, in turn, increases the representation of marginalized identities in new media platforms that are regularly accessed and employed by dominant groups. Lady Gaga converges online and offline activism by first embodying 'othered' identities in the physical world, and then distributing visual recordings of those performances that anyone with access to the Internet may view.

Gaga's HAUS OF Ü videos exemplify how gender transgression as resistance to hegemony can be transferred to the online world, much like the way that dominant social norms may be identified within the world of internet forums and online interaction. According to Chris Brickell, the Internet's disconnection from the physical body allows individuals to 'gender bend', representing themselves differently without the bodily constraints present in the real world $(2012,8)$. He argues that this can be problematic, however, because Internet participation does not fully disconnect a person from their physical being or reality. Although a person may play with identity online, they will still be exposed to limitations in the form of environmental discrimination based on realworld social norms, which transfer to the online world along with our social identity $(2012,33)$, a concept that I outlined previously. Brickell maintains that even if a person plays with identity online, as Lady Gaga and her fans do in their Yoü AND I and HAUS OF 
Ü texts, they cannot escape the reality of their own body and how it is viewed by society $(2012,30)$. Lady Gaga's videos directly challenge this notion with her use of the body as a tool for social change. Rather than distributing transgressive messages about gender in a more word-based or anonymous way (for example, Jo Calderone and Yüyi the mermaid have their own Twitter accounts), Gaga includes images of her body in her online new media texts. This subverts the various environmental Internet limitations outlined by Brickell, such as hegemonic social expectations transferred from the offline world, just as it subverts real-world social constraints by directly challenging normative understandings of gender and sexuality and physically embodying marginalized identities in order to increase their representation in mainstream forums.

According to Stacey K. Renegar and Valerie R. Sowards (2006), activism has evolved along with society's use of technology. As we increase our use of new media platforms to do everyday things, we must reconceptualize our understanding of what constitutes activism and investigate non-traditional modes of seeking social change, despite the new methods' disassociation with conventional real world efforts such as rallies, protests, and sit ins $(2006,59-60)$. Rather than concentrating on the actual form that a social movement takes, judging its credibility by whether it resembles classic examples of activism, Renegar and Sowards argue that we should instead pay attention to whether it actually motivates social change, regardless of how that change is sparked $(2006,61)$. Tactics such as video distribution online can be understood as a nontraditional form of activism. Considering Renegar and Soward's contemporary understanding of what makes a social movement, Gaga's use of the body to transgress gender norms, and audience member perpetuations of those images, constitutes a form of 
contemporary feminist activism. As society develops, the nature of activism changes as well. Consequently, new forms of activism must be acknowledged due to their ability to raise consciousness about important social issues, albeit in unique and non-traditional ways (Renegar \& Sowards 2006, 58-60). According to this conceptualization of activism, Lady Gaga's YoÜ AND I and HAUS OF Ü texts qualify as social advocacy because they challenge stereotypes and labels. By “...resisting gender stereotypes or refusing to adopt gender normativity" (Renegar \& Sowards 2006, 68), Lady Gaga undermines hegemonic conceptions of masculinity and femininity, distributing these messages to audience members who then respond to and distribute their own interpretations of her transgressive images. Despite the fact that new media texts and the Internet may not fall into the category of 'traditional' activism, Gaga's embodiment of transgressive identities in YoU AND I and HAUS OF Ü successfully manages to raise public consciousness as it subverts social expectations.

\section{Convergences of Online and Offline Activism}

YOÜ AND I and HAUS OF Ü comprise sites where Lady Gaga's online and offline activism converges. Building on physical performances such as Jo Calderone's 2011 MTV Video Music Awards monologue ${ }^{2}$ and extending the messages of self-love and acceptance inherent in the actions of the Born This Way Foundation, Gaga's YoÜ AND I and HAUS OF Ü texts allow audience members to link their transgressive images with

${ }^{2}$ Gaga opened the 2011 MTV Video Awards by performing live for a studio and television audience dressed as a male alter ego, Jo Calderone. Calderone identified himself as Lady Gaga's ex-boyfriend, speaking about his relationship with her and addressing not only media-identified quirks (such as the fact that Gaga tries to never let her fans see her in flat shoes), but also personal insecurities that she has historically been skeptical of addressing in interviews (such as whether she prefers to be called by her real name during sex). The monologue can be viewed here: http://www.mtv.co.uk/artists/lady-gaga/video/lady-gagas-jo-calderone-monologue. 
messages about social change in other contexts. This enables the videos to transcend Internet space, despite having been distributed originally through the use of online social networks and media platforms. The convergence of online and offline activism is significant, because it validates Gaga's videos as true social advocacy rather than an example of more ineffective Internet campaigns, such as the viral and controversial Kony 2012 (Casey 2012), that have been popularly termed by many online users as

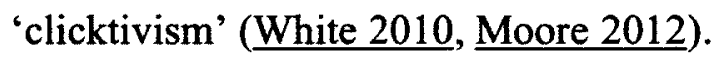

Rasmus Kleis Nielsen (2009) describes some of the inherent issues with online activism that underlie much of the backlash faced by Internet advocacy campaigns. Because social networking websites facilitate quick and easy sharing capabilities, many activist materials fall into the trap of 'over-communication'. This takes place when users are bombarded with repeated exposure to material, to the point that they become disinterested in the message being distributed, potentially ignoring it altogether (Nielsen 2009, 271-3). Although creators of online activist materials seek wide distribution in order to raise awareness of their cause, the risk of over-communication is significant because Internet capabilities potentially take control of the material's distribution from its creators and place it in the hands of general Internet users. Similarly, Nielsen outlines the potential of Internet activism to be marred by miscommunication. Although messages about gender transgression in YOÜ AND I and HAUS OF Ü seem obvious to some, other audience members might misunderstand the purpose of Lady Gaga's creations (and related audience reception texts), conceptualizing them as promoting negative messages about sex and objectification of the body (Nielsen 2009, 273-5). These interpretations 
might serve to diminish the acceptance and public distribution of Gaga's activist materials.

Despite the potential drawbacks of activist involvement on the Internet, Lady Gaga's act of building upon transgressive materials that exist offline serves to reinforce the messages included in HAUS OF Ü. Speaking of the convergence of online and offline materials, Haythornwaite and Wellman (2002) claim that “...the Internet does not function on its own...it is embedded in the real life things that people do" (as cited in Hirzalla \& Van Zoonen 2011, 481). This connection is exemplified in the way that Jo Calderone and Yüyi's images have been extended outside of their specific online material contexts to build upon live performances, magazine photo shoots, and video recordings featured primarily on television. Simultaneously, these texts perpetuate Gaga's messages about gender and sexuality online, as audience reception texts prove. The convergence of activist messages in both virtual and real-world action mitigates the risk of misinterpretation and mis-communication inherent to social advocacy that takes place solely online because it allows audience members to interact with Gaga's messages in both new media and more traditional ways (Hirzalla \& Van Zoonen 2011, 493).

\section{Community Building Through Participatory Culture}

Lady Gaga used interactive Internet platforms Twitter, Facebook and YouTube to post and distribute YOÜ AND I and HAUS OF Ü. This method of disseminating material with an activist message is unique because it facilitates the involvement of a wider group of people at a much faster rate than was previously possible. Because the nature of this new media communication is so interactive, allowing audiences to respond to Gaga's materials and potentially receive a personal reply, the images presented in the videos bear 
another activist quality in their ability to establish a sense of community. Users of these platforms and Gaga's website LittleMonsters.com, do not simply view Gaga's texts, but they can become actively involved in perpetuating Gaga's messages about gender and sexuality limitations. According to Eaton, the Internet offers users space to share values, discuss norms, and establish boundaries while building a sense of 'virtual togetherness' (Eaton 2010, 176). Although it has been theorized that this facilitated closeness is simply a construction based on discourses about community, materials like Gaga's HAUS OF Ü do facilitate participation for individuals who cannot become involved in real-world activist campaigns due to spatial, temporal, or economic constraints. Eaton terms this kind of involvement 'fast activism', stating that public audiences and Internet users can easily interact with new media texts " ... because traditional barriers to activism (career, family, etc.) do not necessarily inhibit one's ability to engage in fast activism...." (Eaton $2010,188)$.

Brunsting and Postmes (2002) also acknowledge the Internet's ability to facilitate some form of community building through the sharing of knowledge. They acknowledge that although social norms often carry over into the online world due to the exchange of ideas, communities develop and benefit individuals because the blurring of differences reinforces group unity (Brunsting \& Postmes 2002, 530). This element of online participation can be seen in many audience members' recreations of Lady Gaga's YOÜ AND I and HAUS OF U texts. Although individuals may use their reception texts as opportunities to express personal beliefs about identity or to agree with Lady Gaga's message, they also become a part of the millions of users interacting with Lady Gaga's Twitter, Facebook, Youtube and LittleMonsters.com accounts on a daily basis. Audience 
members that connect with Gaga's new media texts in this way might participate in the perpetuation of her lobbyist messages by playing an active role in a group that shares a common interest or purpose. Gaga's new media texting constitutes activism by emphasizing that, just as the Internet "...provides the strategic conditions that empower the expression of social identity, it will mobilize people and stimulate collective action" (Brunsting \& Postmes 2002, 530).

The interactive relationship between Lady Gaga's YOÜ AND I performances and corresponding reception texts exemplifies how the use of new media and Internet capabilities may constitute non-traditional forms of consciousness raising as social activism. Lady Gaga embodies 'othered' forms of gender and sexuality identities in her original video, which she distributes to audience members using interactive social networking websites and new media platforms. Gaga's use of her body as a tool of social change, the manners in which her new media texts and real-world activist performances converge, and the establishment of an online community that allows public audience members to actively participate in the perpetuation of her messages hold important social implications. By releasing advocacy materials in this way, Lady Gaga and her responding audiences play an important part in forging the path for new, non-traditional forms of activism to be legitimized. My analysis of Lady Gaga's YOÜ AND I and HAUS OF Ü texts and their corresponding reception texts, and my subsequent conclusions about how these videos work together to form legitimate social advocacy, highlights that activism is evolving technologically along with most other aspects of our modern world. Lady Gaga's messages exemplify the changing face of not only gender and sexuality politics, but also contemporary social activism. 


\section{The Role of the Celebrity in Activism}

The role of the celebrity in social advocacy is contentious within the sphere of activist discourse. While some believe that celebrity endorsement is harmless and even beneficial, others argue that celebrity involvement in social change is ineffective and possibly even detrimental to the success of a particular cause. Whether or not celebrities experience success in their personal activist endeavours is debatable, and scholars have established certain criteria upon which celebrity activism depends and thrives. Jo Reger (2007) maintains that the ability of celebrity figures, particularly musical artists, to incite passion for a particular activist issue lies primarily in the establishment of a fan-base or community and the fundamental link between music and emotion $(2007,1351)$. Huliaras and Tzifakis (2010), however, establish three social and logistical factors and two individual-level factors upon which the success of a celebrity's activist involvement depends in the practical world $(2010,256)$. These five elements of celebrity activism will be explored in further detail in this section. In contrast, Thrall et al. argue against traditional methods of celebrity involvement in activism, which historically employ tools of mass media, and instead favour a more contemporary new media approach as the only effective manner in which celebrity icons can achieve social change $(2010,364)$. Each of these positions on celebrity activism can be identified and deconstructed within Lady Gaga's career, specifically within the context of her trangressive YoÜ AND I and HAUS OF Ü texts and their relationship with both her real-world activist involvement and her "Born This Way" ideology. 
As is the case with identity activism surrounding the social construction of gender and sexuality, notable political figureheads do not always act as the most visible representative associated with an activist cause. Many causes that require public attention for social change lack the involvement of a prominent social leader, and are instead enacted through the efforts of more individually existing groups. Reger argues that, for this reason, celebrities (more particularly musical artists) often become the primary role model identified by individuals involved with a particular social cause $(2007,1351)$. The reason for an affiliation of an activist cause with a celebrity leader or musical figure is two-fold.

Firstly, there is the absence of other politically based national leaders. When a cause lacks visible representation at a higher social level, despite the existence of active individuals enacting practical change at the community level, it becomes easy to associate that cause with a celebrity icon who shares an interest in the same social issue because the celebrity may be the only one speaking about such matters at the national (or international) level. While this person may not necessarily serve to mobilize resources or bodies for the purposes of social action, they still constitute visible leadership by acting as spokesperson to the masses on behalf of community-based advocates (Reger 2007, 1352-3). Individual groups at the community level might choose to affiliate their efforts for social change with a prominent celebrity figure, such as a musical artist like Lady Gaga, when faced with the alternative option of having no visible national leader. As is the case with Gaga, although not all individual community-based groups will agree with every statement she makes regarding GLBTQ rights and anti-bullying discourses in the 
media, there still exists a wide social perception of her as a prominent player and role model in the fight for social change related to these issues.

Secondly, individuals might identify musical celebrities as activist leaders for particular causes based on emotional mobilization, or the ability for music to establish a space for discussion about the emotional connections between individuals and activism (Reger 2007, 1353-4). People's decisions to align themselves with a particular cause are often based on an emotional personal connection with the issue itself. Whether they choose to affiliate themselves with a particular activist movement can be influenced by the mobilization of emotion made possible by music, which many consider an easily relatable method of widely communicating a specific message. This emotional connection provides the basis for musical celebrities like Lady Gaga to become prominent members of specific activist communities based on their ability to act as a public spokesperson for the cause through their music (Reger 2007, 1362). This is exemplified by Lady Gaga's "Born This Way" ideology, a message widely associated with GLBTQ activism that was communicated through her song of the same title, and one that remains visibly perpetuated through her ongoing career, including within the transgressive images presented in her YOÜ AND I and HAUS OF Ü videos.

In contrast to Reger's emotional connection between activism and the celebrity, Huliaras and Tzifakis establish five practical ways that a musical icon like Lady Gaga might be constructed as a leader of social change. While official bodies related to human rights have sought out particular celebrities as representatives, other celebrities have intentionally established their activist status partially for their own benefit. Some have found themselves involved in social causes primarily due to certain freedoms they are 
granted specifically based on their celebrity status (Huliaras \& Tzifakas 2010, 255-6). Lady Gaga's status as a representative for GLBTQ rights can be viewed through these various lenses.

Huliaras and Tzifakis argue that the phenomenon of the celebrity activist was sparked by the desire of large human rights organizations, such as UNICEF and the United Nations, to affiliate themselves with certain famous faces in order to increase visibility of their causes with the public as a whole $(2010,259)$. By teaming up with prominent figures within the entertainment industry, these organizations render their activist messages more accessible to non-politically orientated audiences. Similarly, various non-governmental organizations have actively sought out celebrity cooperation for their campaigns in order to take advantage of the ability of the celebrity to mobilize media tools and serve as an easily recognizable public persona that might attract increased mainstream attention (Huliaras \& Tzifakas 2010, 260). For example, Lady Gaga recently worked in partnership with the UN and UNICEF, visiting an impoverished school in Peru to speak with students about the importance of recognizing their own value and empowering themselves through continued learning and education (Cure 2012). She has also spoken about the need for social change in regards to the treatment of GLBTQ individuals at events worldwide, such as the National Equality March rally in 2009, organized by prominent activist groups Equality Across America and the Courage Campaign (Zak 2009).

Gaga's advocacy primarily falls into Huliaras and Tzifakis' category of celebrities who become involved in social change movements based on the freedom of travel and resources afforded them by their very status as a celebrity $(2010,260)$. As both Gaga's 
fame and revenue have increased, she has been able to become more and more involved in the world of activism. This is epitomized by her previous individual campaign efforts culminating in the establishment of her Born This Way Foundation, which occurred in February 2012, shortly before the launch of her Born This Way Ball world tour. The foundation's success, however, is dependent not solely upon her status as a celebrity, but her willingness to work with professionals who embody the experience of enacting social change at a practical level. This allows Gaga to concentrate her skills on gaining attention for her cause and fundraising; two areas within which Huliaras and Tzifakis argue that celebrities have the most success in the world of activism $(2010,263)$.

Huliaras and Tzifakas also establish a category of celebrities who become involved in activism with the specific intentions of increasing their personal visibility and benefitting from the positive image that an association with social advocacy might render them (2010, 260-1). While Gaga does not fall precisely into this category (her Foundation is promoted and run largely by her mother, Cynthia, and a team of qualified professionals, rather than Gaga personally, which slightly disassociates her stardom from the actual work and success of the foundation), her career has undoubtedly received positive feedback due to her association with GLBTQ activism, primarily in the establishment of her position as one of the biggest musical stars supported by GLBTQ populations as a fan-base, rather than as fellow activists. This does not mean, however, that she has not been subjected to media criticism and claims that she is simply using the GLBTQ community to boost her own image (Fisher 2013). Even so, the relationship between her activism and her musical career puts her on a level of fame already inhabited by the likes of women such as Madonna and Cher, whose careers also skyrocketed as a 
result of support from GLBTQ fan-bases. Gaga's success in this regard has, of course, benefitted greatly by the fact that she has perfected her media mobilization skills throughout the course of her career. According to Huliaras and Tzifakis, the ability of a celebrity to gain the media spotlight effectively enough to perpetuate messages that relate to both an entertainment and an activist career is key to success in the world of social change $(2010,261)$. Lady Gaga's status as one of the most prominent females in contemporary pop culture exemplifies this tactic of celebrity activism.

Huliaras and Tzifakis describe a traditional model of celebrity activism, whereby the celebrity attracts increased audience attention in the entertainment sphere using their fame to mobilize mainstream media and perpetuate messages associated with a particular cause. Thrall et al (2008), however, contend that this method of using fame to enable advocacy is no longer effective in our current media landscape. With the increased use of new media platforms and social networking capabilities, news is being sought and consumed on a much more individualized level, rendering mainstream methods of distributing activist messages less effective than they might have been previously (Thrall et al. 2008, 364). While mainstream media might still be considered effective in terms of rendering a famous face the most visible role model for an activist cause, Thrall et al. build on Huliaras and Tzifakas' argument that the celebrity role models cannot use mainstream media sources to actually enact social change at a practical level, as these only facilitate a spokesperson position (Thrall et al. 2008, 374). Lady Gaga's speeches at various international events, such as Europride 2011, a Europe-wide GLBTQ pride event hosted by a different European city each year, were widely publicized in mainstream media and this contributed to her establishment as one of the most current faces of social 
change in regards to GLBTQ rights and anti-bullying initiatives. Despite the fact that publicity increases awareness about important issues, it does not ensure that action will actually be taken to spark that change at a practical or community-based level.

Instead of relying on mainstream media to capitalize on associations with fame in the world of social advocacy, Thrall et al. propose a new model of celebrity activism within which Lady Gaga can already be seen working. Rather than concentrating on increased visibility in traditional media sources, attention should be shifted to new media and social networking platforms, where audience user-ship has already been transferred as our society's online participation has increased and evolved (Thrall et al. 2008, 378-9). By taking advantage of convergence culture and using tools that facilitate a more dynamic relationship between a celebrity representative and an audience, active steps toward change can be taken both online and offline to perpetuate activist messages and involve individuals at the community level, rather than simply preaching to them from the national or international level (Thrall et al. 2008, 380). This shift in tactic is exemplified by Lady Gaga's mobilization of new media platforms to distribute messages about the limiting nature of the social ideals of gender and sexuality within her YOÜ AND I and HAUS OF Ü texts. Gaga's use of social networking tools works in conjunction with the distribution of her image in association with identity activism in mainstream media, allowing audience members to inhabit both the position of the consumer and the producer of those same activist messages, or to participate not only through usage but also through 'produsage', or the usage of online tools to produce new texts after consuming original materials (Bruns 2008). This avoids some problematic features of the previously described traditional model of celebrity activism, allowing Lady Gaga to serve both the 
role of the celebrity leader and the active campaign member, and mitigating constructions of her involvement as simply for the benefit of her own career.

\section{Symbolic Interaction Theory}

As an extension of these foundational theories surrounding gender, sexuality, and activist new media participation, my analysis is also built upon symbolic interaction theory in my identification of how audience members interact with Gaga's transgressive images in their own reception texts. Working with this notion as part of my theoretical framework enables me to more effectively determine which images within Lady Gaga's performances actually constitute activism, based on how audiences choose to embody or portray gender and sexuality identities.

According to Herbert Blumer, symbolic interaction theory states that human beings act toward things (i.e. language, objects, etc.) based on the meanings that these things hold for us $(1969,2)$. This meaning is primarily derived from social interaction with other individuals and the world around us, and is taken in and modified through an interpretive process (Plummer \& Young 2010, 310; Blumer 1969, 3-5). Because of the potential for interpretation, however, knowledge construction based on meaning is not static. Within the context of my research, for example, a person's interpretation of what 'gender' or 'sexuality' means can be changed based on their interaction with activist or transgressive materials, such as those created by Lady Gaga. Based on symbolic interaction, it follows that new knowledge may be created through social change (Plummer \& Young 2010, 315; Blumer 1969, 88-9). Marilyn Plummer and Lynne E. Young state that symbolic interaction theory is hinged upon human experience, and that the way we have developed our knowledge as a result of interaction with those around us influences how we act, because we base our actions on what we know will be the 
consequences of those actions $(2010,308)$. Interaction with others and our environment, however, is not the only type of interaction that allows us to develop our knowledge and interpret meaning. Plummer and Young posit that self-interaction is also essential to symbolic interaction theory and the ways in which we ascribe knowledge to certain things and determine our actions. This act of turning experience onto the self is often referred to in contemporary feminist research as 'self reflexivity', which “...enables the feminist researcher to locate herself as a subject of history so that her perspective develops from understanding her situatedness in a particular context" (Plummer \& Young $2010,313)$. This process of reflexivity can be seen in many Lady Gaga fan recreations.

\section{Situating YoỦ AND I and HAUS OF Ü in Symbolic Interaction Theory}

Audience reception texts reflect how respondents interpret the representations of gender and sexuality in the YOÜ AND I and HAUS OF Ü texts that they consumed and chose to reproduce. When those reception texts are redistributed, they contribute to and further perpetuate the messages that Lady Gaga communicated in her original performances. They often also build upon those messages in order to take them further and consider facets of subjectivity that the original images perhaps did not address explicitly. In Chapter III, I examine several examples of fan reception texts that not only re-communicate or recreate Gaga's images, but also, in line with symbolic interaction theory, further interpret the concept of transgressive gender or sexuality identity, exposing another non-normative image or an additional aspect of identity politics that Gaga's emphasis on bravery and self-love might influence. 


\section{Reception of Lady Gaga's Work: Emergent Themes}

I investigate Lady Gaga's advocacy within the context of three emergent themes. My association of her work with ideas of empowerment is based on several successful campaigns in which she played a key role in motivating social change for GLBTQ rights and anti-bullying awareness. In contrast, my exploration of her work in the context of hyper-sexualization is informed by various forms of media backlash sparked by her inclusion of overtly sexual language use and imagery. Finally, I question the performativity of Gaga's representations by considering the reception of her persona as existing primarily for media attention and profit, a view that stands in contrast to her reception as transgressive of dominant social norms.

\section{Interpreting Gaga's Work Through the Lens of Empowerment}

My use of the term empowerment is based on Elizabeth Rocha's definition of 'empowerment' as a particular experience of power $(1997,32)$. Specifically, I reference 'Rung 4' on Rocha's 'Ladder of Empowerment', which emphasizes links between individual circumstances and community conditions, developed through united social advocacy in order to challenge oppressive elements within social institutions $(1997,33)$. The establishment of Gaga's Born This Way Foundation for youth empowerment and widespread messages of self-love and acceptance promoted by her "Born This Way" and Body Revolution 2013 ideologies exemplify Rocha's empowerment model. This foundation constructs Gaga as a positive and inspiring role model with whom audiences may relate, and thereby wish to support. Her identification as a victim of bullying in her past ("Lady Gaga Admits Being Bullied In High School Still Hurts"), her revelation about experience with eating disorders throughout adolescence 
(www.littlemonsters.com/abodyrevolution), and her openness about having participated in several bisexual encounters (Hiatt 2009) give her a strong personal connection with the social issues she addresses.

Gaga's acknowledgement of these experiences also provides audiences with the opportunity to establish a feeling of commonality with her and, as Railton and Watson claim, to attribute authenticity to her efforts (Railton \& Watson 2011). The underlying positive messages about Lady Gaga and her career enable audience members to view her as a beneficial role model and an effective example of how individuals can contribute to efforts for social change (Aroxa 2009, Fisher 2002, Fine \& McClelland 2008).

\section{Receiving Gaga's Work as Raunch Culture and Hyper-sexualization}

In contrast to this reception of Gaga as an empwowering celebrity figure, I argue that some audiences may view Lady Gaga's activist campaigns as lacking in appeal due to the sexual nature of her performances on stage and in musical or artistic videos. Lady Gaga advocates publicly for freedom of sexual expression in a very open and overt way, performing in thong underwear and releasing videos in which she appears naked or engaging in sexual acts, all of which she does in YoÜ AND I. This behaviour gives some audience members reason to doubt her appropriateness as an activist because they associate her image with over-sexualization (Railton \& Watson 2011, 145-7). Thus, by displaying herself in ways that arguably objectify her own body, Gaga gives audiences permission to view her sexually (Meyers 2008). This perception can detract audience attention from Gaga's activism and lead some members to define her activist performances as non-serious or inauthentic. 
This type of audience member may not wish to support an icon whose career they believe contributes to the development of 'raunch culture' (Levy 2005). The term raunch culture refers to the concept of over-the-top sexual expression that may be mistaken for sexual empowerment. Raunch culture emerged as a backlash to conservative stances on female sexuality and gradually transformed into willing participation in over-sexualized popular culture practices that objectify one's own body (Levy 2005, 3-45). In supporting the social advocacy efforts of a musician, the public also supports the distribution of that person's image. If particular audience members do not wish to be exposed to or associated with the sexual messages produced by Lady Gaga's musical endeavours, they may be less likely to view her as a valid icon for social change (Oppliger 2008, Hermes 2006, Bragg \& Buckingham 2009, Whiteley 2006). Furthermore, her openness about participating in bisexual acts, but her lack of formally claiming a bisexual identity may cause some public audiences to view her as an invalid activist ambassador for GLBTQ rights (Capulet 2010, 297-300; Zaylia 2009).

\section{Seeing Beyond the Performativity of Gaga's Work}

In addition to the reception themes of empowerment and hyper-sexuality, I argue that audiences express a third perception of Lady Gaga's activist images, particularly related to YOÜ AND I and HAUS OF Ü. Gaga has claimed that her performance does not end when she steps off stage, but extends to ultimately engulf the rest of her life (Garabaldi \& Vena 2012). She has famously stated in interviews that she exists, both as an artist and as a person, half way between the worlds of fantasy and reality (Cheong \& Fang 2011). To examine perceptions of Gaga's work as being 'all for show', I employ the term performativity. Philip Auslander discusses the amalgamation of a musician's 
constructed identity with theatricality and the creation of an extended public image that expands the performance beyond the stage to engulf the artist, making it difficult for others to distinguish between person and persona (Auslander 2006, 106-7).

Using Auslander's paradigm as a template, I contend that some members of the public may view Gaga's activism as simply another aspect of performance rather than something in which she is authentically invested (Auslander 2006). According to Railton and Watson, "...music video can be seen as a key site through which the star image of certain performers is established and circulated" $(2011,69)$. This notion of the music video as a material for building up a 'star image', or public persona, might be interpreted as being contradictory to the music video's function as a medium for communicating activist messages. Can one text genuinely achieve both of these things, or is the image of the artist as an activist figure simply a performative act attempting to build a positive 'star image'? Despite several successes with her activist causes, the highly performative nature of Lady Gaga's career causes some members of the public to question whether her social involvement is genuine, or whether it is simply an attempt to gain further publicity and attract media attention, as so many of her actions do (Railton \& Watson 2011, 66-83, Reger 2007). This sense of performativity, however tends to be viewed by the public in a less negative manner than accusations of hyper-sexualization do. Instead, this way of conceptualizing her activism paints it as inconsequential and not likely to motivate real social change, but not necessarily detrimental to a cause.

\section{Integration of Reception Themes with Theories of Gender and Sexuality}

Each of these thematic undertones within Lady Gaga's new media communications emerges in the context of gender and sexuality as socially constructed 
and performative identities. Throughout my analytical investigation, I employ my three over-arching categories of analysis - transgressions of hegemonic femininity, transgressions of hegemonic masculinity, and representations of the 'improperly' feminine - to examine transgressive images within videos created by Lady Gaga herself and responding texts produced by audience members. I root my analysis in the theoretical framework of how different conceptions of gender and sexuality may be embodied and performed. Specifically, I pay close attention to the ways in which Lady Gaga challenges hegemonic ideals of identity by personifying 'othered' representations of gender or sexuality within her varied productions related to the song "Yoü and I". These nonnormative identities include those that transgress normalized ideas of 'proper' masculinity or femininity, as well as sexual relationships that do not fall within the parameters of heteronormativity (Valocchi 2005). I also consider how audience members apply Gaga's activist images to their own expressions of gender and sexuality, and both include and communicate this in their creation of reception texts. The perpetuation of these images is contentious, even in modern Western society, and is not necessarily accepted by all members of a public audience, rendering this controversial element within her work fit for close analysis.

Those who are critical of erotic public display may believe that Gaga's use of nudity is an unnecessary shock-factor that serves to hyper-sexualize her performances rather than motivate social change. According to Adrienne Evans, Sarah Riley, and Avi Shankar, the "...mainstreaming of explicit, 'up for it' female sexuality represents a shift in public discourses from a heterosexual femininity constituted through passivity, whose sexuality was placed as inferior to her male partner, towards a more active, confident and 
autoerotic sexuality" $(2010,117)$. Although some view this change in discourse as empowering for women, Evans et al. caution that, as the shift takes place alongside an increase in consumer culture, female sexuality risks becoming marketable, another product to be sold, purchased, and consumed $(2010,119)$. This logic has caused some viewers to interpret many of Gaga's performances as hyper-sexualized and bearing negative influence upon younger fans. For example, broadcaster 'Dame Joan' Bakewell was quoted about her dislike for a televised Gaga concert, stating "Lady Gaga was playing up the raunch, which rather spoilt it for me" (Thomas 2012). Bakewell went on to say "when young people get to their own sex life they are either going to be disappointed or they are going to do it badly because they are going to be jumping around like some raunchy singer" (Thomas 2012). Herein lie the concerns of Laura Rival, Don Slater and Daniel Miller, who argue that as raunch culture rises, so does the eroticization of mainstream sex, especially considering the increased access to pornographic materials provided by online participation (Miller et al. 1998, 300).

In addition to questions of hyper-sexualization, some viewers who witness Lady Gaga's displays of semi-human beings having sexual intercourse with humans, or a feminine Gaga kissing a transgender version of herself might interpret her embodiments of gender and sexuality as spectacular and unrealistic. For example, MTV's celebrity blog Buzzworthy posted about Gaga's HAUS OF Ü films in 2011 using the title "Lady Gaga Goes Topless (!!!) In Second 'Haus of Ü’ Fashion Film” (Rubenstein 2011). This title removes all attention from the transgressive and artistic nature of the films, focusing instead on the fact that Gaga appears topless. This fixation on her nudity exemplifies how, for some viewers, the use of the naked body constructs the performance as a ploy 
for attention rather than a social commentary. This, in turn, paints Gaga's consciousnessraising images as sensational and unconventional rather than as a critical exploration of the problematic nature of hegemonic sexuality and gender constructions.

There do exist, however, members of the public who perceive Lady Gaga as a positive and inspiring role model, capable of using her own body as a tool for social change (Van Lenning 2004). According to Ellen Waterman, erotic creativity achieves social change when it is "...committed to accounting for difference" in subjectivity $(2008,6)$. Such spectators view Gaga's new media distributions of non-normative performances of gender and sexuality as empowering. By drawing such widespread attention to images of herself transgressing hegemonic identities and embodying 'othered' forms of masculinity, femininity, and sexuality, Lady Gaga draws attention to what Petra L. Doan refers to as 'the tyranny of gender'. This “... arises when people dare to challenge the hegemonic expectations for appropriately gendered behaviour in Western society" $(2008,365)$. By embodying marginalized identities and performing sexuality in ways that are not only transgressive, but borderline hyper-sexualized, Lady Gaga raises consciousness about the limitations of standard constraints of gender and sexuality (Johnson 2002).

\section{Methodology}

\section{Method}

In order to explore the dynamic texts that arise from participatory culture, as well as the meanings that emerge from these texts, I will conduct an inter-textual analysis of Lady Gaga's use of new media as a form of activism. Specifically, I examine videos, performances, and art pieces related to the song "Yoü and I" that have been posted and 
shared online by Gaga herself. I use these original materials to identify particular embodiments of sexuality and gender as performative representations of identity within her work, and consider how these embodiments serve to draw attention to the transgression of normative social ideals surrounding gender and sexuality. Within the YOÜ AND I video itself, I study each of the characters enacted by Gaga: Bride, Yüyi the Mermaid, Nymph, Jo Calderone, Mother, and Barn Hooker. Each of these characters serves as a personification of non-normative sexual or gender performance. I also consider other representations of gender and sexuality, such as Gaga as a Frankensteinesque being, physically pieced together by a man. In conjunction with the music video itself, I analyze the five related artistic short films entitled HAUS OF Ü (Formichetti et al. 2011, 2012). Each of these performance pieces, once again distributed by Lady Gaga via her own social networking accounts, presents audiences with transgressive enactments of gender and sexuality that fall outside of society's hegemonic conceptualizations of identity (Ward 2010). These performance pieces are key examples of how Lady Gaga uses new media to build her activist platform, drawing public attention to the notion that gender and sexuality are social and historical constructs and may actually be performed in many different ways.

Along with materials related specifically to YOÜ AND I, I contextualize my arguments with brief examinations of other aspects of Lady Gaga's career that tie directly into the key themes these videos present. For example, Gaga's "Born This Way" ideology is clearly identifiable within enactments of non-normative gender and sexuality expressions in these performance pieces, as is her new Body Revolution 2013 ideology. Also, concepts of the grotesque as beautiful, presented in the music video BORN THIS 
WAY, and hegemonic social beauty standards as grotesque, as depicted in the music video BAD ROMANCE, are inherent in the images of Bride, Yüyi, and the various Frankensteinlike Gagas in YOÜ AND I. Linking these common themes between performances, specifically the way that ideas of the 'grotesque' as beautiful can be interpreted within images that resist the notion of the 'improperly feminine', allows me to investigate prevailing social issues for which Lady Gaga advocates social change, through her music. In addition, I make vital connections with other materials distributed by Gaga and her team, such as recordings of live performances (for example, the 2011 VMAs monologue as Jo Calderone), magazine covers and interviews, red carpet appearances, song lyrics, advertisement campaigns, and images or videos created specifically to raise social awareness about particular issues. Though not all of these may originally take place in the context of online social networks, where Gaga provides audiences with links to updates and new material, and communicates with fans at large, each of these career components may be discussed in or transferred via pictures and video to the online world, where audiences can easily access and respond to the information provided to them.

Finally, I analyze a number of audience responses to Lady Gaga's activist performance pieces. Due to her use of new media platforms, fans may access and interact with her work in ways that were not previously possible. This is a key factor in allowing her online and offline performances to converge, which contributes to their actual qualification as perpetuations of social activist messages. When fans view a picture, video, or recording of a performance, they may use their own new media capabilities to produce things such as tribute videos, remixed versions of songs, mash-ups, parodies, or backlash images and blog posts. These individuals can then access their own social 
networking and media accounts and not only distribute their personal perceptions of Gaga's materials to other members of the public, but also respond to her directly. This contributes to Gaga's activist messages because others are able to join her causes, produce and distribute their own interpretations, and express their own perceptions of her musical and artistic performances (Brunsting \& Postmes 2002). What makes this process unique is the fact that, by way of using these interactive media for consciousness raising, Lady Gaga becomes not only the original producer of her activist artifacts, but also a respondent to her audiences when her messages elicit reception texts; the producer becomes the consumer (Jenkins 2006). The importance of this dynamic relationship is that the use of new media platforms yields pivotal implications for developing concepts of online activism. Lady Gaga's career clearly demonstrates how real-world activism in the offline world converges with social advocacy in the online sphere through the act of sharing videos and pictures on social networking websites.

I conduct these analyses within the framework of symbolic interactionism. The application of this theory informs how I interpret audience reception texts, not in a way that influences my investigation or causes a bias, but rather in a manner that will help me determine how a reception text appears to conceptualize Lady Gaga's deconstruction of gender and sexuality. I identify what meanings the concepts of gender and sexuality hold for an individual according to symbolic interactionism, based on how they perform or represent these in their reception text. This, in turn, reveals how particular individuals have actively involved themselves in Lady Gaga's social causes and rendered themselves as participants in her developing activist community. 


\section{Scope and Limitations}

Within the process of conducting my research, there are several limitations of which I have remained very cognizant. Firstly, I must acknowledge that I cannot assume to know the specific intentions of Lady Gaga when she created and posted her original texts. Additionally, although I can analyze the social implications of her images, I am forced to rely upon other sources (ex. interviews) in order to gain some understanding of how she might perceive audience responses to her own work, because I do not (yet) possess the ability to conduct an interview with her myself. Similarly, I cannot presume to know the basic intentions of those audience members that distribute their reception texts. Although I can analyze these texts based on the aforementioned theoretical concepts, I must acknowledge that my examination will inherently involve the use of my own skills of analysis, which naturally risks the misappropriation or misinterpretation of what message an individual may have been attempting to convey in their text. This issue also constitutes my primary ethical concern. Because of the public nature of the online materials I am working with, however, I am not required to complete a Carleton University ethics approval process. All reception texts included within my investigation have previously been intentionally displayed on public Internet forums where others may view them freely.

In addition, I have actively kept in mind during my analysis that, due to the online nature of the new media materials I am working with, the scope of the population within the reception texts will not be representative of Lady Gaga fans worldwide. Despite common misconceptions that the Internet is a borderless, global community that allows the social involvement of individuals that would otherwise not be able to do so, online 
participation is privileged and exclusionary (Gorski 2010, 351-3). I can, therefore, only analyze reception texts disbursed by individuals who possess access to the technology and freedom necessary to create and post materials in a public Internet forum.

Finally, I bear the responsibility of addressing my own status as an avid Lady Gaga fan. Having closely followed her career since 2008 and attended seven concerts during the years prior to the submission of my thesis, it becomes essential for me to acknowledge that my conclusions may not necessarily correspond with my own personal opinions about Gaga's work. Despite this, and the involvement of my own interpretation based on the fact that I am acting as a viewer of reception texts, I am obliged to stay true to the reception texts that I have chosen to work with, regardless of what they reveal about Gaga's work as activism. 


\section{Chapter III}

\section{Analysis of Lady Gaga's Yoü AND I Video and Haus of Ü: Representations and Transgressions of Hegemonic Femininity, 'Othered' Femininity, and Masculinity}

Lady Gaga's 2011 music video YoÜ AND I and its five corresponding short films can be seen to offer an artistic study in the transgression of hegemonic identity norms through the use of both artistic performance and online new media participation. Each of the texts contains images of Lady Gaga purposefully embodying her YOÜ AND I personas in order to depict dominant constructions of gender and sexuality as inherently interdependent and rigidly defined, as well as to represent transgressive understandings of these same identities as fluid, impossible to categorize, and infinitely performative. These concepts that can be identified in her "Born This Way" ideology and campaigns like Body Revolution 2013.

In this chapter, I use three overarching categories of analysis to deconstruct the YOÜ AND I materials in order to examine Gaga's performance of these personas and to uncover several emergent themes. I also employ the fundamental theoretical tools outlined in Chapter II in order to identify instances of gender and sexuality transgression and examples of new media as a tool of activism. The first category of analysis is the representation and transgression of hegemonic femininity; here, I look at Nymph, Mother, and Barn Hooker and consider how different understandings of gender and sexuality are communicated through their stories, modes of dress, and behaviours. The second category of analysis is the representation and transgression of 'othered' femininity; here, I investigate Bride and Yüyi and connect notions of gender and sexuality as they relate to ability and the non-normatively female body. The third 
category of analysis is the representation and transgression of hegemonic masculinity; here, I explore Jo Calderone and concentrate on the dis/association of gender, sexuality, and the physical body and the inclusion of a transgender identity in a mainstream media phenomenon. Within each analytical section, I compare important images from the YOÜ AND I materials with dominant conceptions of identity, stereotypical media representations of femininity and masculinity, and problematic hegemonic constructions of ability and the differently abled body.

\section{Transgressions of Hegemonic Femininity: Lady Gaga's Performances of Nymph, Mother, and Barn Hooker}

\section{The Nymph-Jo Relationship in YoÜ AND I: Representations and Transgressions of Heterosexual Norms}

Nymph, played by Lady Gaga, is portrayed as demurely feminine and innocent; even her name suggests that she shares stereotypically feminine characteristics with the nymphs of Greek mythology, often portrayed as immortally young, beautiful maidens (Matadin \& Van Lamsweerde 2011). She appears in the YOÜ AND I music video to be the embodiment of hegemonic female identity, particularly when entertaining her lover Jo Calderone. Nymph's normative performances of gender and sexuality are challenged, however, when audiences realize that Jo Calderone is also Gaga, this time dressed in drag (Brewis et al. 1997). This revelation changes the scope of the Nymph-Jo relationship, destabilizing the apparent heterosexuality between a man and a woman by portraying, in effect, a relationship between two women, despite the outward masculine appearance of Calderone (Beasley 2010). The representation here invites the audience to reflect upon the very nature of the sexual relationship. Is it one that is based on performed heterosexuality? 
The transgressive nature of the relationship between Nymph and Jo Calderone also serves to destabilize concepts of hegemonic femininity as it relates to sexuality, even though Nymph embodies an outwardly normative image of 'girl' or 'woman'. Notions of compulsory heterosexuality comprise a key component of society's dominant understandings of the 'properly' feminine (Butler 1988). Stereotypical images of women as passive actors who devote their time to caring for and attempting to impress their men are widespread in modern media. At first glance, this normative relationship is presented to viewers through the dynamic between Nymph and Jo Calderone in YOÜ AND I. When the true nature of their relationship is uncovered (for those who do, in fact, realize it), however, it is not only Calderone's gender performance that is called into question, but also Nymph's. If society understands femininity and heterosexuality as being inherently linked, then Nymph's performance of femininity becomes 'othered' through her relationship with another woman, especially one that seems to be improperly performing her own gender identity. Lady Gaga includes an element of artistic performance here as well, adding another layer of 'other'-ness to the relationship simply because Nymph and Jo Calderone are not only both physically women, but are also both Gaga herself; the relationship exists between two alter egos of the same person, or two varying performances of the same individual's gender.

Nymph's relationship with Jo Calderone transgresses her outwardly hegemonic femininity due to the fact that mainstream language fails to identify certain relationships that exist outside of heterosexist norms (Bordo 1992, 164). Nymph cannot be concretely classified as 'heterosexual' because the physical sex of Jo Calderone is not male. Similarly, Nymph would not necessarily be categorized as a lesbian because Jo 
Calderone's gender identity is not female. Lady Gaga's video overtly presents an 'othered' relationship for which there exists no mainstream vocabulary (some might consider such a relationship under the umbrella of 'queer', but this term does not specifically refer to a biological woman who identifies as a woman engaging in a relationship with a biological woman who self-identifies as a man) and this draws specific attention to the ways in which gender and sexuality cannot be absolutely classified according to dominant social norms. It also effectively highlights how multiple facets of society, even something as simple as a lack of vocabulary, constrain and limit individual identity and marginalize certain behaviours, relationships, and people (Young 1986).

Gaga's portrayal of Nymph in both YOÜ AND I and the short film HAUS OF Ü FEAT. NYMPH can also be understood to disseminate an image of a non-heterosexual woman that is not in keeping with dominant social stereotypes of women who eschew strict heterosexuality. Women who are involved in relationships with other women are typically depicted in the media according to two binary conceptions: the butch 'manhating dyke' or the feminine 'lipstick lesbian'. These two stereotypes allow society to discredit female sexual autonomy and disregard that a woman may consciously choose to engage in a sexual or romantic relationship with another woman, rather than a man, because of genuine feelings of attraction or love (Walters 2001, 166). Although some pop culture depictions use the term to refer simply to a lesbian woman who adopts a glamorous feminine identity, the 'lipstick lesbian' stereotype often carries with it the stigma that she is simply distracted by the beauty of other women, but would likely be interested in a man if he pursued her hard enough, as though he could change her 
romantic preferences by impressing her sexually (Jackson \& Gilbertson 2009, 207). For example, this stereotype (in both of its forms) can be seen within the popular television show Glee in the characters Brittany and Santana. ${ }^{3}$ While some specifically GLBTQ media rejoice in the subversive element afforded to these characters by way of remaining unlabeled, many mainstream media outlets cling to this lack of categorization in order to question the legitimacy of Brittany and Santana's relationship and sexualities, constructing them as confused lipstick lesbians (Snarker 2010). The flawed logic about the lipstick lesbian is the result of society's hesitation to separate the concepts of 'femininity' and 'heterosexuality', discrediting female sexual autonomy by insinuating that any woman who still dresses and acts according to normative femininity in her gender identity must also behave according to heterosexuality (Jackson \& Gilberston 2009, 201).

Opposing this image is the stereotype of the more masculine 'man-hater' who engages in relationships with other women out of spite for men. This image is often treated in media depictions with confusion or disdain, as though the woman makes choices about sexual relationships based on a jealousy of men rather than any real desire for women. For example, the animated television series Family Guy often includes jokes about character Meg's sexuality, referencing her boyish style of dress and unfeminine appearance as signifiers that she must be a lesbian, and this is often linked to negative

${ }^{3}$ Brittany and Santana are two attractive young women who adhere to heteronormative standards of beauty and dress, who have both shared sexual relationships with men, and who eventually find themselves discovering their sexuality in a relationship with each other, despite eventually engaging in relationships with men once more. This is significant because Brittany and Santana do not explicitly identify as bisexual, nor as a lesbian couple; while Santana does spend several episodes dealing with coming out as a lesbian, Brittany avoids openly claiming any sexual identity. 
things such as her lack of friends and boyfriends. ${ }^{4}$ Once again, this depiction of the butch lesbian (real or perceived) discredits female sexuality by attempting to marry the concept of heterosexuality with that of 'proper' femininity; if a woman refuses to be with men, then she must be constructed negatively. She is therefore designated as 'butch' and painted as ugly and masculine because she is failing to do what society thinks 'real' femininity entails (Jackson \& Gilbertson 2009, 208).

As I will analyze in this section, Lady Gaga's embodiment of Nymph directly opposes this harmful binary conception of female non-heterosexuality by portraying a normatively feminine woman who happily engages in a non-heterosexual relationship, one that lacks a concrete name in mainstream language, and yet still maintains her normatively feminine gender identity.

Nymph's Performance of Gender and Sexuality in HAUS OF Ü FEAT. NYMPH

In HAUS OF Ü FEAT. NYMPH, viewers discern Nymph as an individual subject, separate from Jo Calderone, as she is featured as the sole figure in the video. She is dressed in the same girlish outfit that she wears in the YOÜ AND I video-a delicate shift dress and soft leather ballet shoes like the kind often worn by young girls in dance class, and perhaps an homage to the way that mythical nymphs are depicted as lovers of dance in Greek stories. Her hair is worn long down her back, allowing for it to flow and wave in a pretty, feminine manner as she begins to move. Her makeup is soft and natural, which avoids overpowering her girlish appearance, while at the same time emphasizing her eyes

\footnotetext{
${ }^{4}$ In one episode, Meg is even depicted giving in to the assumptions about her sexuality, pretending to claim a 'super huge mega lesbian' identity in an attempt to meet new people ("Brian Sings and Swings", Family Guy). In this scene, the girls she befriends are stereotypically butch in appearance, with deep voices and 'manly' attire, and they congregate in their own 'lesbian alliance' group, explicitly separating themselves from men.
} 
and lips and giving her flawless skin. She begins dancing with soft, balletic movements, presenting audiences with an image of her as young, innocent, and very feminine. As she moves, her gaze shifts towards the camera, shy and fleeting at first, but accompanied by a flirty smile. This image is augmented by certain behaviours stereotypically associated with girlish femininity; she covers her mouth as though giggling, smiles sweetly into the camera, and plays with her hair. As the video progresses, her movements become more sensual in nature. Nymph even mirrors the classic pose of Marilyn Monroe, a modern icon of femininity and sexiness, holding her skirt down in the wind. Finally, Nymph's behaviour becomes more sexual in nature, as she writhes on the ground and lifts her dress, keeping the most intimate features hidden with her legs while exposing her naked thighs and stomach. The more she moves and reveals her body to the camera, the more her gaze shifts from being unassuming and slightly timid to being direct, as though she is looking brazenly at her audience as her dance intensifies. The video concludes with an image of Nymph covering her mouth passively and looking demurely once more into the camera. This image, however, contrasts with the rest of the video because it is the only one that includes colour. Soft, pastel hues have been added to Nymph's hair, dress, and cheeks, causing her to look youthful, healthy, and excited.

Gaga's depiction of Nymph in this short film achieves several goals that serve as artistic commentary about social conceptions of femininity. Firstly, it presents a normative image that contrasts with several of the other female characters within the You AND I complex of texts, and thus serves to highlight the transgressive nature of those characters. Nymph's normative image also contrasts with her behaviour as the latter becomes more sexual in nature, serving as a visible representation of how society 
constructs young women, largely through media depictions (Levy 2006). These depictions influence how society understands dominant femininity and consequently, young women are held to very specific expectations for the performance of their gender through their appearance and behaviour. While Nymph is girlish and innocent looking, she is sexualized by the act of lifting her dress and revealing herself to an audience. I argue that Nymph's representation here is not a commentary on negative constructions of female sexuality nor is she objectified; rather, the representation connects with the common expectation that women should be simultaneously innocent and sexy-they should be sexually available, but should refrain from actual sexual behaviour unless they wish to have their actions demonized (Youdell 2005, 260-2). This dichotomy is presented visually to Gaga's audience through Nymph's act of writhing, smoothing her hands across her breasts, and lifting her dress to show that she is wearing nothing beneath, all while keeping the intimate details of her lower body just out of sight and hidden by her legs.

As part of the complex of the YOÜ AND I texts, Nymph's representation in the HAUS OF Ü video must be considered in relation to her representation in the original YoÜ AND I music video. In the supplementary short film, Nymph seems to participate in hegemonic feminine stereotypes. Her representation in the official video, however, communicates a more transgressive story, as Nymph relates to Jo Calderone in not only heterosexual, but also non-heterosexual contexts.

\section{Responding to Nymph: Fan Reception Texts}

In response to HAUS OF Ü FEAT. NYMPH, I have chosen to analyze two fan-made interpretations that display viewer understandings of Lady Gaga's original character. The 
first fan video, created by YouTube user Zelda Joyce is a recreation of Gaga's original HAUS OF Ü video, mirroring Nymph's representation of hegemonic femininity (http://www.youtube.com/watch?v=JNALbnamprQ\&list=UU9HAonnvNu0PoamLZYVfoQ\&index $=5$ ). I chose this video for analysis as a result of a YouTube search because this user has created several other fan videos in response to various Lady Gaga materials throughout the past three years, indicating that she has followed Gaga's career and might therefore be familiar with some of the elements of new media usage and activism that $I$ have discussed in my research. In addition, the video contains various images that interpret and build upon Gaga's original performance, the significance of which I will explain in the section. Zelda Joyce's video was published to YouTube in August 2012 and has received 59 views (as of March 2013). The second video, by YouTube user nashoesponjal, presents viewers with a remix of Gaga's original texts, drawing more heavily on the transgressive themes embodied by Nymph (http://www.youtube.com/watch?v=ynFemBts4rA). This video, also yielded by a random YouTube search, was chosen because of its unique remixing of images, and because it was the only video I found where an outwardly male person performed the role of Nymph. The video was posted in January of 2012 and has received 621 views (as of March 2013). Each of these videos employs the kind of interpretive license afforded to viewers by Gaga's use of interactive new media capabilities to distribute her original materials, facilitating the identification of her own activist messages as they are understood and perpetuated by individual social media participants.

YouTube user Zelda Joyce embodies the role of Nymph in her reception text, just as Gaga does in the original video. Like Nymph, Joyce wears a small, girlish dress and 
long flowing hair, both of which she uses in her movements to express a sense of femininity. Joyce mimics Nymph's behaviours, dancing in a balletic way, touching her mouth, playing with her dress and hair, and smiling demurely at the camera. Her portrayal of Nymph establishes the same image of hegemonic femininity seen in the original text, while at the same time capturing a hint of transgression in the almost aggressive energy behind her behaviour, the large space that her movements require, and the sensual nature of some of the dance moves she performs. Overall, however, Joyce's portrayal of Nymph communicates a connection with Gaga's images of innocent, hegemonic femininity, although it is slightly more energetic and aggressive than Gaga's original.

Joyce's interpretation of female gender and sexuality differs from Gaga's in her deliberate exclusion of the scenes that show Nymph lifting her dress to reveal her naked body and touching herself in an overtly sexual way. Whether this is due to an understanding of these actions as unfeminine or simply a desire to avoid displaying her naked body in a public online forum remains unclear. In place of these sexual images, however, are several shots of Joyce cradling a little girl in her arms, dancing with her and spinning her around to make her laugh, and giving her nurturing kisses on the cheek. Though the intention of the creator cannot be assumed from simply watching the video, these images connect her version of Nymph with other hegemonically female YOÜ AND I characters, such as Mother. The inclusion of a child, also dressed in a very feminine manner, communicates an image of femininity as being connected to children and motherhood, childcare, or other stereotypically care-based female roles, and establishes an interpretation of Nymph as caring and nurturing. This does not necessarily insinuate 
that Joyce is opposed to the more transgressive images of Nymph in Lady Gaga's original video, but rather that she identifies with representations of Nymph's more hegemonic behaviour and connects with them based on her own socially constructed understanding of femininity and female sexuality as they relate to the child in her video.

In contrast with Zelda Joyce's feminine recreation of Nymph's HAUS OF U, YouTube user nashoesponjal uses the creative license of the new media fan to create a remix of Gaga's original text, concentrating more on transgressive elements of Nymph's character. Although nashoesponjal appears to adopt the behaviours of Nymph in his reception text, he includes the phrase "Lady Gaga Dancing with me" in the title of his video, and has set up his images such that the first half of the video depicts himself dancing aggressively and baring his teeth, while the second half is composed of images of Gaga as Nymph from the original text. The effect of this remixing of images serves to directly contrast nashoesponja 1's interpretation of Nymph with Nymph herself, exemplifying the manner in which new media capabilities enable Internet users to almost literally interact with and then re-communicate Gaga's materials and corresponding activist messages. Viewers are able to clearly identify the aspects of nashoesponjal's performance that mirror Nymph's character, and those that exist as expressions of his understanding of Nymph's gender and sexuality, and possibly even expressions of himself using the space that Gaga's original text created for this kind of exploration as an empowering motivation to investigate his own identity. Similarly, audiences can see how nashoesponja1's performance contributes to Gaga's theme of identity transgression.

The fan-made portion of this reception text depicts a young man performing similar balletic-yet-sensual dance movements to those of Nymph in her installment of 
HAUS OF Ü. Though he does not wear a slip dress like Nymph does, he uses his long, loose fitting shirt in his dance movements the same way that Nymph does her dress. Where Zelda Joyce chose to omit a recreation of Nymph's more sexual actions, nashoesponja1 includes images of himself gyrating his hips, and even performs shirtless and in his underwear in several frames of the video. Whether this is indicative of a desire to remain true to the original text without exposing his lower body to a public audience, or an alternative interpretation of Gaga's inclusion of nudity based on his male identity and social acceptance of men exposing their chest, is unknown. This does, however, highlight to viewers that the person performing the movements that Lady Gaga fans associate with the female Nymph is, in this case, biologically male.

Despite the fact that nashoesponjal has constructed his video as though he and Nymph are dancing together, or perhaps as though he is simply imagining them dancing together when he puts on his blindfold (which insinuates that they are two separate beings), he also deliberately embodies many of Nymph's characteristics and behaviours. This embodiment serves as a visual clash between gender and the body; viewers that associate his actions with the female Nymph are now seeing her performance embodied by a physically male individual. Nashoesponjal's reception text interprets and then builds upon Lady Gaga's messages of gender transgression by depicting a male person temporarily appropriating the identity of a female alter ego, without attempting to mask his 'male-ness' or actually pass as a woman. Nashoesponjal communicates an understanding of gender as not being rigidly defined by our body or our actions through his explicit identification as male even as he intentionally performs a female character, thereby exploring and playing with the limitations of hegemonic gender norms. Viewers 
might understand him as identifying as either Nymph or the 'Nebraska guy' mentioned in the song lyrics, or perhaps both. In either case, his movements and gender performance resist stereotypical conceptualizations of both normative femininity and normative masculinity.

Each of these fan reception texts exemplifies how Gaga's audiences can not only recreate her original materials in order to perpetuate an activist message, but how they can also use their creative licenses in order to change the images to communicate a new message and add additional elements of hegemonic identity representation or transgression. Zelda Joyce's inclusion of the scenes in which she dances with a little girl draws connections between images of a young adult female expressing herself through dance and normative ideas about femininity based on traditional understandings of the purpose of female sexuality - to create a child. Though Gaga's original short film does not explicitly link Nymph to any reproductive future, Joyce's reception text serves to connect her age and relationship status with normative social expectations of young women. In contrast, nashoesponjal's reception text adds a transgressive element that was not expressed visually in Nymph's original fashion film. By disseminating images of a male-bodied individual performing the role and actions of a female character, this user transgresses normative expectations of male gender performance through movement. Though nashoesponja1 does not hide his male-ness or appropriate female dress, the stereotypically feminine nature of his movements and expressions are apparent, and would likely be recognized as 'improperly' male even by audience members who were not familiar enough with the original material to know that he was also embodying Nymph's performance, rather than simply 'dancing with her', as his video title denotes. 
This could, perhaps, explain the single comment below nashoesponjal's video, in which YouTube user drhesslesn expresses confusion by saying "ummmmm no comment" (http://www.youtube.com/watch? v=ynFemBts4rA). nashoesponjal's disassociation between his perceived sex and his gender performance in this video transgresses social expectations.

Mother and Barn Hooker: Representing Binary Conceptions of Female Sexuality in YOŨ AND I

The short film HaUS OF Ü FEAT. BARN HOOKER AND MOTHER (Matadin \& Van Lamsweerde 2011) includes a hegemonic representation of femininity in the form of Gaga as a zombie-like bride named Mother. Not to be confused with the robotic alter ago named Bride, Mother is depicted as a pale, modestly dressed woman ready for her wedding day. She appears in the music video for YOÜ AND I in a smaller role than more active female characters like Yüyi and Nymph. Even so, Lady Gaga's embodiment of Mother serves a significant purpose within the overarching commentary of the YOU AND I and HAUS OF Ü texts because her more normative performance of femininity contrasts with other transgressive characters. Each time Mother appears in YOU AND I, she is depicted gazing intensely through her bridal veil upon the man she is about to marry. She does not sing any of the song lyrics, make any large movements, or change her loving facial expression much further than a smile. While other female characters in the video dance, jump, run, sing, play the piano, and splash water around, Mother simply stands calmly, waiting to be married. She represents hegemonic stereotypes of woman as the passive, seemingly asexual housewife whose goal in life is marriage to a good man; only this time, Gaga has used the art of performance to highlight social normativity by over- 
exaggerating certain characteristics, rendering Mother's identity a subtle satire (Phillips $2000,43)$.

Mother is dressed all in white, and her skin and hair are so pale that they nearly match the material of her wedding dress. This costume and makeup thus plays upon the social usage of the colour white to represent virginal purity and innocence. Mother's skin is pale to the point that her cheeks bear a blue-ish tinge, as though she is extremely ill or even dead. The skin colour here makes a visual connection to the images of the Frankenstein-like monster that Mother's her husband-to-be is attempting to piece together as his ideal woman; Mother is his final product, his perfect fabricated wife compared to all of the previous eccentric versions that did not meet his standards. Because her lover has actually created Mother, Gaga achieves commentary through exaggeration of social ideals about women's role as the passive housewife. Mother not only looks and acts the part, but viewers have seen the various stages of development the man in the video has gone through to make her the way she is. She has literally been created to be his wife, and she exists solely to devote herself to him. While the character appears virginal in her clean white dress, Gaga has also linked Mother to ideas of motherhood, something that necessitates sex, through the use of her own mother's actual wedding dress as her character's costume (http://www.youtube.com/watch?v=FUtWDd6FaUU, 5:20). This personal connection to the concept of motherhood mirrors the social contradiction inherent in expectations that women should fulfill their role as wife and mother, and yet remain chaste in order to avoid the negative demonization of overt female sexuality; they should be sexually available, but not sexual (Phillips 2000, 42). Though Mother is the man's final choice, Gaga does not present her as an ideal that women should work 
toward, but rather as a satire of social expectations through her zombie-like pallor and stare, her lack of contact with other characters, and her literally fabricated reality. She is constructed as an individual for whom no other options were presented, and whose fate was sealed from the moment of her conceptualization, in order to highlight that this is not, in fact, the reality for women, despite stereotypical notions of femininity constructed by social norms.

In both YOÜ AND I and HAUS OF Ü, the character that Mother contrasts with most directly, as is evident even in their names, is Barn Hooker. Where Mother is pale, white, and devoid of impurity or colour, Barn Hooker wears black and flaunts her bright turquoise hair. Where Mother is modestly dressed, behaves passively, and moves minimally, Barn Hooker is dressed in a revealing dominatrix-like outfit and spends her time in the YOU AND I music video caressing her exposed curves and dancing sensually and aggressively with her crew of fellow scantily clad barn hookers. She serves as an overt visual representation of precisely what her name infers; she is the 'dirty' sexual being (she lives in a barn, after all) to Mother's pure, virginal creature. Together, the two might be interpreted as representing some kind of contradictory ideal for the purposes of male fantasy; would a woman possessing, in the appropriate circumstances, both the passive devotion of Mother and the confident sexuality of Barn Hooker be the ideal woman? Barn Hooker's active displays of sexuality through dance and fashion serve both as an embodiment of demonized female sexuality and as a transgression of normative ideals of femininity. Her name is a reminder of the ways in which women who actively seek physical pleasure through sex are negatively constructed in society through things like slut-shaming and media objectification (Valenti 2008). Images of her erotic dancing 
are interspersed in the YOÜ AND I video with images of other female characters, most prominently serving as a direct juxtaposition to Mother's chaste presence. Barn Hooker is also significant because she behaves in such an openly sexual manner, and yet she never actually makes contact with another person, nor is she ever featured in the same shot as any character other than her fellow dancing barn hookers. This qualifies her as a transgressive character because she embodies sexuality as an independent concept from other social factors; she is not concretely heterosexual, non-heterosexual, or even actually physically sexual. She is, rather, a positively independent character, depicted as being confident, happy, and desirable. Whether or not she acts upon her desirability and sexuality, however, is not depicted; perhaps this is not the viewer's business? Barn Hooker represents a separation of sex, sexiness, and sexuality from femininity that is often overlooked by society's insistence on associating 'proper' woman (and man) -hood with heterosexuality, as well as a social tendency to ignore discourses of female pleasure entirely (Butler 1989).

\section{The 'Virgin-Whore' Dichotomy: Mother and Barn Hooker in HAUS OF Ü}

The contrasting dynamic between Mother and Barn Hooker continues in their installment of the HAUS OF Ü series. It is here that we see Mother begin to resist her normative existence as she explores a sexuality not expressed in YOÜ AND I. At first, Mother behaves according to stereotypical femininity; adjusting her dress, smelling her flowers, and hiding her face shyly behind her veil. Her gaze at the camera is soft and demure. These shots are alternated with the more prominently featured Barn Hooker, who appears to be a manifestation of her name. Barn Hooker, still in her revealing outfit made of leather straps and fishnet stockings, dances and touches herself seductively, confronts 
the camera head on with a smile, and is covered in dirt as though she has in fact been in a barn. Her character is in direct contrast to Mother's clean, white appearance and her sexual behaviour juxtaposes Mother's more mild and 'appropriate' actions. As audiences consider the two women, they are presented with an embodiment of a problematic social binary, the 'virgin-whore dichotomy' (Phillips 2000, 43). Mother and Barn Hooker draw public attention to the ways in which female sexuality is demonized and female virtue deified (which, of course, assumes that sex somehow threatens 'virtue'), negatively constructing women who practice open sexuality and seek physical pleasure (Youdell $2005,255)$. The fact that Bam Hooker never actually comes into physical contact with another person, however, transgresses the social connection between female sexuality and negative sexual behaviour, separating the two and establishing an image of overt female sexuality that is not directly identified as heterosexual. The more Barn Hooker dances and displays her sexuality, the more Mother starts to transgress her hegemonically feminine state as she makes larger, more sexual dance movements and lifts her skirt up above her hips to reveal her underwear and touch herself intimately. These images, as well as the short film's final shot where Mother is kissed and caressed by her male lover (actor Taylor Kinney) despite her newly expressed sexuality, serve as a social commentary to the fact that a woman's position as a bride, wife or 'Mother' is not mutually exclusive from her ability to exist as a sexual being. Responding to Mother and Barn Hooker: Fan Reception Texts

In order to explore public reception of HAUS OF Ü FEAT. MOTHER AND BARN HOOKER, I analyze a reception text created by YouTube user lennonvalim (http://www.youtube.com/watch?v=p4DgHqkclho\&list=UUZ8cYUMadShpGFyp2R1Py 
ow\&index $=12$ ). This video was shared to YouTube in August of 2012 and has received 1,333 views (as of March 2013). I chose this particular fan response because, once again, it exemplifies the ability of fans to not only recreate and redistribute Gaga's original materials, but also to employ a creative license in order to add additional layers of social commentary and normative transgression. Following Lady Gaga's theme of gender bending (i.e. Jo Calderone) in order to draw audience attention to the limitations of hegemonic gender identities, lennonvalim uses artistic performance and cross dressing in order to further perpetuate Gaga's activist message. He does so by embodying the characters Mother and Barn Hooker in his own recreation of their installment of HAUS OF Ü. Images of a male individual dressed in fishnet tights and an outfit made of leather straps behaving in the sexual manner of Barn Hooker are alternated with images of the same man dressed as a bride and mimicking Mother's shy and passive persona. As the video progresses, lennonvalim stays true to Gaga's original text, and his Mother character unleashes her sexuality by lifting her skirt to reveal Barn Hooker-like fishnet stockings. Audiences are also introduced to another male individual playing Taylor Kinney's character, Mother's husband-to-be. Although this person is in costume, wears a wig and dons a long white coat, viewers are presented with a contrast of identity between the man embodying two female personas and performing femininity, and the man embodying a male persona and performing masculinity. Regardless of the actual sex or gender identity of the individuals in the video, it is apparent to audiences that both masculinity and femininity are performative constructs here. lennonvalim's text adds a layer of transgression to Gaga's original images, portraying both the juxtaposition of hegemonic 
and demonized femininity between Mother and Barn Hooker, and the resistance of rigid gender norms presented by these female characters who are embodied by a man.

In addition to transgressing normative conceptualizations of gender identity, lennonvalim's video interacts with activist messages by resisting notions of heteronormativity. This is achieved in a similar manner to how Gaga resists heteronormativity through the portrayal of Nymph and Jo Calderone's relationship. lennonvalim's video concludes, as Gaga's original does, with an image of Mother and her lover embracing and kissing. Here, however, a man embodies Mother, causing viewer realization that this normative display of love is actually based on performed heterosexuality. Just as Gaga does with Jo Calderone, lennonvalim uses his new media capabilities to associate a mainstream musical piece with 'othered' identities, including images of drag or transgenderism. His video includes representation of a male same-sex relationship (albeit a complicated one based on the performed gender of the Mother character), which goes above and beyond the identities displayed in Lady Gaga's original texts. This additional layer of transgression exemplifies the activist nature of new media recreations such as this, because it demonstrates how a Gaga fan can not only consume and recreate her materials, but interact with and interpret them in order to both perpetuate and further extend the activist messages about hegemonic constraints on gender and sexuality therein. Exemplifying theories of Judith Butler, as discussed in Chapter II, lennonvalim's video, like Gaga's performance of the Jo-Nymph relationship, incites its audience to consider gender and sexuality as unlimited social constructions. 
'Improper' Femininity and Transgressions of the Physical Body: Lady Gaga's

Performances of Bride and Yüyi

The Robotic Bride: Sexuality, Ability, and the Non-Normative Female Body

In HAUS OF Ü FEAT. BRIDE, the public is presented with a high fashion, partially robotic Gaga who, according to the storyline within the YOÜ AND I video, has walked all the way from New York City to Nebraska in search of her love (Daw 2011). Bride resembles the embodiment of a cyborg, visibly a female, but not entirely human (Matadin

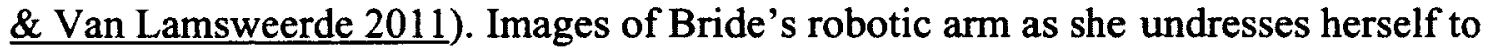
reveal an otherwise human female body draw audience attention to the relationship between hegemonic femininity and the normative body. Can Bride be 'properly' female despite her inhuman features?

Bride differentiates herself from dominant ideologies of femininity through her movements and behaviours, as well as through the way she looks and is dressed. Her role in the YOÜ AND I music video is a very active one. She is an independent character who has taken control of her situation and put her feelings into action. Rather than simply lamenting about a lost love, Bride is depicted as having made an arduous journey to find this person while confidently stating in the song lyrics that she will not leave him behind again. Bride's words and actions contrast greatly with other more passive female characters in the YOÜ AND I music video, and this sense of active independence is further enhanced by the fact that, apart from one small scene with an ice cream vendor, Bride does not come into contact with any other characters during the video. Instead, she struts around the countryside without a care for how out of place her robotic, high fashion presence seems in that setting, and acts as a sort of narrator for the story contained in the 
song by singing, dancing, gesticulating, and making direct eye contact with the camera and her audience. Not once does she seem to mind that she is never actually reunited with the lover she returned to Nebraska for; this could suggest that Bride is fulfilled by the simple fact that she took independent action, regardless of the outcome. Perhaps this even insinuates that Bride is a contemporary version of the various Franken-Gaga's and, after some evolution, Mother, and that the scenes featuring Kinney are flashbacks to her complicated past. Whatever the details, Bride's independent characteristics serve as a transgression of normative ideals of femininity as dependent and passive, and they give Bride a much more dominant presence than characters like Mother and even Nymph.

In addition to the way that Bride acts, the way she looks transgresses society's notions of 'proper' femininity. Although she has long flowing hair and wears heels, she is dressed in a severely cut suit, resembling an image of the confident, modern woman in her 'power suit', another stereotypical social figure whose femininity is often questioned because of active, domineering behaviour typically associated with men and an apparent disregard for the home and children, a realm often constructed as the woman's responsibility (English 2003, 237). Bride's most prominent physical feature is her robotic arm, which complements the metallic features on her face. She displays her arm by wearing her coat off her shoulder and by physically maneuvering it with her other arm for viewers to see. Bride's partially mechanical state transgresses not only her humanity, but also her femininity based on discourses surrounding gender and ability as they pertain to social beauty standards. Mainstream media outlets notoriously lack representation of any form of body image that does not adhere to a strict and unattainable standard of thinness, beauty, and the ability to move or perform in ways deemed 'attractive' by dominant 
institutions such as the fashion industry (Hammar et al. 2009). Bride's existence as both high fashion and 'othered' in body image due to her robotic features transgresses these marginalizing social ideals of beauty and ability by presenting to audiences an image of 'othered' femininity that manages to be both independent and beautiful, as opposed to dependent and 'abnormal'. Lady Gaga uses Bride's robotic arm as a metaphor for perceived imperfection and flaw that renders women feeling as though they fall short of the ideal female body. At the same time, she resists social standards of beauty and its relationship with ability by using Bride's robotic arm to maintain her air of strong independence and even establish a sense of hyper-ability; she has, after all, walked all the way from New York to Nebraska in heels so high that most people would fail to walk in them at all. Despite the element of humanity included in the fact that her feet appear swollen and bleeding after such a journey, a sense of robotic hyper-ability ties Bride to notions of the cyborg feminine and post-humanism. Gaga may have included her robotic features in connection with her new media existence, a visual representation of how subjectivity, the body, and the self evolve along with the rest of our increasingly technological existence (Toffoletti 2007).

Undressing the 'Improper' Female Body: Lady Gaga's Performance of Bride in HAUS OF $\underline{\ddot{U}}$

In HAUS OF Ü FEAT. BRIDE, themes of gender and ability extending from YOÜ AND I are further related to sexuality through Bride's behaviour. Bride starts out fully clothed and, as the video progresses, she sheds her fashionable layers, removing her hat, wig, and jacket and spending most of the video topless with her breasts covered only by her hands. As she does so, she stares defiantly into the camera, as though challenging audiences to 
comment on the contrast between her robotic arm and her scarred human flesh. While some media sources interpreted this solely as a shock factor intended to gain attention based on the inclusion of nudity (Rubenstein 2012), clear connections can be made between Gaga's overarching commentaries on femininity and sexuality throughout her YOÜ AND I and HAUS OF Ü texts. By undressing Bride in HAUS OF Ü, Gaga transgresses notions of women that exist outside of ideals of 'proper' femininity (as Bride would with her robotic arm) as being non-sexual beings, or as lacking sexuality and sexual desire. Bride's act of bearing her partially naked, but also partially mechanical, female body resists social interpretations of differently abled individuals as being asexual (Kim 2011, 481-7). I argue that her nudity does not objectify her, but rather that it draws attention to her humanity and her very female-ness despite the physical difference between her and the normative female image. At the same time, the manner in which the video alternates images of Bride's body with images of other individuals (largely lucky fans and members of Gaga's creative team) serves to simultaneously contrast the normative human body with Bride's transgressive physical characteristics, as well as highlight her similarities with these people despite her robotic features. This once again establishes Bride as an exemplary character for the pushing of social limitations concerning assumptions about how the human body should look and function.

\section{Responding to Bride: Fan Reception Texts}

Several Little Monsters have posted artistic interpretations of Bride on LittleMonsters.com in the form of drawings, paintings, and pictures edited using various image-based computer programs. For example, user Marrow Melow shared a picture of Bride depicting her in black and white against a turquoise background, posing in a way 
that draws viewer attention to her hat, veil and sunglasses - all symbols of her high fashion existence (http://littlemonsters.com/post/502e739af35c0c4405003211). In contrast, LittleMonsters.com user Taylor shared a beautifully lifelike drawing depicting a close-up of Bride's face. The drawing leaves out Bride's attire and hair, but does include the metallic piece on Bride's chin, drawing audience attention to the juxtaposition of human and robotic elements that her character presents (http:/littlemonsters.com/post/50108e7cc84b0a8a7a000605). While Lady Gaga's other HAUS OF Ü characters have been immortalized by fan-made videos, however, Bride's representation and actual embodiment in this genre of reception text lacks greatly in comparison. Her unfortunate absence in fan videos might possibly be due to confusion and misunderstanding elicited by Bride's character and body among audiences, or perhaps it is simply due to the fact that her attire is among the most complicated to recreate.

Bride's presence in fan-made videos is largely limited to two different types of short films. The most common inclusion of Bride consists of videos that use clips of Lady Gaga's original images in order to create a visual remix video to a different song. For example, YouTube user GagaFanMonster cut images from Bride's installment of HAUS oF Ü, rearranged them, and set them to an instrumental recording of Lady Gaga's song Electric Chapel as it was arranged for Twinkle Twinkle Little Rockstar, a CD collection of popular songs reconceptualized as children's lullabies (http://www.youtube.com/watch? $v=\mathrm{i}$ TpY08KoCY). This video was posted to YouTube in February of 2012 and has received 385 views (as of March 2013). Videos such as this 
one exemplify the ability of fans to evolve from the consumer to the producer using their individual new media capabilities.

The second type of video that features Bride combines images from all of the five HAUS OF Ü films. The majority of these, once again, use Gaga's original images, cut and rearranged by fans in order to create one full video featuring all of the Yoü AND I characters as they appear in their individual HAUS OF Ü installments. My extensive online exploration, however, did reveal one video in which Bride's character is actually embodied by a fan, rather than simply portrayed using original images. This video, created by YouTube user FashionedByLies, was an original take on the combination of all five HAUS OF Ü films (http://www.youtube.com/watch?v=fx_YHHsGBB4\&list=UUyE39mRtoFetsVWxHldp MhQ\&index $=25$ ). It was shared publicly to YouTube, Twitter, and LittleMonsters.com in September of 2012 and has received 468 views (as of March 2013). By enacting a detailed HAUS OF Ü themed cos-play, featuring homemade costumes and makeup artistry, this user's reception text presents viewers with an extensive visual contrast of Bride with her fellow HAUS OF Ü personas. By alternating images of each character in their more simplified and stripped down state, as they appear in HAUS OF Ü short films, FashionedByLies allows audience members to draw more effectively upon the ways in which Bride's gender, ability, and sexuality transgress more stereotypical representations of femininity, such as Nymph and Mother. By mimicking the movements and dress of each character, FashionedByLies brings the unique transgressive qualities of all of Lady Gaga's personas to one place, facilitating closer consideration of the ways in which the characters juxtapose and resist one another. Through a cumulative video such as this, 
Bride's independent nature and non-normative embodiment of femininity and sexuality are highlighted well in comparison with the rest of the HAUS OF Ü cast.

\section{Understandings of Dependence and the Non-Normative Body: Yüyi the Mermaid in YOÜ AND I}

Following themes of femininity, ability, and the physical body, Yüyi the mermaid, once again played by Lady Gaga, can be analyzed as a transgressive presence in the YoÜ AND I music video. Though Yüyi bears female characteristics, her fish tail and gills mark her as clearly inhuman (Matadin \& Van Lamsweerde 2011). Questions of gender and sexuality arise, however, when Yüyi engages in physical intimacy with a human man, representing some sort of inter-species relationship (Fausto-Sterling 1993). These images compel audience members to reflect upon the social limitations of sexuality. If Yüyi's status as a human female is questioned, what are the social implications of her physical relationship with a human male?

Yüyi's relationship with Taylor Kinney's character in Yoü AND I resists normalized ideals of sexuality in several distinct ways. Yüyi can be recognized as existing outside of dominant ideals about gender and femininity based on her partially human status. Comparably to Bride, Yüyi embodies the 'improperly' feminine, and might therefore be constructed as a non-sexual being according to social assumptions about sexuality and who can or should engage in sex. This is largely based on the fact that she is a mermaid, and is therefore differently abled than human beings with two legs living in a human world. Yüyi is depicted as dependent upon Kinney, and audiences see him holding an oxygen mask to her face and bathing her in water while she lies in the barn, seemingly confined to a small washtub. Yüyi's stationary existence and perceived 
dependence as a result of her difference in ability might be seen as a fantastical interpretation of discourses surrounding the way our world constructs disability through normalized assumptions about what functions the 'average' body should be able to perform. Sex often falls under the umbrella of these functions, and dis- or differentlyabled individuals who possess full sexual capability and active sexual desire are falsely assumed to be asexual or un-sexual based on normative understandings of ability, as well as hegemonic assumptions about the logistics of sexual relationships and what constitutes "sex" (Kim 2011, 488-90). More blatantly, the fact that Yüyi is quite clearly a mermaid satirically represents marginalizing constructions of differently abled individuals, especially women, as non-human, or less human, based on ability (Garland-Thomson 2005, 1567).

The relationship between Yüyi and Kinney resists social assumptions about ability and sexuality in several ways. Firstly, Yüyi's confident movements and sensual actions when she dances and touches herself in the wash tub express a desirability and sexiness that transcend her assumed dependence based on her mermaid tail, as well as assumptions about differently abled individuals as non-sexual. Scenes depicting sexual intercourse between her and her human male lover serve as visual resistance to normative ideals about what constitutes sexual intercourse, who partakes in sexual intercourse, and whether or not individuals that exist outside the parameters of the normatively abled body can be sexual beings who actively engage in sexual relationships. Yüyi and Kinney also resist assumptions about the dynamic of power between differently abled and normatively able-bodied individuals engaging in a romantic or sexual relationship. Because Kinney is seen providing physical, life-sustaining care for Yüyi, establishing a 
sense of her dependence on his care, their relationship might be interpreted as possessing an imbalance of power. Based on this, assumptions might be made about a romantic or sexual relationship between them, claiming Kinney's actions to be an abuse of power and, consequently, an abuse of Yüyi. While sexual assault is a clear and present danger to the lives of any person depending on another for physical assistance and care (Di Giulio 2003,60 ), assumptions about romantic relationships made on the basis of normative understandings of ability and sexuality deny the sexual autonomy of people living with disabilities and construct them as incapable of choosing sexual partners and making consensual sexual decisions (Kim 2011, 482).

Lady Gaga resists harmful normative assumptions about the power dynamic between Yüyi and Kinney by concluding their story with images of Kinney lying naked and vulnerable in Yüyi's wash tub, clinging to her like a child while she cradles him and gently caresses his head. These images position her as being an individual with a certain amount of power within their relationship, and balance out images of his care for her in order to establish a sense of trust and equality. One might even argue that these images serve as a reference to mythical stories of sailors being lured to their deaths by sirens; beautiful female mermaids who unleash an irresistible power over men with their hypnotizing singing voices. Viewing Yüyi as Lady Gaga's interpretation of a siren allows for a shift in analysis of the power dynamic between Yüyi and Kinney. Rather than relying upon him for survival based on limited ability, Yüyi can be constructed as having enchanted Kinney with her beauty and voice, luring him into servitude out of devotion and desire. Despite the fact that stories about sirens present an image of women as evil creatures with bewitching powers who seek to control men and lead them to their demise, 
the interpretation of Yüyi as a siren in the context of these caring images serves to establish more of a sense of female empowerment (Wiley Todd 1993, 208). Kinney does not appear to be in danger because of his relationship with Yüyi, but has instead been mesmerized into a state of caring worship for her. Yüyi, therefore, is not necessarily an isolated, incapable creature, but rather a powerful manifestation of male fantasy. Alternative Ability and Femaleness: Performing Yüyi in HAUS OF Ü

The fashion film HAUS OF Ü FEAT. YÜYI builds upon themes of ability and sexuality, established through Yüyi's character in YOÜ AND I, as they relate to gender and femininity. The film alternates images of Yüyi sitting in a tall chair performing actions and dance moves that draw attention to both her inhuman characteristics and her feminine physicality, with intermittent images of her being carried to the barn by two men past tents and equipment, suggesting that they are present on the set of the YoÜ AND I music video. The images of her being carried at first seem to further highlight her dependence; because of her mermaid tail, she is incapable of getting herself from one place to another without assistance. As she is carried, however, she performs a series of feminine, balletic movements with her arms that exude a sense of confidence and sexuality, as opposed to helplessness. Her dependence is further offset by images of several assistants running around her, carrying things for her, and holding a sheet in front of her to cover her from view. ${ }^{5}$

Within the overall themes and discourses that Gaga has established throughout the series of films, the scenes of her being carried and shielded can be interpreted in several

\footnotetext{
${ }^{5}$ In reality, this sheet was to hide Gaga's costume from fans that had infiltrated security on the video set in Nebraska. This behind-the-scenes YOÜ AND I footage depicts Gaga being carried by staff from her trailer to film Yüyi's scenes ("Lady Gaga Surprised to See Fans in Cornfield").
} 
ways. Firstly, audiences can fixate upon Yüyi's dependence and her physical difference from normative ideals about body image and ability. Within this context, the assistants might appear to be hiding her 'improper' body, as though it is not fit for viewing or is somehow offensive. Interpreted within the scope of Gaga's themes of resistance and transgression, however, images of Yüyi being carried and shielded from view present a construction of her as an ethereal creature being catered to by normatively abled individuals, as though her mermaid tail and gills mark her as special, unique, or someone that should be protected and coveted. Just as Yüyi might be interpreted as a powerful siren through the relationship between her and Kinney in YoÜ AND I, images of her being supported and catered to in HAUS OF Ü construct her once again as a fantastical siren, full of female power, control, and desirability, despite (or perhaps because of) her inhuman body.

Along with images of Yüyi being carried, audiences are presented with shots of her sitting in a high film director's chair. Here, she moves aggressively, smoking and removing her sunglasses to toss them to the ground. These actions contribute to the manner in which her partially human state highlights a sense of 'improper' femininity. Much like Bride's body might be constructed as unfeminine based on her independent behaviour and robotic arm, which violates normative beauty standards and compulsory able-bodiedness in terms of social expectations about gender performance, Yüyi's aggressive smoking and mermaid tail construct her as similarly unfeminine. She is not a human woman and she does not meet the social criteria that constitute feminine behaviour and body image. Lady Gaga resists dominant notions about normative bodies as determining femininity, however, by embodying Yüyi while she performs sensual 
dance movements that draw attention to her breasts, cheekbones, hair, lips and eyes; all physical characteristics that the media often concentrate on as features that constitute female-ness or female attractiveness. These actions highlight Yüyi's gender performance by denoting that she actively claims the feminine features of her body in order to identify as a woman, despite the fact that other parts of her body are viewed as 'inhuman'. The sensuality of her movements, such as when she pauses to openly caress her breasts, draws attention to her ability to act as a sexual being and express sexual desire, even if her body does not follow society's dominant guidelines of what is 'sexy' and who should be 'sexual' (Kim 2011, 486).

In addition to transgressing marginalizing notions of ability in relation to gender and sexuality, Lady Gaga uses Yüyi's edition of HAUS OF Ü to resist notions of the differently abled body as incapable, passive, and dependent. This is done through images of Yüyi pulling herself out of the director's chair and standing, despite the fact that she possesses a mermaid tail rather than human legs and feet. She proceeds to move around on the ground with the chair, even lifting it in the air and throwing it. These images might be interpreted as highlighting the performative nature of Gaga's normatively abled body masquerading as the alternatively abled Yüyi. I argue, however, that these images follow Gaga's themes of resistance and transgression to serve as a visual commentary of how dominant discourses about disability as a form of incapability overlook an individual's capability to express or exhibit strength and power, regardless of the limitations presented by the physical body in an ableist world. Yüyi's aggressive actions with the chair and her insistence on standing and moving without assistance in these scenes symbolize strength 
of will and power of mind, visually transcending dominant assumptions about passivity associated with differently abled bodies.

\section{Responding to Yüyi: Fan Reception Texts}

Although she is not as absent as Bride in the world of fan reception videos, Yüyi's embodiment in video recreations is not as common as some of Lady Gaga's other personas. This is perhaps due to the complicated nature of creating and moving in a mermaid tail. YouTube user BenWay08, however, created his tail from duct tape and plastic and performed his own interpretation of Yüyi the mermaid (http://www.youtube.com/watch?v=UbJ2kF-q5Ac). This video was uploaded to YouTube in October of 2011 and has received 482 views (as of March 2013). It is interesting to note that this video is only 56 seconds long - much shorter than many of the other fan reception texts I chose to analyze. This could likely be because of the limitations to movement caused by BenWay08's mermaid tail, a detail that I consider further on in my investigation of the video. I chose this text for analysis because BenWay08's embodiment of the female Yüyi despite his own male appearance adds an additional layer of transgression to Gaga's original HAUS OF Ü. Viewers are presented with an image of BenWay08 sitting in his bathtub, singing his heart out, and dancing as energetically as his tail will allow. The video does not directly mirror Yüyi's HAUS OF Ü film, excluding images of her standing and throwing her chair, likely due to a lack of space or resources common with many homemade videos, as well as the restriction of movement based on maneuvering with a mermaid tail in a human bathroom.

BenWay08's stationary performance in the bathtub, however, does allow for connection with images of Yüyi in her washtub in the barn in YOÜ AND I. 
BenWay08's video presents audiences with images that resist ideas of gender, sexuality, and ability beyond Gaga's already transgressive original performance. As with each of the reception texts I have analyzed, viewers are witnessing a homemade video, causing the air of fantasy to be replaced by one of reality. This is especially significant here, however, because the shift in context makes BenWay08's restricted movement due to his tail all the more apparent, as it confines him to the bathtub and only facilitates a certain range of motion within that space. While some audiences might interpret this restriction of motion as an indication that he has been 'dis-abled' by the tail, it also effectively draws attention to the limiting nature of our physical world. BenWay08 never identifies his real-world ability during the video, but audiences might assume he is ablebodied based on the physical actions required to move all parts of the body while wrapped in a layer of duct tape and sitting in a small, confined space. Conclusions can be drawn, therefore, that differently-abled individuals might experience difficulty navigating the geographical (and institutional) makeup of our everyday world, due to how heavily it is based upon hegemonic assumptions of able-bodiedness (Mavin \& Williams 2012). Even as a person who has experienced the use of the space he is in with a normatively abled body, BenWay08 finds himself confined to the bathtub for the duration of the video when his body is altered in a way that his bathroom does not accommodate. His limited movement thereby resists assumptions that disability is a concept inherent to the body, rather than the way we have physically constructed our world based upon normative notions of movement and ability. As a result, BenWay08's video draws attention to how our structures, buildings and rooms cater to the normatively abled-body only, and thereby 
limit 'othered' bodies and constrain their manner of function or movement, effectively marginalizing them (Mavin \& Williams 2012).

Finally, BenWay08's video presents images of transgression based on gender and sexuality. Audiences that have viewed Lady Gaga's original texts before this recreation will know Yüyi as a female character, a mermaid. Here, however, a male individual performs Yüyi. BenWay08 does not attempt to hide his maleness, nor does he dress in drag or deliberately transcend his own gender through performative femininity. Audiences are presented with an alternative conceptualization of Yüyi, moving in the same slightly aggressive and yet sensual manner and possessing significant physical similarities, with the exception of those based on sex. BenWay08 is not masking his identity in order to perform as a mermaid, but has instead adapted the concept and appropriated Yüyi's name and character as a merman. Mermen are not well-known fantasy creatures, often depicted by mainstream society in reference to or in periphery of mermaids while constructing them as existing primarily within the world of little girl's fairytales. The concept of the merman has thereby become feminized based on stereotypical conceptions of masculinity; let us recall how Ariel overlooked all of her fellow ethereal mermen in favour of marrying a more masculine and capable human man in Disney's The Little Mermaid. By embodying not only a persona that was originally presented as female, but also a creature that is stereotypically feminized, BenWay08 presents audiences with images that reconceptualize Yüyi and free the character of limiting social norms. Is there, after all, any reason that an artistic alter ego must be identified with a certain sexuality or gender identity? This reception text exemplifies Iris Marion Young's theories, as outlined in Chapter II, about the construction of certain 
identities as 'othered', or existing outside of the social norm. By embodying an 'othered' identity, BenWay08 compels fans to adjust their understanding of an individual from normative assumptions based on social categories of identification.

Transgressions of Hegemonic Masculinity: The Complexities of Jo Calderone

The fourth fashion film, HAUS OF Ü FEAT. JO CALDERONE, features Lady Gaga dressed in drag and explores a direct transgression of normative gender identities (Matadin \& Van Lamsweerde 2011). Jo Calderone challenges heteronormative conceptions of sexuality by having a relationship with Gaga as Nymph in Yoü AND I, and Gaga as herself according to Calderone's 2011 VMA monologue ("Lady Gaga's Jo Calderone Monologue"). His segment of HAUS OF Ü deliberately includes images of transgender identity; Calderone undresses to reveal Gaga wearing a jock strap and having bound down her breasts to more closely resemble the physique of a man (Davis 2008, Rupp et al. 2010). It is important to note that as Jo undresses, his image is alternated with that of the openly female Barn Hooker. These images beg audience consideration of what 'masculinity' and 'femininity' entails, and who can be 'masculine' or 'feminine'. In addition, Calderone's act of disrobing in the perceived vicinity of Barn Hooker presents audiences with a direct confrontation of person and persona and once again draws attention to heterosexuality as a performance.

\section{Perceived Maleness: Jo Calderone in YoŨ AND I}

By the time Jo Calderone appeared in the music video for YoÜ AND I, he had already been featured on the cover of Vogues Hommes Japan magazine and performed at the 2011 MTV Video Music Awards. His presence in the Yoú AND I and HAUS OF Ü texts therefore serves as a concrete connection between Lady Gaga's online and offline artistic 
creations. The YoÜ AND I music video presents audiences with several scenes featuring Calderone alongside Nymph, and their interactions make it clear that a relationship exists between the two characters. This relationship is significant for both its normative and transgressive elements. At first glance, it appears to represent the most heterenormative relationship within the video, considering the fact that the only other male character is Kinney, and all of his female lovers are but partially human. Audiences (or, at least, those that realize Calderone's true identity) are confronted with the reality, however, that Jo Calderone is indeed Lady Gaga; he is the manifestation of a biological woman performing the part of a man for artistic purposes. This revelation achieves several things within both YoÜ AND I and HAUS OF Ü.

Firstly, the disassociation between Calderone's sex and gender draws attention to gender as a performative construct. Although his physical body is not revealed during the YOU AND I music video, the fact that he is really Lady Gaga is made visually apparent by his close association with another of her alter egos. The audience can therefore conclude (or so it seems) that what they are witnessing is not true hegemonic masculinity; despite the fact that Calderone's body language and relationship follow normative expectations, audiences are actually viewing a performed masculinity. Although Gaga is biologically female, she is able to adopt a style of dress and behaviour for the YOÜ AND I music video that exudes masculinity based on stereotypical portrayals of what composes 'male-ness'. Calderone is depicted drinking beer, smoking, and stomping his feet aggressively. These seemingly manly actions contrast sharply with the normatively feminine Nymph in order to further highlight the masculine nature of his behaviour. He is even positioned so that he sits higher than Nymph in the frame, perched on top of the upright piano to hover 
above her and look down on her while she serenades him. This serves as a visual commentary on patriarchal understandings of masculinity and femininity, but it is transgressed by the fact that Calderone's masculinity is a performative construct. The omniscient fact that the man on the screen is, in reality, a woman undermines mainstream understandings of 'male-ness' and renders his masculinity a form of resistance, by virtue of the fact that these inherently male characteristics have been appropriated by a woman.

The relationship between Jo and Nymph in YoÜ AND I simultaneously represents and transgresses hegemonic understandings of heterosexuality as they relate to gender, and masculinity in particular. Patriarchal notions of sexuality have long associated masculinity with compulsory heterosexuality, hinging the success of a male individual's 'manliness' on his ability to attract women (Garlick 2003, 163). This concept, in itself, is a performance based on the personal need to meet social expectations and exist as a part of the dominant social group. Jo Calderone's heterosexuality is therefore additionally performative based on the fact that his gender is already a performance enacted by a woman. Calderone behaves in a stereotypically masculine manner, grabbing at Nymph as she sings, kissing her powerfully and caressing her body publicly in order to openly and firmly establish his claim on her. His behaviour also establishes heterosexuality, which is significant due to normative expectations of men as actively sexual beings, especially in comparison to women, whose active sexuality is often socially demonized (Valenti 2008). Once again, however, Calderone's displays of male sexuality with Nymph transgress their seemingly heternormative nature by virtue of the fact that his character is being performed by a woman. 
The manner in which Calderone's disassociation between sex and gender confuses normative understandings of masculinity and heterosexuality (and has also confused many audience members) highlights the truly fluid nature of gender and sexuality based on their existence as performative social constructions. If Calderone appears to be male, but is not a man, and yet he is in a relationship with a woman, how might society attempt to classify him in terms of sexuality? He cannot be 'properly' heterosexual, because he is not 'properly' male. He is not necessarily homosexual, however, because he is not 'genuinely' female based on his gender performance, despite Gaga's physically female body. Calderone is not 'straight' because he is not physically male, but he is not gay because he loves a woman, nor is he a lesbian because he is not understood as entirely female according to social criteria. The transgressive relationship between Jo Calderone and Nymph in YoÜ AND I presents audiences with a visual conundrum of gender and sexuality that forces them (or, at least, those that realize the paradox of Jo Calderone) to question the very nature of how and why we understand gender and sexuality a certain way and how limiting these dominant conceptualizations truly are.

\section{Undressing Transgressive Gender Performance: Jo Calderone in HAUS OF Ü}

Unlike the music video for YOÜ AND I, the short film HAUS OF Ü FEAT. Jo CALDERONE directly confronts audiences with the visual disassociation between gender and the body. Although many viewers know that Calderone, in YOÜ AND I, is actually played by Lady Gaga (confusion surrounding this persona was discussed in Chapter I), and is therefore physically female, they do not see the body beneath his clothes. In Calderone's installment of HAUS OF Ü, however, Lady Gaga uses her body as a physical 
resistance against normative understandings of gender and sexuality by baring it for viewers to see, making the separation between biology and gender identity blatantly apparent. Calderone is introduced fully clothed and the frame alternates between images of him smoking heavily and Barn Hooker dancing sensually with her crew of other barn hookers. The way these images are interspersed, as though Calderone is the sole man among all of these scantily clad women, once again establishes him as performing heterosexuality while simultaneously displaying his masculinity. Viewers are not left to infer his sexuality based on the relationship between 'male-ness' and compulsory heterosexuality, but are actually presented with images that solidify Calderone's interest in women, even as that same heterosexuality is questioned or undermined based on the knowledge that Jo Calderone is Lady Gaga.

Calderone's contrast with Barn Hooker in HAUS OF Ü further transgresses assumptions about Calderone's sexuality based on the fact that both of these characters are Gaga's alter egos. What viewers are indeed witnessing is Gaga's performance of stereotypical masculinity, which is often problematically assumed to include heterosexuality. This assumption is reinforced by the way Calderone's image alternates with Barn Hooker's, but it is also thrown into question by the fact that Barn Hooker is also Lady Gaga. This leaves the dynamic between the two characters open ended and free for interpretation; is it fair to make assumptions about Calderone's sexuality when the woman he is being associated with is an alternative gender performance of himself? Extending from this concept, is it fair to make assumptions about Calderone's sexuality at all? Perhaps the fact that the women in his life are all alternative versions of himself signifies that Calderone is asexual, and not truly sexually attracted to any other person? 
Perhaps this is a satirical take on male ego and sexuality; is he actually simply attracted to himself? Once again, Gaga uses artistic performance to establish a sense of fluidity about identity by forcing a confrontation of person and persona, transcending social barriers and limitations.

As the HAUS OF Ü video progresses, Calderone begins to undress and reveals Lady Gaga's body. For the first time, viewers have visual proof of his masculinity as performance and are openly confronted with images of a gendered man possessing female anatomy. Calderone begins by lifting his shirt, exposing Lady Gaga's breasts, which have been bound down in order to more closely resemble a male physique. He then removes his pants to expose a false jock strap in men's briefs, which he confidently grabs in a stereotypically male gesture, leaving his shirt pulled up and thrusting his middle finger in the air. With these images, Lady Gaga uses her body to present viewers with a direct and blatant confrontation of gender and sex, dislodging assumed connections between gender identity and the physical body. She also uses her status as a musical artist to present mainstream audiences with images of the transgendered body; a marginalized identity often omitted from the world of popular music. In case the act of baring her body in contradiction to her gender performance failed to be transgressive enough, Gaga salutes normative body expectations with her middle finger to drive the point home. The direct resistance of rigid categorical understandings of gender and sexuality constructs these identities as fluid, performative expressions that cannot truly be limited to a handful of prescribed labels. It also disconnects notions of gender and sexuality as being inherently reliant on the physical body. 


\section{Responding to Jo Calderone: Fan Reception Texts}

YouTube user janssencox 93 produced a recreation of Lady Gaga's HAUS OF $\ddot{U}$ FEAT. JO CALDERONE that virtually mirrors the original text, and yet differs in several significant ways (http://www.youtube.com/watch? $v=\mathrm{pKj}$-D9zIm1I). These differences, which effectively exemplify the new media phenomenon of the consumer becoming the producer, are why I chose this particular reception text for analysis. janssencox 93 posted the video to YouTube in October 2011 and it has received 960 views (as of March 2013). The video depicts a female individual dressed in men's clothing, much like the original version. This person, however, has avoided taking as drastic steps as Gaga to hide her outwardly feminine characteristics, leaving her hair in a long braid down her back and refraining from binding her breasts. This signifies a fluid and less concrete understanding of gender; she does not attempt to fully hide her own identity, and yet she intentionally embodies characteristics associated with another gender. This individual seems comfortable and confident in a slightly androgynous state, bearing characteristics of both the masculine and the feminine. This embodiment not only recreates Lady Gaga's 'othered' gender performance, but it also adds an additional layer of transgression; this person is performing neither a normative feminine identity, nor fully appropriating a masculine one. Near the conclusion of the video, janssencox93 uses creative license, distinguishing her text from complete recreations and qualifying it as a unique audience interpretation. Rather than undressing and displaying physically female characteristics in order to highlight the transgressive nature of this persona's embodiment, janssencox93 uses a lipstick tube to signify 'the feminine'. After a look of confusion and aggravation, 
the lipstick is thrown to the ground and discarded, much like the personification of Calderone discards normative gender roles.

A preoccupation with sexuality is less prevalent in janssencox93's recreation. Unlike the original, this video does not include alternating images suggesting that Calderone is surrounded by female individuals. Similarly, the recreated Calderone does not undress and reveal breasts, although these are discernible to viewers during several angry pulls at his $t$-shirt collar. Instead of the revealing scenes, janssencox 93 includes a shot where Calderone stands in a nonchalant yet assertive and masculine position, while the camera surveys up and down his fully clothed body. There may be several reasons that the more overt displays of sexuality included in Lady Gaga's original video are absent from this particular reception text. Perhaps janssencox 93 simply did not have the time to create more complicated shots that involved Jo Calderone's image alternating with a female counterpart. It seems likely, however, that scenes involving Calderone undressing and revealing Gaga's body were deliberately omitted, replaced instead by the clothed full-body shot. This does not necessarily signify that janssencox 93 opposes Gaga's displays of sexuality or is uncomfortable with the extremely transgressive implications of Calderone's physical body; this video does, after all, recreate almost every other aspect of Gaga's 'othered' gender performance. It is possible, however, that janssencox 93 simply practiced discretion, choosing not to expose her naked body publicly on the Internet. This discretion highlights how, as outlined in Chapter II, a person's image, art, or activist involvement might lose credibility in the eyes of its viewers, should it include elements that might be constructed as hyper-sexualized. janssencox 93 contributes to activist messages of gender and sexuality, while at the same 
time protecting herself from personal criticism and accusations that she was influenced by Lady Gaga to objectify her own body by exposing herself on the Internet.

Like janssencox93, YouTube user LadyLurdys chose to embody Jo Calderone in a recreation video

(http://www.youtube.com/watch?v=60P0S0G1Yy0\&list=UURo9hF7uGgQgraPigtnWFi w\&index $=3$ ). This video was published on YouTube in March 2012 and has received 5,385 views (as of March 2013). I chose this video response specifically for its integration of certain elements of identity that were not taken into consideration by any of the original YOÜ AND I and HAUS OF Ü texts, nor any of my other chosen reception texts. Mirroring the original HAUS OF Ü FEAT. JO CALDERONE adequately, this reception text depicts a large woman dressed in drag, smoking heavily, behaving in an aggressive and masculine manner, and even lifting her shirt to expose her stomach and bound breasts. In addition to highlighting issues of gender and sexuality the way that Lady Gaga's and janssencox93's videos do, LadyLurdys' text presents audiences with another visual element for consideration: aging. The majority of the fan-made videos found online are created and shared by younger audiences members, ranging from young teens to individuals in their early thirties. Many of them include statements with their videos about using them as a creative outlet, a step in exploring their own identity, an expression of their connection with Lady Gaga's music, or an attempt to engage with activist messages. Bodies are often bared in the reception videos, as they are in the original texts, and while they do not necessarily represent an image of society's unattainable normative body standard, they are most often the bodies of youthful people that are either in or approaching an age typically associated with sexual discovery and prime sexuality. 
LadyLurdys, however, is much older than the individuals depicted in the other videos I have featured in my analysis. Because of this, her video serves as a resistance against assumptions associated with gender, sexuality, age and body image.

Dominant social understandings of aging often associate the process of growing old with a decline of sexual behaviour and a lack of sexuality. Elderly persons are constructed as lacking sexual need and desire through stereotypical portrayals and commonly used adages about behaving 'like an old couple' to describe younger couples that have lost their sexual drive or compatibility. Younger generations cringe to think of their grandparents, or even their parents, behaving sexually. 'Old' bodies are constructed as unattractive, associated with failing ability and dilapidation, and it is concluded that they should be covered or hidden (Hodson \& Skeen 1994, 220-2; Calasanti 2007, 336-9). These assumptions deny the ongoing sexual autonomy of individuals perceived as 'old' and construct age as a negative process that robs one of their sexual capabilities and their need to feel desireable and express their sexuality. LadyLurdys' performance of Jo Calderone, however, resists these notions as she lifts her shirt, bares her bound breasts, and fondles her imaginary male genitalia. By publicly sharing a recording of herself performing these actions, she serves as a representative for Lady Gaga fans who are older than the dominant population creating these trasngressive texts. LadyLurdys' reception text serves as an example of Susan Bordo's notion of 'decentering the self' in order to bring attention to marginalized identity, as discussed in Chapter II. She separates her body from dominant conceptions of aging, exposing it in a video that openly identifies her as part of a group stereotypically thought to consist of young adults and teens. 
LadyLurdys' video also resists concepts of sexuality and age as they specifically pertain to her gender. Although negative constructions of age are ultimately applied to all people at some point, society ascribes these judgments and assumptions to women much earlier and far more harshly than it does to men (Calasanti 2007, 343-8). While men are often viewed as 'getting better with age' and becoming wise, distinguished, and even more desirable based on experience, women are often assumed to have 'let themselves go', past their prime, and ceased being productive in contrast to needing care. Even if a woman has kept her figure and cares for herself, those who continue to express sexuality or engage in sexual activity are often constructed as 'cougars', particularly if the male partner is younger. This conception bears a negative connotation, conjuring these women as predators. LadyLurdys' embodiment of Jo Calderone, however, resists these notions by serving as an expression of sexuality that does not depend on sexual activity with another person, but rather on the simple act of moving and behaving in a sexual manner despite her perceived age. She is a large woman with big hands and her body does not adhere to social ideals of women as impossibly thin and beautiful. Nonetheless, she reveals her stomach and breasts to the camera, directly transgressing social constructions of the aging body as something that should be hidden. LadyLurdys re-conceptualizes the audience's understanding of Jo Calderone as a young, attractive, sexual being, and instead presents them with the reality that age and the aging body does not define, nor necessarily limit, a person's sexual capacity or desire. It is important to note that this video includes the memorable scene from the original HAUS OF Ü FEAT. JO CALDERONE, in which Calderone salutes the camera with his middle finger while fondling his (prosthetic) manhood. Here, the gesture appears to signify a challenge to society, as 
though LadyLurdys is warning social norms to back off and stop policing her body. Her video presents an additional layer of transgression and resistance to those already present in Lady Gaga's performance of Jo Calderone, and thereby exemplifies the significance of fan interaction with Gaga's original new media texts.

\section{Summary}

My analysis of Lady Gaga's YOÜ AND I and HAUS OF Ü texts reveals how new media platforms such as YouTube (among others) enable a shift in the positionality of the audience member, allowing for an evolution of the individual from passive consumer to active producer. My exploration of specific fan reception texts exemplifies the dynamic relationship between Lady Gaga and her little monsters due to her use of the Internet to perpetuate activist messages, as discussed in Chapter II. Themes of empowerment, hypersexuality, and performativity can be identified within the images communicated in my chosen reception texts, particularly in those that take Lady Gaga's original messages and build upon them in order to perpetuate further representation of non-normative identities. Those texts that extend the messages in Gaga's original materials also serve as a clear illustration of symbolic interaction theory, exemplifying how individual interpretation of specific images can be influenced and recommunicated in order to create new knowledge and understanding, and thereby contribute to social change. Finally, Butler, Bordo, and Young's theories about gender, sexuality, and subjectivity can be clearly identified in the way that both Gaga and her responding little monsters use their bodies as political tools to transgress hegemonic social norms connecting gender and sexuality to the physical body, as well as to embody the idea of identity as an unlimited performative construct. 


\section{Chapter IV \\ Discussion and Conclusion}

In this chapter, my goal is to tie together my analysis from Chapter III and the central theories and key points that have been pervasive in my investigation of Lady Gaga's work. I intend to show the critical intersections between gender, sexuality, and subjectivity theories and theories about new media, participatory culture, and online activism that presented themselves within my analysis of Lady Gaga's YoÜ AND I and HAUS OF Ü texts, as well as the corresponding fan reception texts included in my exploration. With these connections, I hope to reveal the ways in which Lady Gaga's work exemplifies how the relationship between new media capabilities and normative identity transgression bears great potential for the future of social advocacy.

\section{Discussion}

\section{Lady Gaga's Personas, Transgression, and New Media as Activism}

In addition to their importance in the world of fashion based on their co-creation by fashion photographers Inez Van Lamsweerde and Vinoodh Matadin and designer Nicola Formichetti, as well as their critical connections with other aspects of her career, Lady Gaga's YOÜ AND I and HAUS OF Ü texts illustrate the convergence of activism and new media. Gaga's embodiment and portrayals of 'othered' identities increase representation for several marginalized groups within the normative world of mainstream popular music videos. In a forum primarily populated by beautifully feminine women, strongly masculine men, and young, agile, able bodies, Gaga exposes her audiences to 
characters that exist outside of normative conceptions of gender identity, sexuality and desire, and the body. Her YOÜ AND I and HAUS OF Ü texts expose several critical intersections between society's core systems of power, illustrating how identity is shaped by gender, sex, sexuality, ability, and age. Her use of fashion, music and her own body as tools of expression facilitates her social commentary on the ways in which these elements of identity are limited and constrained by stereotypical social understandings. Simultaneously, her embodiment of characters that transgress the parameters of normativity serve as a form of resistance, drawing attention to identities that exist outside of dominant social binaries; that is, hetereosexual versus non-heterosexual, able bodied versus dis- or differently abled, male versus female, etc. Gaga's videos constitute a form of activism due to their ability to raise consciousness about how social norms regulate our bodies and our identities, as well as the attention that her characters draw to the marginalized realities of individuals whose identities, bodies, and behaviours are not accounted for in dominant epistemologies and language. Nymph, Bride, Yüyi, Jo Calderone, Mother, and Barn Hooker individually constitute transgressive identities that purposely oppose or contrast with each other, exemplifying to audiences the performative nature of gender and sexuality. Based on this understanding of performativity, each character also raises awareness about the unlimited number of ways that our gender, sexuality, bodies, and relationships can be alternatively performed and re-conceptualized independently of their dominant historical and social construction.

The activist nature of Lady Gaga's Yoú AND I and HAUS OF Ü texts extends beyond their simple inclusion of transgressive images and embodiment of marginalized identities. Gaga's use of social media platforms and new media capabilities to share and 
distribute these videos constitutes them as activist materials in several ways. Firstly, their existence as online phenomena facilitates the consumption of activist messages by audiences that would not otherwise be able to actively view her transgressive performances, nor necessarily become exposed to the social messages therein. By virtue of distributing the images on a global scale (although acknowledging the privileged nature of technological and Internet access is key here), the use of new media platforms allows for international viewership that physical, real-world activism and performance do not easily facilitate. Gaga's mobilization of new media also enables her to discuss and distribute her messages in a more direct way, removing the intermediary elements of things like television distribution and allowing her to post her materials directly from her own social networking accounts to her fans. This truly unique aspect of new media usage establishes a personal connection between Gaga and the messages of advocacy that she purposefully communicates, allowing her to acknowledge the transgressive nature of her materials, express her intentionality, and actively link images from the online world with real-world activist campaigns and performances.

In addition to enabling the distribution of Gaga's activist images on a wider, faster, and more accessible scale, the use of new media platforms facilitates dynamic interaction between Gaga herself and the viewers consuming her transgressive images, as well as between the viewers themselves. This is a significant characteristic for consciousness raising materials such as the YOÜ AND I and HAUS OF Ü texts, because it allows greater discussion of complex topics such as the fluid reconceptualization of gender and sexuality in relation to sex and the body. Audiences mobilize their own social networking accounts for the purposes of redistributing Gaga's messages and discussing 
their social implications with a larger and more diverse population than was previously available before such platforms were developed. The act of sharing and discussing these materials spreads Gaga's messages of normative resistance further, communicating her images to viewers that might not otherwise come into contact with them or consider their validity, and increasing mainstream representation for several marginalized identities. Perhaps the most inherently activist quality of Lady Gaga's mobilization of new media to distribute transgressive materials, however, is the way in which these materials enable audience consumers of her texts to also become active producers of new materials.

\section{Fan Reception Texts, New Media, and Activist Participation}

The creation and distribution of fan reception texts, such as those that I chose to deconstruct in my analysis, exemplifies several characteristics about the ways in which new media facilitates dynamic interaction with Lady Gaga's original texts. The use of the body to attract attention to alternative gender performance, the connections between 'othered' personas and similarly transgressive offline performances, and the interactive process by which the original videos were distributed and consequently viewed by each user constitute characteristics that validate Lady Gaga's use of new media as a form of activism. Unique online capabilities provided by social networking platforms such as Facebook, Twitter, YouTube, and LittleMonsters.com allow audiences to absorb, consider, and discuss the messages that Lady Gaga distributes, while interacting with, reconceptualizing, building upon, and perpetuating these messages. Productions such as those fan recreations produced by my selected YouTube users exemplify how Gaga's unique activist materials have inspired others to expand their understanding of gender, sexuality and the body, beyond dichotomous social constructions. These individuals then 
actively contribute to the ongoing perpetuation of consciousness raising efforts by using artistic expression and their bodies to resist their own social pressures by embodying transgressive personas and communicating these images in a public forum.

Little monster participation in activist messages goes beyond increasing visibility for marginalized populations and perpetuating critical discussion about social limitations, as can be seen in texts depicting Jo Calderone. Discourses of love and acceptance generated by ideologies such as "Born This Way" and Body Revolution 2013, partnered with viewer mobilization of new media platforms, give voice to individuals struggling to self-identify within exclusive social constraints. Gaga's use of new media to communicate messages of identity resistance solidifies her as a forerunner in the growing use of Internet, technology, and social networking to create space for discussion and establish communities based on common interest that transcend physical and geographical real-world limitations. These unique characteristics of new media usage enable audience members to go beyond simple interaction with and response to Lady Gaga's activist materials, as can be seen by those YouTube users in my analysis who built upon and extended her ideas to intersect with other marginalized groups. For example, LadyLurdys' reception text was not simply a recreation of Gaga's HAUS OF Ü FEAT. JO CALDERONE, but an extrapolation of how society uses age to regulate and constrain the bodies and identities of individuals as it relates to gender and sexuality; a concept that Gaga did not deconstruct in her original materials but that extends directly from their core themes. Herein lies the inherently unique activist quality of Lady Gaga's videos and new media usage, based on their ability to not only enable fan interaction and discussion, but also legitimize audience participation in the ongoing communication of 
those messages and the development or evolution of the key concepts presented in her original work.

\section{Risks of Online Activism: Voyeurism, Misinterpretation, and Over-communication}

As with any activity that takes place in a public, online forum, the act of conducting activism through the Internet inherently involves several problematic risks that can detract from the original message and influence the efficacy of consciousness raising materials. Lady Gaga's YOÜ AND I and HAUS OF Ü texts are no exception, especially considering their mass appeal, dissemination to 30 million-plus Twitter followers, and then re-communication on an unlimited scale from there. The exposure of transgressive and contentious images to a diverse and international audience inherently risks voyeurism of those identities embodied in her materials, the misinterpretation of her artistic and slightly abstract representations, and the over-communication of activist messages based on their existence in the sphere of new media and social networking. Each of these problematic possibilities, facilitated by Internet participation, influences the ability of Gaga's message to effectively impact normative social discourses.

Because Lady Gaga's activist campaigns are largely a result of her celebrity status, the reality manifests that some audiences interact with her transgressive messages out of the desire to connect with Gaga herself, or even to simply follow a trend. When the 'trend' in question bears real implications for the social experience of marginalized individuals, however, it becomes harmful when fan reception texts include the embodiment of non-normative identities out of a desire to follow Gaga's lead for the sake of simply being a part of her community, rather than sharing a genuine interest in participating in social change. While celebrity activism can, in fact, play a large role in 
raising fan consciousness about important social issues, not everyone interacting with the activist materials created for that purpose might fully comprehend the complexities of identity politics and the constraining social limitations on gender, sexuality, and the body. As a result, those who embody marginalized identities in their reception texts solely out of reverence for Lady Gaga as a pop star, or out of a desire to attract her attention, as opposed to an interest in focusing on how the body can resist normative conceptions of gender and sexuality, inflict a certain level of voyeurism upon individuals whose lived experiences reflect exclusion based on social binaries. This form of participation does not render Gaga's activist efforts ineffective, but one might argue that fan depictions of marginalized identities by those who do not exist as a part of those populations, especially when they are used to gain attention, border on exploitation. For example, users can be seen on LittleMonsters.com posting pictures that they found through general search engines of same-sex couples or children living with disabilities, accompanied not just by energetic exclamations about being "Born This Way", but also requests for other people to like their post, follow their profile, and increase their popularity in the social network. Even if such an individual harbours a genuine belief in the ideals of love, acceptance, and equality, using images of 'othered' persons in order to benefit themselves within a cause, rather than contributing to the cause for the sake of social change, is arguably a form of voyeuristic oppression. The act of pinning an ideology such as "Born This Way" upon another person already existing outside of normative conceptions of identity and the body further marginalizes that identity and opposes what Lady Gaga's campaign is actually attempting to achieve. Because her movement exists primarily 
through new media platforms, however, it is impossible to thoroughly educate individual participants on the problematic nature of voyeuristic behaviour masked as 'activism'.

Just as certain identities can be voyeuristically marginalized by dominant populations on the Internet, online activism involves the risk of misinterpretation, especially in an artistic context like Lady Gaga's, where abstract images might appear confusing to the general audience. Following the release of each HAUS OF Ü film, the majority of the resultant media coverage concentrated on how naked Lady Gaga was in each video and how intimately she touched herself. This fixation on nudity as being inherently related to sex serves to over-sexualize images of Gaga revealing her body, even if the persona she embodies at the time communicates a deeper message about the body, gender, and sexuality. Through misinterpretation of her nudity, Gaga's social commentary might be overlooked in favour of media coverage constructing her images as inappropriate or objectifying. Several media outlets also misinterpreted, or failed to understand, the more transgressive characters like Jo Calderone, claiming that their function was entirely performative or intended simply to confuse viewers and gain media attention due to unconventionality. For example, Kelsey Wallace, who posted an opinion piece about Jo Calderone's 2011 VMA monologue to the website for Bitch Magazine, expressed a great deal of confusion about whether Gaga's performance as Calderone was supposed to serve as transgressive or self promotional. In her piece, Wallace acknowledges the potential for Calderone to spark some positive feminist attention in the world of identity activism based on his gender-bending nature. She questions, however, whether statements about Gaga's personal sex life (if allusions to Gaga having a sexual relationship with a male character enacted by herself can be considered personal details) 
were thrown in simply for shock value. Wallace accuses this part of the monologue, along with its length and Calderone's 'cheesy accent' to be simply 'self-indulgent' (Wallace 2011). While Calderone's scenes certainly do raise consciousness due to their taboo nature and their upturning of what is 'normal', the deeper implications of Gaga's representation of a transgender identity are lost when he is constructed as existing solely as a publicity stunt. Although Gaga's new media capabilities enable her to converse with audiences and discuss the meaning behind her images and personas, the speed at which her materials are shared and redistributed once posted is too fast, and the distance they can travel too far, for her to ensure that each person interacting with her videos avoids misinterpreting her use of nudity and the body as meaningless over-sexualization.

Another problematic characteristic of online activism lies in the ability of new media and social networking to enable quick and easy sharing. Lady Gaga's original texts, and activist materials similar to these, can be redistributed at the simple click of a button. Because she has amassed such a significant online following, this process takes place for Gaga's texts at an extremely fast rate and on an extremely large scale. During periods when she is especially active in the public sphere or behaves in a way that attracts significant attention, there is scarcely a media or pop culture source worldwide that does not 'weigh in' on her career or actions in some way. This, in combination with the redistribution and recreation of her materials at an individual online level, can result in the over-communication of her image, productions, and activist messages. If online users are virtually assaulted with Lady Gaga-related information, the importance of her message might diminish due to a loss of interest in the details of her cause, based on the over-zealous sharing of individual audience members. When viewers become tired of 
repeated exposure to the same material, the efficacy of that material is compromised, even if it is exemplary in its transgressive nature. Such is the curse of not only celebrity activist efforts, but the career of a pop music star in its entirety. Lady Gaga must strategize the release of her materials according to her own desires and needs, the needs of the activist movement, and the wants and desires of her audience. Activist new media texts must be produced and released at a speed that keeps viewers interested and engaged with new materials, but not so fast that the details of the message and the importance of her transgressive images are lost in an effort to over-communicate with the masses.

Each of these problematic characteristics of enacting social change via new media platforms is inherent in any online activist campaign, and Lady Gaga's movement is no exception. By converging her social agenda with her musical career using the idea of being "Born This Way" as both an ideology and a musical theme, however, she establishes a more concrete association between herself and her consciousness raising efforts. The extension of her original ideology of acceptance and self-love into a new phenomenon, the Body Revolution 2013, ensures that the scope of her activist involvement develops along with the evolution of her musical and artistic career. These connections, along with her continued active participation through new media in her online community of fans - facilitating a more direct communication with her audience helps to minimize the negative effects resulting from the problematic risks inherent in online activism. Gaga mobilizes her new media capabilities effectively enough to maintain a tangible connection between her music, art, and activist involvement, resulting in the constant distribution of revolutionary messages through her ever-increasing artistic expression and musical creation. 


\section{Conclusion}

My inter-textual analysis breaks new ground on the relationship between online and offline activism, as well as what factors of celebrity status are perceived by the public to either benefit or hinder a celebrity's activist involvement. Although a small body of literature already exists on both the topic of developing forms of online activism and the public's response to celebrity behaviours such as performativity, over-sexualization, and empowerment, my research fills the existing theoretical gaps focused on how these elements converge. By analyzing public conceptualizations of Lady Gaga's activist images, I hope to add to the understanding of how celebrity status and activism are negotiated to address public perceptions and how celebrities, Lady Gaga in particular, use those perceptions to promote social change (Hermes 2006).

With the completion of my analysis, I believe that I have uncovered several important results. I conclude that widespread support for Lady Gaga's activism has been exemplified due to her extensive fan base and her use of social networking websites and new media to connect with the public on a wider scale. I also believe, however, that an opposing, and yet highly important theme has become apparent, constructing her advocacy as a negative example of social activism. In consequence, her career is perceived by some audience members as contributing to the development of 'raunch culture', as opposed to positively inciting social change. Finally, I argue that certain reception texts have indicated that Lady Gaga's activist images are understood by some members of the public as mainly performative, thereby detracting from the authenticity of her work and defining her activism as a mere desire for increased fame. I believe that new findings of this kind add significantly to our understanding of Lady Gaga, modern 
art and fashion, and social perceptions of her activism, as well as to the theoretical analysis of performativity, empowerment, and 'raunch culture'. In addition, a deeper comprehension of how new media may be used to promote alternative performances of sexuality and gender as they relate to the body, ability, and age has been gained, highlighting the problematic nature of society's dominant normative constructions of these identities and drawing attention to the fact that they are performative concepts that can be embodied in different ways.

My conclusions regarding the relationship between offline and online activism contribute to the body of work on the development of Internet consciousness raising and the use of new media in social advocacy (Brunsting \& Postmes 2002, Caroll \& Hackett 2996, Hirzalla \& Van Zoonen 2011, Jenkins 2006). Because this research interest is relatively new, limited literature exists on the topic of the politics of online participation and self-construction by celebrities who use online forms of communication (Nielson 2009, Nunes Puente 2011, Earl 2006). Academic discussion of specific case studies, such as my examination of Lady Gaga's YOÜ AND I and HAUS OF Ü texts, is less prevalent.

In addition, my research contributes to the existing body of knowledge on how changing understandings of overt displays of sexuality in pop music influence audience actions and beliefs. Considerable literature exists on the subject of fan response to public persona (Auslander 2006, Smith 2011, Railton \& Watson 2011). Information about, for example, perceptions of Lady Gaga's establishment of her own foundation for youth empowerment, however, offers an analysis of the specific relationship existing between celebrity and activism. This topic is not new to the academic arena (Reger 2007), but my 
use of Lady Gaga and YOÜ AND I-related texts as a case study provides an alternative view of that research material.

Finally, my research actively contributes to an area of study that is currently in its infancy, but which has quickly developed enough to approach a more legitimate academic standing. The concept of critical Lady Gaga studies has gained support since the outset of her musical career, and more importantly since the launch of the website Gaga Stigmata, established in March 2010. Set to publish a book comprised of the best public submissions to the site sometime in 2013 , the editors of this forum have spent the last few years revising, editing, verifying, and posting writings about Lady Gaga's musical career and all that it encompasses ("About"). In addition to this forthcoming publication, the University of South Carolina has played a large role in bringing the area of Lady Gaga studies into the academic sphere. Professor Mathieu Deflem began teaching a sociology course entitled Lady Gaga and the Sociology of the Fame in the spring of 2011, breaking news headlines by giving legitimate academic attention to Lady Gaga and her work ("University Offers Lady Gaga Sociology Course"). By conducting this research project and concurrent analysis, I intended to build upon these initial efforts to break ground in the academic world and provide legitimacy to the concept of Lady Gaga's phenomenological social presence as an area of scholarly interest, especially as her work pertains to discourses of gender and sexuality and identity politics. 


\section{Works Cited}

"About." Web log post. Gaga Stigmata. Blogger. Web. 31 Jan. 2012. <www.gagajournal.blogspot.com>.

"Britney Spears and Lady GaGa Blasted for Soft Pornography Videos." Ace Showbiz.

World Entertainment News Network, 11 Aug. 2010. Web. 15 Feb. 2012. <www.aceshowbiz.com>.

"Gay Advocates Hail Lady Gaga's Activism, VMA Drag Act." International Business

Times. The International Business Times Inc., 31 Aug. 2011. Web. 25 Feb. 2012. <www.ibtimes.com>.

"Lady Gaga Admits Being Bullied In High School Still Hurts." Access Hollywood. NBC Universal, 23 May 2011. Web. 31 Jan. 2012.<www.accesshollywood.com>

"Lady Gaga's 'Don't Ask, Don't Tell' Speech: The Full Transcript." MTV News. VIACOM International Inc., 20 Sept. 2010. Web. 25 Feb. 2012. <www.mtv.com>.

"Lady Gaga's Jo Calderone Monologue." MTV UK. MTV Networks 2011. Web. 15 Feb. 2012. <www.mtv.co.uk>

"Maria Aragon Signs Record Deal." Toronto Sun. Fatwire, 25 July 2011. Web. 25 Mar. 2012. $<$ http://www.torontosun.com>.

"A Body Revolution 2013". <www.littlemonsters.com/abodyrevolution>.

"Brian Sings and Swings". Family Guy. Fox. WXIA, Atlanta. 8 Jan. 2006. Television.

“L.A. Reid Regrets Dropping Lady Gaga: 'I Was Having A Bad Day'”. Hello Beautiful. Interactive One 2013. 11 Oct. 2011. Web. 28 Feb. 2013. $<$ www.hellobeautiful.com> 
"Lady Gaga Confirms She’s Split From Beau Luc Carl” Los Angeles Times. Tribune. 16 May. 2011. Web. 28 Feb. 2013. <www.latimesblog.latimes.com> "Lady Gaga Launches Born This Way Foundation". ABC News. ABC New Internet Ventures. 1 Mar. 2012. Web. 2 mar. 2013. <www.abcnews.go.com $>$ "Lady Gaga Surprised to See Fans in Cornfield". Teen Music. TeenHollywood.com II Inc. 2011. Web. 22 Nov. 2012. <www.teenmusic.com>.

“Lady Gaga: Biography”. Bio. True Story. A+E Television Networks, LLC. Web. 28 Feb. 2013. <www.biography.com>

“Looking Meatier! Lady Gaga Shows Off Her New Fuller Figure After 'Gaining 30lbs' in Her Favourite Carnivorous Creation". The Daily Mail UK. Associated Newspapers, Ltd., 19 Sept. 2012. Web. 2 Oct. 2012. <www.dailymail.co.uk>. “Looking This Wacky Doesn't Come Cheap! Lady Gaga Admits She Went Bankrupt After Spending Millions on Tour Costumes". The Daily Mail UK. Associated Newspapers, Ltd., 31 May. 2011. Web. 28 Feb. 2013. <www.daiymail.co.uk $>$ “University Offers Lady Gaga Sociology Course". BBC News: Education \& Family. British Broadcasting Coroporation, 2 Nov. 2010. Web. 4 Mar. 2011.

Aroxa, Mariana. "'Pop Will Never Be Low Brow': The New Representation of the Female in Popular Culture" Paper presented at the annual meeting of the NCA 96th Annual Convention, Hilton San Francisco, San Francisco, CA, Nov 13, 2 010.

Attwood, Feona. Mainstreaming Sex: The Sexualization of Western Culture. London; New York: New York: I.B. Tauris; In the United States of America and Canada distributed by Palgrave Macmillan, 2009. Print. 
Aune, Sean P. "15 Celebrity-Inspired Social Networking Sites”. Mashable. Wright's Media. 11 Jun. 2008. Web. 4 Mar. 2012.< http://mashable.com/2008/06/11/celebrity-social-networks/>.

Auslander, Philip. "Who Can I Be Now?: David Bowie and the Theatricalization of Rock." Performing Glam Rock: Gender and Theatricality in Popular Music. Ann Arbour: University of Michigan, 2006. 106-49. Print.

Bain, Becky. "Jo Calderone (a.k.a Lady Gaga in Drag) on the Cover of 'Vogue Hommes Japan"”. Idolator. BuzzMedia, 25 Aug. 2010. Web. 2 Oct. 2012. <www.idolator.com $>$

Beasley, Chris. "The Elephant in the Room: Heterosexuality in Critical Gender/Sexuality Studies." NORA-Nordic Journal of Feminist and Gender Research 18.3 (2010): 204-9

Bell, Elizabeth. "Sex Acts Beyond Boundaries and Binaries: A Feminist Challenge for Self Care in Performance Studies." Text and Performance Quarterly 25.3 (2005): $187-219$.

BenWay08. "Yüyi is real". Video. 19 Oct. 2011. Web. 2 Jan. 2013. $<\underline{\text { http: } / / \text { www.youtube.com/watch? } \mathrm{v}=\mathrm{UbJ} 2 \mathrm{kF}-}$ q5Ac\&list=UUtNcEQk2Zh3XsxwFpuehIuQ\&index $=17 \&$ feature $=$ plcp $>$.

Blumer, Herbert. Symbolic interactionism: Perspective and method. Berkeley: University of California Press, 1969.

Bordo, Susan. "The Body and The Reproduction of Femininity: A Feminist Appropriation of Foucault." Gender/body/knowledge: Feminist Reconstructions of 
Being and Knowing. By Alison M. Jaggar. New_Brunswick, NJ: Rutgers UP, 1 989. 13-33.

--. "Postmodern Subjects, Postmodern Bodies." Feminist Studies 18.1 (1992): 159-75.

Bragg, Sara, and David Buckingham. "Too Much Too Young?: Young People, Sexual Media and Learning." Mainstreaming Sex: The Sexualization of Western Culture. Ed. Feona Attwood. New York; London: I.B. Tauris, 2009. 129-46. Print.

Brewis, Joanna, Mark Hampton, and Stephen Linstead. "Unpacking Priscilla:

Subjectivity and Identity in the Organization of Gendered Appearance." Human Relations 50.10 (1997): 1275-304.

Brickell, Chris. "Sexuality, Power and the Sociology of the Internet." Current Sociology 60.1 (2012): 28-44.

Brown, Gavin, and Jenny Pickerill. "Space for Emotion in the Spaces of Activism." Emotion, Space and Society 2.1 (2009): 24-35.

Bruns, Axel. Blogs, Wikipedia, Second Life, and Beyond: From Production to Produsage. New York: Peter Lang, 2008. Print.

Brunsting, Suzanne, and Tom Postmes. "Social Movement Participation in the Digital Age." Small Group Research 33.5 (2002): 525-54.

Burman, Erica. "Contemporary Feminist Contributions to Debates Around Gender and Sexuality: From Identity to Performance." Group Analysis 38.1 (2005): 17-30.

Burns, Lori, and Alyssa Woods. “Devouring Popular Music Hits: Lady Gaga's Appropriations on Fame Monster (2009)." Paper presented at the international conference Feminist Theory and Music 11, Phoenix, Arizona, September 2011. 
Butler, Judith. "Performative Acts and Gender Constitution: An Essay in Phenomenology and Feminist Theory." Theatre Journal 40.4 (1988): pp. 519-531.

--. "Foucault and the Paradox of Bodily Inscriptions." The Journal of Philosophy 86.11, Eighty-Sixth Annual Meeting American Philosophical Association, Eastern Division (1989): pp. 601-607.

--. Gender Trouble Feminism and the Subversion of Identity. 10th anniversary ed. New York: Routledge, 1999.

Calasanti, Toni M. "Bodacious Berry, Potency Wood and the Aging Monster: Gender and Age Relations in Anti-Aging Ads." Social Forces 86.1 (2007): 335-55.

Capulet, Ian. "With Reps Like these: Bisexuality and Celebrity Status." Journal of Bisexuality 10.3 (2010): 294-308.

Carroll, William, and Robert Hackett. "Democratic Media Activism through the Lens of Social Movement Theory." Media, Culture \& Society 28.1 (2006): 83-104.

Casey, Liam. "Kony 2012 Campaign to Capture Warlord Goes Viral, But Also Draws Some Critics". The Star World News. Toronto Star Newspapers Ltd. 7 Mar. 2012. Web. 2 Mar. 2013. <www.thestar.com>

Cheong, Denise and Charlene Fang. "Lady Gaga: 'I Live Halfway Between Reality and Fantasy". CNN Travel. Disqus, 8 Jul. 2011. Web. 2 Oct. 2012. $<$ www.travel.cnn.com $>$

Cure, Eduardo. "Lady GagaVisits Child Friendly School in Peru". UNICEF: A Glance at Peru. UNICEF. 14 Dec. 2012. Web. 6 Mar. 2013. <www.unicef.org>. 
Davis, Erin Calhoun. "Situating "Fluidity": (Trans) Gender Identification and the Regulation of Gender Diversity." GLQ: A Journal of Lesbian and Gay Studies 15.1 (2008): 97-130.

Daw, Robbie. "Lady Gaga Discusses "You And I" Video Concept During Radio Interviews." Idolator. BuzzMedia, 26 Jul. 2011. Web. 15 Feb. 2012. $<$ www.idolator.com $>$.

Di Giulio, Gina. "Sexuality and People Living with Physical or Development Disabilities: A Review of Key Issues." The Canadian Journal of Human Sexuality 12.1 (2003): 53-68. EBSCO. Web. 28 Mar. 2011.

Doan, Petra L. "The Tyranny of Gendered Spaces - Reflections from Beyond the Gender Dichotomy." Gender, Place and Culture 17.5 (2010): 635-54.

Duerst, Austin. "Bette Midler Accuses Lady Gaga of Stealing Wheelchair Bound Mermaid Persona". Nerve. Nerve.com, Inc. 18 Jul. 2011. Web. 12 Mar. 2013. < http://www.nerve.com/news/music/bette-midler-accuses-lady-gaga-of-stealingwheel-chair-bound-mermaid-persona>.

Earl, Jennifer. "Pursuing Social Change Online." Social Science Computer Review 24.3 (2006): 362-77.

Eaton, Marc. "Manufacturing Community in an Online Activist Organization." Information, Communication \& Society 13.2 (2010): 174-92.

English, Holly. Gender on Trial: Sexual Stereotypes and Work/life Balance in the Legal Workplace. New York, NY: ALM Pub., 2003 
Evans, Adrienne, Sarah Riley, and Avi Shankar. "Technologies of Sexiness: Theorizing Women's Engagement in the Sexualization of Culture." Feminism \& Psychology 20.1 (2010): 114-31.

FashionedByLies. "Haus of U: Fan-Made”. Video. 7 Sept. 2012. Web. 2 Jan. 2013. $<$ http://www.youtube.com/watch? $=\mathrm{fx} \quad \mathrm{YHHsGBB} 4 \&$ list $=\mathrm{UU}$ yE39mRtoFetsVW xHldp MhQ\&index $=15 \&$ feature $=$ plcp $>$.

Fausto-Sterling, Anne. Sexing the Body: Gender Politics and the Construction of Sexuality. New York, NY: Basic, 2000. Print.

Fine, Michelle and Sara I. McClelland. "Rescuing a Theory of Adolescent Sexual Excess: Young Women and Wanting." Next Wave Cultures: Feminism, Subcultures, Activism. Ed.

Fisher, Caitlin. "The Sexual Girl Within." Jane Sexes It Up: True Confessions of Feminist Desire. Ed. Merri Lisa Johonson. New York: Four Walls Eight Windows, 2002. 53-63. Print.

Fisher, Kelly. "Lady Gaga Slams Claims She's Using the Gay Community to Boost Record Sales”. Pop Eater Music News. Aol Inc. 5 Jul. 2011. Web. 6 Mar. 2013. $<$ www.popeater.com $>$.

Frank, Priscilla. "Lady Gaga Invites Young Tumblr Artist Helen Green to Join Haus of Gaga". The Huffington Post. AOL lifestyle, 14 Sept. 2012. Web. 20 Jan. 2013. <www.huffingtonpost.com>.

Friedman, Jaclyn, and Jessica Valenti. Yes Means Yes!: Visions of Female Sexual Power \& a World without Rape. Berkeley, Calif: Seal Press, 2008. Print. 
GagaFanMonster. "Lady Gaga- Bride feat. Electric Chapel”. Video. 18 Feb. 2012. Web. 2 Jan. 2013.

$<$ http://www.youtube.com/watch?v=i TpY08KoCY\&list=PL8B39BD4A31E72C EB\&id $\mathrm{ex}=28 \&$ feature $=\mathrm{plcp}>$.

Gagapedia. Creative Commons Attribution-Share Alike License 3.0. <www.ladygaga.wikia.com $>$.

Garabaldi, Christine, and Jocelyn Vena. "Why Did Lady Gaga Go To VMAs As Jo Calderone?" MTV. VIACOM International Inc., 31 Aug. 2011. Web. 31 Jan. 2012. <www.mtv.com>

Garland-Thomson, Rosemarie. "Feminist Disability Studies." Signs: Journal of Women in Culture and Society 30.2 (2005): 1557-587. EBSCO. Web. 28 Mar. 2011.

Garlick, Steve. "What is a Man?" Men and Masculinities 6.2 (2003): 156-72.

Gibson, Laurieann. "You and I." Perf, Lady Gaga. Streamline/Interscope Records 2011. <www.ladygaga.com $>$

Gorski, Paul. "Insisting on Digital Equity." Urban Education 44.3 (2009): 348-64.

Hanna, Judith Lynne. "Dance and Sexuality: Many Moves." Journal of sex research 47.2-3 (2010): 212-41.

Halberstam, Judith. Gaga Feminism: Sex, Gender, and the End of Normal. Boston: Beacon, 2012. Print.

Hammar, Görel, et al. "Body Image in Adolescents with Cerebral Palsy." Journal of Child Health Care 13.1 (2009): 19-29.

Hanna, Judith Lynne. "Dance and Sexuality: Many Moves." Journal of sex research 4 7.2-3 (2010): 212-41. 
Harris, Anita. Next Wave Cultures: Feminism, Subcultures, Activism. New York; London: Routledge, 2008.

Hermes, Joke. "'Aly McBeal', 'Sex and the City' and the Tragic Success of Feminism." Feminism in Popular Culture. Ed. Joanne Hollows and Rachel Moseley. New York; London: Berg, 2006. 79-95. Print.

Hermes, Joke. Re-reading Popular Culture. Malden, MA: Blackwell Pub., 2005. Print. Hiatt, Brian. "New York Doll." Rolling Stone Magazine 11 June 2009: 59-61. Print, Web <www.rollingstone.com>

Hirzalla, Fadi, and Liesbet Zoonen. "Beyond the Online/Offline Divide: How Youth's Online and Offline Civic Activities Converge." Social Science Computer Review 29.4 (2011): 481-98.

Hodson, Diane, and Patsy Skeen. "Sexuality and Aging: The Hammerlock of Myths." The Journal of Applied Gerontology 13.3 (1994): 219-35.

Hollows, Joanne, and Rachel Moseley. Feminism in Popular Culture. Oxford, Uk ; New York: Berg, 2006. Print.

Howe, Cymene, and Jakob Rigi. "Transnationalizing Desire: Sexualizing Culture and Commodifying Sexualities." Ethnos 74.3 (2009): 297-306.

Hsieh, Kevin. "Maria Aragon Discovered By Lady Gaga." Channel APA: Broadcasting Asian America. Autotrader.ca, 21 Feb. 2011. Web. 25 Mar. 2012. $<$ http://www.channelapa.com $>$.

Huliaras, Asteris, and Nikolaos Tzifakis. "Celebrity Activism in International Relations: In Search of a Framework for Analysis." Global Society 24.2 (2010): 255-74. 
Inside the Outside. Dir. Davi Russo. Perf. Lady Gaga and Nicole Pusateri. MTV, 2011. Web. 28 Feb. 2013. <www.mtv.com>

Jackson, Sue, and Tamsyn Gilbertson. "'Hot Lesbians': Young People's Talk about Representations of Lesbianism." Sexualities 12.2 (2009): 199-224.

janssencox93. "Haus of U ft. Jo Calderone". Video. 13 Oct. 2011. Web. 2 Jan. 2013. $<$ http://www.youtube.com/watch?v=pKjD9zIm1I\&list=UUfgagPte $5 i$ NEOvd $7 \mathrm{GZuVg} \&$ index $=1$ \& feature $=$ plcp $>$. Jenkins, Henry. Textual Poachers: Television Fans \& Participatory Culture. New York: Routledge, 1992. Print.

-- Convergence Culture: Where Old and New Media Collide. New York: New York UP, 2006. Print.

-- Confronting the Challenges of Participatory Culture: Media Education for the 21st Century. Cambridge, MA: MIT, 2009. Print.

Johnson, Merri Lisa. Jane Sexes it U: True Confessions of Feminist Desire. New York: Four Walls Eight Windows, 2002.

Kaufman, Gil. "Lady Gaga Debuts New Song 'You and I' at Elton John Benefit". MTV. Viacom International Inc. 28 Jun. 2010. Web. 28 Feb. 2013. <www.mtv.com> Kim, Eunjung. "Asexuality in Disability Narratives." Sexualities 14.4 (2011): 479-93. Lace, Sydney. "Hip-Hop Rumours: Did Akon Lie About Discovering Lady Gaga?" All Hip-Hop. WordPress.com VIP. 21 Sept. 2012. Web. 28 Feb. 2013. $<$ www.allhiphop.com $>$

Lady Gaga. "You and I". Born This Way. Streamline/Interscope, 2011. Music Video. Laurieann Gibson. <www.youtube.com/ladygagavevo $>$. 
LadyLurdys. "Haus of U ft. Jo Calderone”. Video. 2 Mar. 2012. Web. 2 Jan. 2013. $<$ http://www.youtube.com/watch?v=6QP0S0G1Yy0\&list=UURo9hF7uGgQgraPj gtnWFjw\&index $=3 \&$ feature $=$ plcp $>$.

Lamb, Bill. "Lady Gaga's 'You and I' Video Leaks and Is Released Early”. About.com Entertainment. About.com. 16 Aug. 2011. Web. 2 Mar. 2013. $<$ www.top40.about.com>

lennonvalim. "LennonGaga Revolution- You and I feat. Barn Hooke and mother". Video. 24 Aug. 2012. Web. 2 Jan. 2013. $<$ http://www.youtube.com/watch?v=p4DgHqkclho\&list=UUZ8cYUMadShpGFy p2R1Pyow \&index $=6 \&$ feature $=$ plcp $>$.

Lessig, Lawrence. Remix: Making Art and Commerce Thrive in the Hybrid Economy. New York: Penguin, 2008. Print.

Levy, Ariel. Female Chauvinist Pigs: Women and the Rise of Raunch Culture. 1st Free Press Trade pbk. ed. New York: Free Press, 2006. Print.

Lindner, Emilee. "Lady Gaga cancels Born This Way Tour, Needs Surgery". MTV. Viacom International, Inc. 13 Feb. 2013. Web. 28 Feb. 2013. <www.mtv.com> Lloyd, Moya. "Performativity, Parody, Politics." Theory, Culture \& Society 16.2 (1999): 195-213.

London, Bianca. "On the Edge of Glory: Lady Gaga Offers Student Artist a Job on Her Team After Being Wowed by Her Tumblr Sketches". The Daily Mail UK. Associated Newspapers, Ltd., 14 Sept. 2012. Web. 20 Jan. 2013. <www.dailymail.co.uk $>$. 
Maccoby, Eleanor E. "Gender as a Social Category." Developmental psychology 24.6 (1988): 755-65.

Marrow Melow. "The Bride”. Drawing. $<$ http://littlemonsters.com/post/502e739af35c0c4405003211 $>$.

Matadin, Vinoodh and Inez Van Lamsweerde. "Haus of U feat. Nymph." Perf, Lady Gaga. Streamline/Interscope Records 2011. <www.inezandvinoodh.com>

--. "Haus of U feat. Bride." Perf, Lady Gaga. Streamline/Interscope Records 2011. <www.inezandvinoodh.com>

--. “Haus of U feat. Yüyi.” Perf, Lady Gaga. Streamline/Interscope Records 2011. $<$ www.inezandvinoodh.com $>$

--. "Haus of U feat. Jo Calderone." Perf, Lady Gaga. Streamline/Interscope Records 2012. $<$ www.inezandvinoodh.com $>$

--. "Haus of U feat. Mother and Barn Hooker". Perf, Lady Gaga. Strealine/Interscope Record 2012. <www.inezandvinoodh.com>

Maya. "The Wednesday Weigh-in: Lady Gaga's Body Revolution Edition". Feministing. Command C Design, LLC. 26 Sept. 2012. Web. 2. Oct. 2012. <www.feministing.com $>$

McGinnis, Sara. "Lady Gaga Egged After Mermaid Wheelchair Performance". SheKnows Entertainment. AtomicOnline LLC, 14 Jul. 2011. Web. 2 Oct. 2012. $<$ www.sheknows.com $>$

McLuhan, Marshall, and Quentin Fiore. The Medium Is the Massage. New York: Random House, 1967. Print.

--. Understanding Media: The Extensions of Man. New York: McGraw-Hill, 1964. Print. 
Meyers, Marian. "Women in Popular Culture: All Sexed Up and Global to Go." Women in Popular Culture: Representation and Meaning. Ed. Marian Meyers. Cresskill, New Jersey: Hampton, 2008. 3-26. Print.

Miller, Daniel, Laura Rival, and Don Slater. "Sex and Sociality." Theory, Culture \& Society 15.3 (1998): 295-321.

Miller, Vincent. Understanding Digital Culture. London: SAGE Publications, 2011. Print.

Moore, Garth. "When Clicking Counts: In Defense of Slacktivism and Clicktivism". One: join the Fight Against Extreme Poverty. 3 May. 2012. Web. 1 Mar. 2013. $<$ www.one.org $>$

MultiAlthani. "Lady Gaga: MTV interview 2011 (PART 1)", 19 Aug. 2011. Web. 28 Feb. 2013. < http://www.youtube.com/watch?v=FUtWDd6FaUU $>$. nashoesponjal. "House of u ft NYMPH Lady Gaga Dancing with me". Video. 6 Jan. 2012. Web. 2 Jan. 2013. $<$ http://www.youtube.com/watch?v=ynFemBts4rA\&list=UUIZf2ACDPuK55U8 OVryp9SQ\&index $=28 \&$ feature $=$ plcp $>$.

Nessif, Bruna. "Sharon Osbourne and Lady Gaga Feud: The Talk Cohost Asks Singer to Take Action Against 'Violent' Fans”. E! News. Bell Media Television. 14 Jan. 2013. Web. 28 Feb. 2013. <www.eonline.com>

Nielsen, Rasmus Kleis. "The Labors of Internet-Assisted Activism: Overcommunication, Miscommunication, and Communicative Overload." Journal of Information Technology \& Politics 6.3-4 (2009): 267-80. 
Nuñez Puente, Sonia. "Feminist Cyberactivism: Violence Against Women, Internet Politics, and Spanish Feminist Praxis Online." Continuum 25.3 (2011): 333-46. O'Keefe, Ed. "Lady Gaga at VMAs Calls for Repeal of 'don't Ask, Don't Tell"' The Washington Post. The Washington Post Company, 12 Sept. 2010. Web. 25 Feb. 2012. <www.voices.washingtonpost.com>.

Oksala, Johanna. "Anarchic Bodies: Foucault and the Feminist Question of Experience." Hypatia 19.4 (2004): 97-119.

Oppliger, Patrice A. Girls Gone Skank: The Sexualization of Girls in American Culture. Jefferson, N.C: McFarland \& Company, 2008. Print.

Parker, Suzi. “Lady Gaga's 'Don't Ask, Don't Tell' Activism is Getting Results”. Politics Daily. Aol News, Sept. 2010. Web. 15 Feb. 2012. $<$ http://www.politicsdaily.com $>$

Paxton, Blake A. "My Bad Romance: Exploring the Queer Sublimity of Diva Reception." Communication, 2011.

Perpetua, Matthew. "Lady Gaga Egged Over Wheelchair Stunt". Rolling Stone. Wenner Media Websites, 15 Jul. 2011. Web. 2 Oct. 2012. <www.rollingstone.com>

Peters, Michael A. "On the Edge of Theory: Dadaism, (Ca-Caism), Gagaism." Review of Education, Pedagogy, and Cultural Studies 34.5 (2012): 216-26.

Phillips, Lynn M. Flirting with Danger: Young Women's Reflections on Sexuality and Domination. New York: New York UP, 2000. Print.

Plummer, Marilyn and Young, Lynne E. "Grounded Theory and Feminist Inquiry: Revitalizing Links to the Past." Western Journal of Nursing Research, vol. 32, no. 3 (2010): pp. 305-321 
Poole, Megan Shaffner. "The Role of Power in Regard to Womens Sexual Empowerment." Carleton University (Canada), 1995. Canada: Dissertations \& Theses at Carleton University; ProQuest Dissertations \& Theses (PQDT). Web. 31 Jan. 2012.

Railton, Diane, and Paul Watson. "Making It Real: Authorship and Authenticity." Music Video and the Politics of Representation. Edinburgh: Edinburgh UP, 2011. 66-84. Print.

Reger, Jo. "Where are the Leaders? Music, Culture, and Contemporary Feminism." American Behavioral Scientist 50.10 (2007): 1350-69.

Renegar, Valerie R. and Stacey K. Sowardds. "Reconceptualizing Rhetorical Activism in Contemporary Feminist Contexts" Howard Journal of Communications (2006).

Robertson, James. “All Hail, Beliebers! Justin Bieber Overtakes Lady Gaga as Most Followed Person on Twitter”. Mirror 3 am. Mirror Online. 22 Jan. 2013. Web. 28 Feb. 2013. <www.mirror.co.uk >

Rocha, Elizabeth. "A Ladder of Empowerment." Journal of Planning Education and Research 17.1 (1997): 31-44.

Rubenstein, Jenna Hally. “Lady Gaga Goes Topless in Second 'Haus of U' Fashion Film”. MTV. VIACOM International Inc., 14 Sept. 2011. Web. 2 Oct. 2012. <www.buzzworthy.mtv.com>

Rupp, Leila, Verta Taylor, and Eve Shapiro. "Drag Queens and Drag Kings: The Difference Gender Makes." Sexualities 13.3 (2010): 275-94.

Scholz, Trebor. "Where the Activism Is." Digital Media and Democracy. Ed. Megan Boler. Cambridge: Massachusetts Institute of Technology, 2008. 355-65. Print. 
Sheppard, Denise. "Lady Gaga Changing Lives With Touring Youth Services". Rolling Stone Music. Wenner Media. 22 Jan. 2013. Web. 4 Mar. 2013. $<$ www.rollingstone.com $>$.

Sinnreich, Aram. Mashed Up: Music, Technology, and the Rise of Configurable Culture. Amherst: University of Massachusetts, 2010. Print.

Smith, Emily Esfahani. "Performance Art: The Faux Creativity of Lady Gaga." Acculturated. Ed. Naomi Schaefer Riley and Christine Rosen. West Conshohocken: Templeton, 2011. 99-106. Print.

Snarker, Dorothy. "What Brittana Looks Like to The Straight World". AfterEllen. Logo Online. 14 Oct. 2010. Web. 6 Mar. 2013. <www.afterellen.com>.

TakeABiteOfMeBoy. "Lady Gaga Inside The Outside". Video. 23 Jul. 2012. Web. 28 Feb. $2013<$ http://www.youtube.com/watch?v=AMcP0OBp2ng. $>$

Talarico, Brittany. "Lady Gaga Splits From Long-Time Beau Luc Carl". OK! Magazine. American Media, Inc. 13 May. 2011. Web. 20 Sept. 2011. <www.okmagazine.com>

Taylor. "Started a new drawing of Gaga recently". Drawing. $<$ http://littlemonsters.com/post/50108e7cc84b0a8a7a000605 $>$.

The Born This Way Foundation. Blue State Digital, 2012. <www.bornthiswayfoundation.org >

Thomas, Liz. "All This Sex Is Just Gaga, Says Dame Joan: Broadcaster Attacks Pop Industry's Obsession With Raunch." The Daily Mail UK. Associated Newspapers, Ltd., 5 Jan. 2012. Web. 15 Feb. 2012. <http://www.dailymail.co.uk $>$ 
Thrall, A., et al. "Star Power: Celebrity Advocacy and the Evolution of the Public Sphere." The International Journal of Press/Politics 13.4 (2008): 362-85.

Toffoletti, Kim. Cyborgs and Barbie Dolls: Feminism, Popular Culture and the Posthuman Body. London: I.B. Tauris, 2007. Print.

Us Weekly. "Lady Gaga Breaks Up With Boyfriend Luc Carl”. Rolling Stone. Wenner Media Websites. 13 May. 2011. Web. 17 Sept. 2011. <www.rollingstone.com> Vaiani, Mauro. "Full Transcript of Lady Gaga's Speech in Rome at Europride." Diverso Toscana. Blogger, 21 June 2011. Web. 25 Feb. 2012. <www.diversotoscana.blogspot.com>

Valenti, Jessica. The Purity Myth: How America's Obsession with Virginity Is Hurting Young Women. Berkeley, CA: Seal, 2009. Print.

Valocchi, Stephen. "Not Yet Queer enough." Gender \& Society 19.6 (2005): 750-70.

Van Lenning, Alkeline. "The Body as Crowbar." Feminist Theory 5.1 (2004): 25-47.

Wallace, Kelsey. “Gaga's Jo Calderone Confuses VMA Audiences, Me”. Bitch

Magazine. Bitch Media, 29 Aug. 2011. Web. 2 Oct. 2012. <www.bitchmagazine.org $>$

Walters, Susan D. All the rage: The story of gay visibility in America (Chicago: University of Chicago, 2001)

Ward, Jane. "Gender Labor: Transmen, Femmes, and Collective Work of Transgression." Sexualities 13.2 (2010): 236-54.

Waterman, Ellen, et al. "Naked Intimacy: Eroticism, Improvisation, and Gender."Critical Studies in Improvisation / Études critiques en improvisation 4.2 (2008): 102. 
West, Candace, and Don Zimmerman. "Doing Gender." Gender \& Society 1.2 (1987): $125-51$.

White, Micah. "Clicktivism is Ruining Leftist Activism". The Guardian. Guardian News and Media Ltd. 12 Aug. 2010. Web. 1 Mar. 2013. <www.guardian.co.uk> Whiteley, Sheila. "Popular Music and the Dynamics of Desire." Queering the Popular Pitch. Ed. Jennifer Rycenga and Sheila Whiteley. New York: Routledge, 2006. 249-62. Print.

Wiley Todd, Ellen. "Sex For Sale: Reginald Marsh's Voluptuous Shopper." The "New Woman" Revised: Painting and Gender Politics on Fourteenth Street. Oxford: University of Carolina, 1993. 178-223.

Williams, Jannine, and Sharon Mavin. "Disability as Constructed Difference: A Literature Review and Research Agenda for Management and Organization Studies." International Journal of Management Reviews 14.2 (2012): 159-79.

Youdell, Deborah. "Sex-gender-sexuality: How Sex, Gender and Sexuality Constellations are Constituted in Secondary Schools." Gender and Education 17.3 (2005): 249-70.

Young, Iris Marion. "Throwing Like a Girl: A Phenomenology of Feminine Body Comportment Motility and Spatiality." Human Studies 3.2 (1980): 137-56.

--. "The Politics of Un-Identified Women." Noûs 20.1, 1986 A. P. A. Central Division Meetings (1986): p. 52.

--. "Gender as Seriality: Thinking about Women as a Social Collective." Signs 19.3 (1994): 713-38. 
Zak, Dan. "Lady Gaga, Already a Gay Icon, Shows She's an Activist Too”. The Washington Post. The Washington Post Company, 12 Oct. 2009. Web. 2 Oct. 2012. <www.washingtonpost.com>

Zaylia, Jessica Leigh. "Toward a Newer Theory of Sexuality: Terms, Titles, and the Bitter Taste of Bisexuality." Journal of Bisexuality 9.2 (2009): 109-23.

Zelda Joyce. "NYMPH”. Video. 16 Aug. 2012. Web. 2 Jan. 2013. $<$ http://www.youtube.com/watch?v=JNALbnamprQ\&list=UU9HAonnvNu0PoamLZYVfoQ\&index $=4 \&$ feature $=p l c p>$. 